PNL-4693

NUREG/CR-3581

PNL-4693

\title{
Steam Generator Group Project
}

Annual Report - 1982

Prepared by R. A. Clark, M. Lewis

Pacific Northwest Laboratory

Operated by

Battelle Memorial Institute

Prepared for

U.S. Nuclear Regulatory

Commission 


\section{NOTICE}

This report was prepared as an account of work sponsored by an agency of the United States Government. Neither the United States Government nor any agency thereof, or any of their employees, makes any warranty, expressed or implied, or assumes any legal liability of responsibility for any third party's use, or the results of such use, of any information, apparatus, product or process disclosed in this report, or represents that its use by such third party wouid not infringe privately owned rights.

\section{Availability of Reference Materials Cited in NRC Publications}

Most documents cited in NRC publications will be available from one of the following sources:

1. The NAC Public Document Room, 1717 H Street, N.W. Washington, DC 20555

2. The NRC/GPO Sales Program, U.S. Nuclear Regulatory Commission, Washington, DC 20555

3. The National Technical Information Service, Springfield, VA 22161

Although the listing that follows represents the majority of documents cited in NRC publications, it is not intended to be exhaustive.

Referenced documents available for inspection and copying for a fee from the NRC Public Document Room include NRC correspondence and ir.ternal NRC memoranda; NRC Office of Inspection and Enforcement bulletins, circulars, information notices, inspection and investigation notices; Licensee Event Reports; vendor reports and correspondence; Commission papers; and applicant and licensee documents and correspondence.

The following documents in the NUREG series are available for purchase from the NRC/GPO Sales Program: formal NRC staff and contractor reports, NRC-sponsored conference proceedings, and NRC booklets and brochures. Also available are Regulatory Guides, NRC regulations in the Code of Federal Regulations, and Nuclear Regulatory Commission /s:uances.

Documents available from the National Technical Information Service include NUREG series reports and technical reports prepared by other federal agencies and reports prepared by the Atomic Energy Commission, forerunner agency to the Nuclear Regulatory Commission.

Documents available from public and special technical libraries include all open literature items, such as books, journal and periodical articles, and transactions. Federal Register notices, federal and state legislation, and congressional reports can usually be obtained from these libraries.

Documents such as theses, dissertations, foreign reports and translations, and non-NRC conference proceedings are available for purchase from the organization sponsoring the publication cited.

Single copies of NRC draft reports are available free upon written request to the Division of Technical Information and Document Controi, U.S. Nuclear Risgulatory Commission, Washington, DC 20555.

Copies of industry codes and standards used in a substantive manner in the NRC regulatory process are maintained at the NRC Library, 7920 Norfolk Avenue, Bethesda, Maryland, and are available there for reference use by the public. Codes and standards are usually copyrighted and may be purchased from the originating organization or, if they are American National Standards, from the American National Standards Institute, 1430 Broadway, New York, NY 10018. 
NUREG/CR-3581

PNL-4693

\section{Steam Generator Group Project}

Annual Report - 1982

Manuscript Completed: March 1983

Date Published: February 1984

Prepared by

R. A. Clark, M. Lewis

Pacific Northwest Laboratory

Richland, WA 99352

\section{Prepared for}

Division of Engineering Technology

Office of Nuclear Regulatory Research

U.S. Nuclear Regulatory Commission

Washington, D.C. 20555

NRC FIN B2097 



\section{ABSTRACT}

The Steam Generator Group Project (SGGP) is an NRC program joined by additional sponsors. The SGGP utilizes a steam generator removed from service at a nuclear plant as a vehicle for research on a variety of safety and reliability issues. This report is an annual summary of progress of the program for 1982. Information is presented on the Steam Generator Examination Facility (SGEF), especially designed and constructed for this research. Loading of the generator into the SGEF is then discussed. The report then presents radiological field mapping results and personnel exposure monitoring. This is followed by information on field reduction achieved by channel head decontaminations. The report then presents results of a secondary side examination through shell penetrations placed prior to transport, confirming no change in generator condition due to transport. Decontamination of the channel head is discussed followed by plans for eddy current testing and removal of tube plugs placed during service. Results of a preliminary profilometry examination are then provided. 

SUMMARY

INTRODUCTION

ACCOMPLISHMENTS FY-82

Steam Generator Examination Facility (Task 1)

Position Generator into SGEF (Task 2)

Health Physics (Task 3)

Data Storage Retrieval System/Statistical Analysis (Task 4 )

Reopen Preshipment Penetrations (Task 5)

Channel Head Decontamination (Task 6 )

Baseline Eddy Current ISI (Task 7).

Tube Unplugging (Task 8).

Secondary Side Access (Task 10) . . . . . 94

Tube Sheet Section Removal (Task 11) . . . . 94

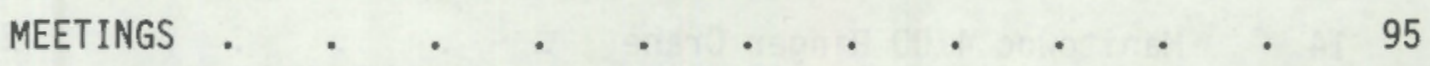

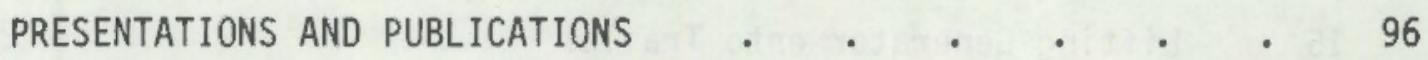

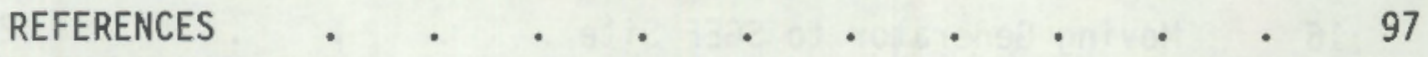

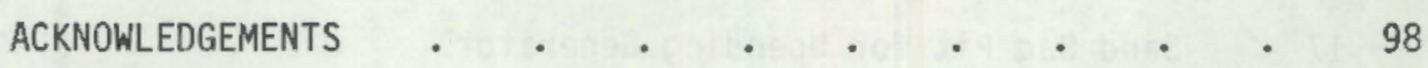

APPENDIX A $\quad . \quad . \quad . \quad . \quad . \quad . \quad . \quad . \quad A-1$

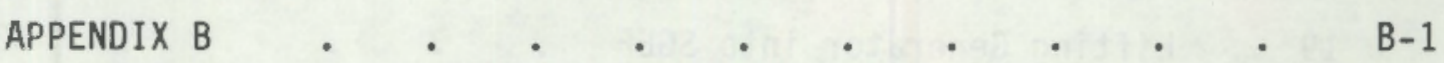




\section{LIST OF FIGURES}

Figure

Page

1 SGGP Milestone Chart . . . . . . 4

2 Excavation for SGEF . . . . . . 6

3 Casting SGEF Shielding Walls . . . . . 7

4 SGEF Framework . . . . . . . . 8

5 Placement of Tilt-Up Slabs . . . . 9

6 View of SGEF with Removable Roof Panel in Foreground . . . . . . . . . 10

7 View of SGEF $\quad . \quad . \quad . \quad . \quad . \quad . \quad 11$

8 Cut-Away of SGEF Showing Position of Steam Generator . . . . . . 12

9 Plan Drawing of SGEF Main Floor . . . . 13

10 View of SGEF Cranes . . . . . . . 15

11 HEPA-Filtered Laboratory Hoods, Access Door to Tower . . . . . . . . 16

12 HEPA Filter Bank in Equipment Room . . . . 17

13 Breathing Air System in Equipment Room . . . 18

14 Manitowoc 4100 Ringer Crane . . . . 20

15 Lifting Generator onto Trailer . . . . 21

16 Moving Generator to SGEF Site . . . . 22

17 Sand Bag Pit for Upending Generator . . 23

18 Lifting Generator into SGEF . . . . . 24

19 Lifting Generator into SGEF . . . . . 25

20 Lowering Generator into SGEF Tower . • . . 26

21 Replacing Roof Panel on SGEF . . . . . 27

22 Radiation Levels at Contact with the Steam Generator . . . . . . 28 


\section{LIST OF FIGURES (Cont'd)}

Figure

$\underline{\text { Page }}$

23 Radiation Levels Three Feet from the

Steam Generator . . . . . . . 28

24 Radiological Map - 1st Floor Level . . . . 29

25 Radiological Map - 2nd Floor Level . . . . 30

26 Radiological Map - 3rd Floor Level . . . . 31

27 Radiological Map - 4th Floor Level . . . . 32

28 Radiological Map - Basement Level . . . . 33

29 Radiation Monitoring Locations in the

SGEF Vicinity . . . . . . . . 35

30 Initial Radiation Readings - Cold Leg . . . 39

31 Final Radiation Readings - Cold Leg . . . 40

32 Radiation Reading Change - Cold Leg . . . 41

33 Initial Radiation Readings - Hot Leg . . . 42

34 Final Radiation Readings - Hot Leg . . . . 43

35 Radiation Reading Change - Hot Leg . . . . 44

36 NDT Computer System . . . . . . . . 46

37 Tube Plugging Map with Reasons . . . . 47

38 Location of Inspection Penetrations . . . 49

39 Penetration Access in SGEF at Cut 1 . . . 51

40 Shielding Arrangement in SGEF at Cut 1 . . . 52

41 Penetration Access in SGEF at Cut 4 . . . 53

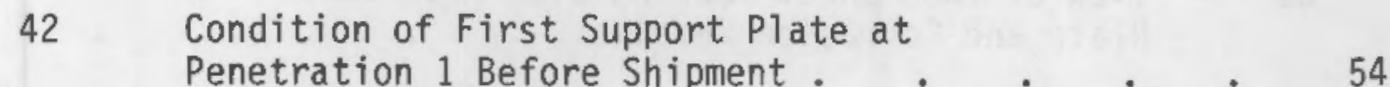

43 Same as Figure 42 after Generator Transport . . 54

44 Bottom Surface of First Support Plate Viewed

Upward from Handhole (Composite Photograph) . . 55 


\section{LIST OF FIGURES (Cont'd)}

Figure

Page

45 Loose Support Plate Piece Near Tube -

Tube Support Junction . . . . . 56

46 Separated Support Plate Piece at Lower Handhole . 57

47 Piece of Support Plate from Figure $46 \quad$. $\quad . \quad$. 58

48 Blowdown Piping and Top of Tube Sheet in

Tube Lane . . . . . . . . . . 58

49 Blowdown Piping and Top of Tube Sheet

Further in Along Tube Lane . . . . 59

50 View in Handhole $\quad . \quad . \quad . \quad . \quad . \quad 559$

51 Flow Slot Deformation . . . . . 60

52 Detail of Inner Row U-Bends at Surry . . $\quad 60$

53 Inner Row U-Bend Detail after Transport . . . 61

54 Large Longitudinal Failure $\quad$ • . . 61

55 Bottom of Tube Sheet . . . . 63

56 Materials of the Channel Head . . . . . 65

57 Dimensions of the Channel Head . . . 66

58 Initial Condition of Channel Head Surfaces -
Cold Leg Side.

59 Initial Condition of Channel Head Surfaces -
Hot Leg Side . . . . . . . 68

60 Drilling Core Sample from Channel Head . . $\quad 69$

61 Core Sample of Channel Head . . . . 70

62 View of Tube Sheet Showing S.S. Protective

63 Corrosion Specimens • . . . . . 72

Manway Cover with Piping and Instrumentation
Connections . . . . . . . 73

65 Liquid Waste Transfer Tank . . . . 75 


\section{LIST OF FIGURES (Cont'd)}

Figure

Page

66 Resin Slurrying Apparatus . . . . . 76

67 Analytical Laboratory . . . . . . 77

68 London Nuclear Pump Skid . . . . . . 78

69 London Nuclear Ion Exchange Columins . . . 79

70 London Nuclear Heater Skid . . . . . 80

71 Flow Effect on Film . . . . . . . 82

72 Splotchy Appearance of Film . . . . . 83

73 Electropolishing Operation . . . . . 84

74 Tube Unplugging Map . . . . . . . 86

75 Equipment for the Baseline Eddy Current ISI . . 87

76 Tubes Selected for Profilometry Experiment . . 88

77 Occurrence of Maximum Denting per Unplugged 90

78 Occurrence of Maximum Denting per Unplugged

Tube - Cold Leg $\quad . \quad$. . . . 91

79 Distribution of Denting in Unplugged . . . 92

80 Distribution of Denting in Unplugged

Tubes - Cold Leg . . . . . . . . 93 


\section{$\underline{\text { LIST OF TABLES }}$}

Table

SGGP Objectives

Radiation Levels Inside the Tube Bundle .

Page

2

3

Radiation Levels in the SGEF Vicinity SGEF Personnel Radiation Exposures .

38

5

Analysis of Water Removed from Surry Steam Generator. 
STEAM GENERATOR GROUP PROJECT

ANNUAL REPORT - 1982

\section{SUMMARY}

Progress during 1982, the first full year of the Steam Generator Group Project (SGGP), was according to schedule (Ref. 1) until the last month of the year. The Steam Generator Examination Facility (SGEF) was completed and the Surry $2 A$ steam generator was installed in it on schedule and within budget. Radiation fields were mapped in and around the generator, identifying areas that could be profitably shielded, which was done with steel plates. Measuring techniques and work practices were utilized that may be useful to industry in efforts to achieve ALARA objectives. The preshipment inspection was repeated, confirming the research suitability of the unit, and the fact that shipping had not damaged it. In fact, the entire transport operation, including reviews and approvals, stands as a guide to future steam generator disposal efforts.

Historical operating data for the unit were entered into the data storage system, as were the results of ongoing tasks and personnel radiation exposures. Data analysis provided a basis for tube selection in a gauging experiment of a 96-tube sample. Analysis of blowdown chemistry data was initiated.

The channel head region was decontaminated, each side by a different dilute chemical process, in preparation for tube unplugging and baseline eddy current inspection. Experience gained during the decontamination effort will be invaluable during future reviews of applications for licensing similar processes.

Equipment for the eddy current inspection and the secondary side inspection was accumulated and tested. The profilometry (gauging) experiment was performed. Visual examination of the secondary side was initiated.

The first schedule slippage was experienced as a result of difficulties in negotiating a satisfactory unplugging contract. At year end, this problem appears to be resolving, but a three-months delay in the start of the unplugging task is inevitable.

\section{INTRODUCTION}

The Steam Generator Group Project (SGGP) initiated in FY82 is a continuation and expansion of the Steam Generator Integrity Program (SGIP), a multiphase, multitask laboratory program to investigate the behavioral characteristics of defected PWR steam generator tubing. Under the SGIP, mechanically and chemically produced defects were placed in steam generator tube lengths to simulate service degradation. Specimens with 
defects were then nondestructively characterized and destructively tested to determine the remaining integrity under burst or collapse failure modes. Constitutive equations were subsequently established relating defect morphology and severity to remaining tube integrity. Other SGIP objectives included studying the reliability and accuracy of nondestructive flaw characterization by eddy current testing of steam generator tubes. Experiments are continuing to determine the consequences of tube failure in terms of leak rate. Stability of throughwall flaws is a consideration in these experiments.

Models of remaining tube integrity that were developed using defect simulations during the SGIP will be verified in the SGGP using actual service-defected tubing. To obtain the necessary specimens and to address increasing concerns on various other aspects associated with steam generator integrity, a retired-from-service nuclear steam generator was acquired. A generator removed after 6 years of service from the Surry II nuclear plant (Surry, Virginia) was judged suitable for this research.

Initial efforts on the Surry generator were concerned with 1 icensing and transport activities to bring the unit from Virginia to Hanford, Washington. The unit was temporarily stored awaiting the completion of the specially designed containment facility, the Steam Generator Examination Facility (SGEF). The SGEF is equipped to allow both nondestructive examination (NDE) and physical sectioning of the generator and includes capabilities to perform chemical cleaning and decontamination.

Because of the potentially unique opportunities presented by the availability of the retired-from-service steam generator and the recognition that both the NRC and the world nuclear community could benefit from interaction on this program, Pacific Northwest Laboratory (PNL) was requested to organize a Group Project for this research. A Group Project organizational meeting was held in Richland in February 1982. Representatives of five foreign countries and several U.S. organizations were introduced to the program and toured the SGEF. Several trips were made to present programmatic details to potential participants. At the end of 1982 final negotiations or contract signing had been accomplished with four consortiums joining the program. The participating consortiums are EPRI in the United States, and one each from Italy, France and Japan. Negotiations continued with three other potential program participants.

The content of the SGGP was influenced by the desire to broaden participation. The core of the program is designed to answer NRC-originated needs. However, the depth of the study in some research areas, such as secondary side cleaning and primary side decontamination, was expanded to incorporate issues of method development and generator reliability in conjunction with NRC's safety interests. Table 1 lists the objectives of the program. To achieve these objectives, the SGGP was divided into 21 tasks or work packages. Task leaders were appointed for most of these tasks, and task action plans were prepared. Figure 1 shows the project task milestone structure. 
TABLE 1. SGGP objectives

Use the Surry $2 A$ steam generator as a source of realistic service degraded steam generator tubing and other specimens

1. Provide validation of the accuracy and reliability of current NDE equipment and practice via destructive metallographic comparison with nondestructive test data.

2. Proof testing and development work on next generation NDE devices for primary and secondary side inservice inspections.

3. Mechanical integrity tests of steam generator tubes degraded in service.

4. Leak rates associated with failure of degraded tubes under operating or accident conditions.

5. Relate NDE accuracy and reliability of detection with remaining tube integrity and failure consequences. Provide input to tube plugging and inservice inspection criteria.

6. Improve accuracy and methodology of personnel exposure monitoring and health physics dose estimating for various repair and maintenance operations.

7. Provide a test bed for developing repair/maintenance equipment and techniques, with health physics inputs for minimizing exposure in operating units.

8. Provide a test bed for repair techniques.

9. Test solutions/techniques for secondary side cleaning and primary side decontamination on realistic service corrosion films to optimize methods, establish potential damage to an operating unit.

10. Confirm degradation mechanisms.

11. Assess generic degradation; tube sheet crevice, support structure. 


\section{MILESTONE CHART}

\section{SURRY GENERATOR PROGRAM}

1. Construct SgeF

2. POSITION GENERATOR IN SGEF

3. HEALTH PHYSICS

4. oata stopage/petrieval system

4. statistics - data management analysis

5. AEOPEN PRESHIPMENT PENETRATIONS

- decontaminate channel head

7. BASELINE EDDY CURAENT IS

a. TUeE UNPLUgGinc

9. NOT ROUND ROBIN

10. SECONDARY SIDE ACCESS

11. TUBE SHEEt SECTION REMOVAL

12. SPECIMEN REMOVAL

13. NDT VALIDATION STUDIES

14. MEchanical integaity TESTING

15. SECONDAAY SIDE CLEANING - LAB

10. PRimaAY Side decontamination lab

17. ESTABLISH MOCK. UP BUNDLE

11. cleaning demonstration

19. Decontamination demonstration

20. hepair demonstrations

21. DECOMMISSIONING

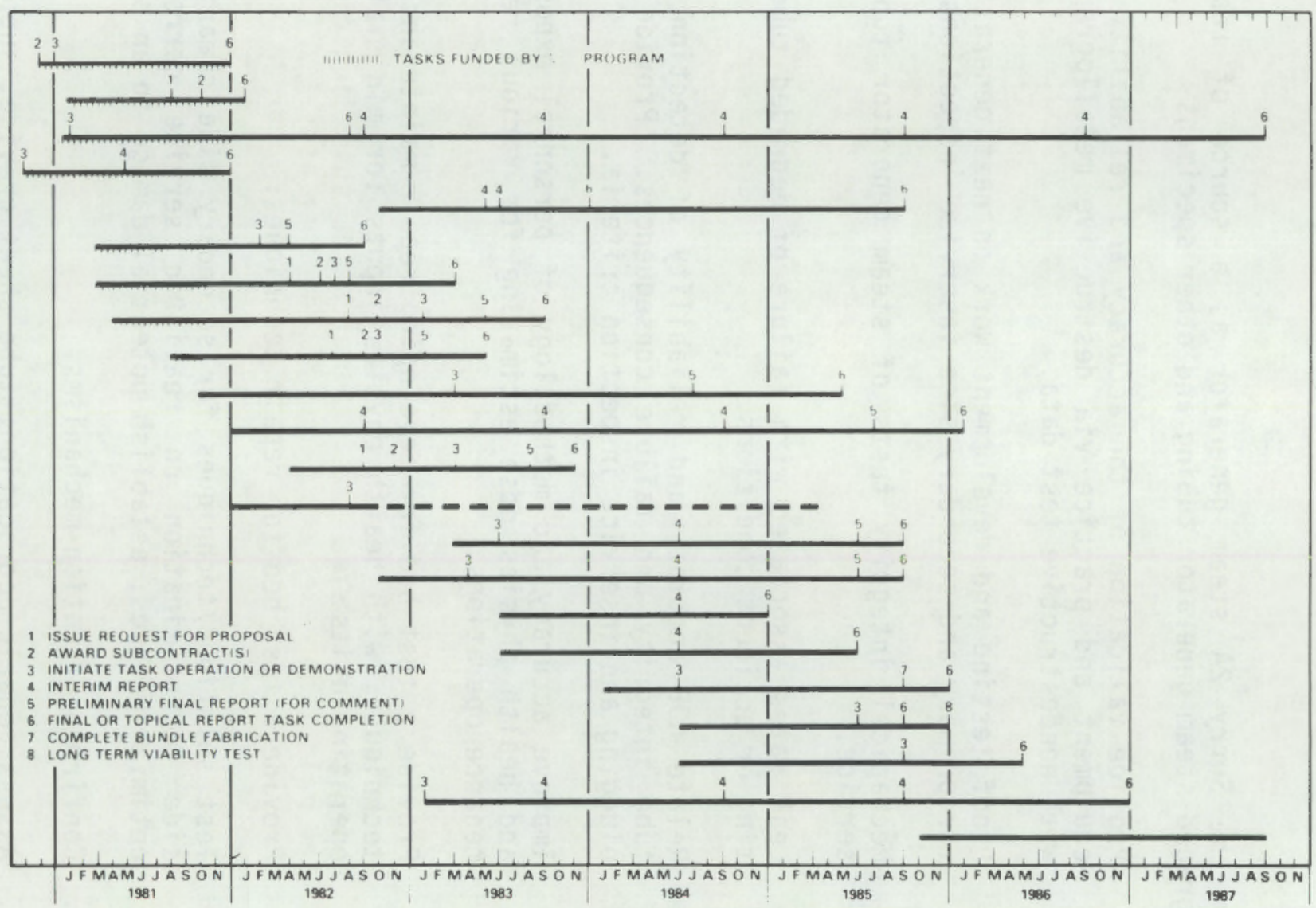

FIGURE 1 . 
Accomplishments directly related to the SGGP completed prior to 1982 were the transport of the Surry steam generator to Hanford, and the construction of the SGEF. This report will not discuss the details of transportation activities. The construction of the SGEF, however, will be detailed.

\section{ACCOMPL ISHMENTS FY-82}

\section{Steam Generator Examination Facility (Task 1)}

The Steam Generator Examination Facility (SGEF) was completed in December 1981. This is an especially designed and constructed facility for conducting nondestructive examinations, destructive sectioning and specimen removal, cleaning and decontamination experiments. The $\$ 1.7$ million facility was constructed mostly with tilt-up sandwich slabs made of concrete on the outside with a styrofoam center. The basement and first floor tower walls are one-foot thick reinforced concrete. Figures 2 through 5 show construction progress, beginning with the basement excavation, and proceeding through concrete casting, erection of the framework, and placement of the tilt-up slabs. Figures 6 and 7 are views of the finished SGEF.

- Figure 8 shows an artists cut-away rendition of the SGEF with the research generator in place. The generator is in its operating position allowing nondestructive examinations, decontamination experiments, etc., to be performed under normal orientation conditions. The SGEF has a four story high bay, or tower, portion which is the generator containment. Each above-ground floor has an emergency exit leading to an exterior steel safety staircase. Owing to its massive size, to match the shielding of the concrete, the ma in floor emergency door has a power assist. Connected to the tower is a two story support area. The upper story of this area contains HVAC equipment, HEPA (high efficiency particle acceptor) filters, the breathing air system, and other building control and support equipment. The main floor is comprised of air locks, change rooms, a cask handling facility/loading dock, and a small laboratory with triple HEPA filtered hoods. A control room for remote monitoring of tower operations is also located here. Figure $g$ is a plan drawing of the main floor. The tower portion of the SGEF has both a bridge crane and a gantry crane to assist in removal of generator sections. Tower services include electric power at 110V, $220 \mathrm{~V}$ and $440 \mathrm{~V}, 90 \mathrm{psig}$ compressed air, bottled nitrogen and argon, vacuum for air samples, breathing air, and cold water. Intermediate floors utilize removable gratings to ease positioning of equipment at different heights. The gratings also permit free flow of building air. A portable rigid greenhouse is provided to contain contamination produced during cutting and grinding operations. The portable greenhouse may be positioned at any point in about a $180^{\circ}$ arc around the steam generator. It may be easily moved between the first and second floors. Another rigid greenhouse, not portable, was constructed on the third floor. The 


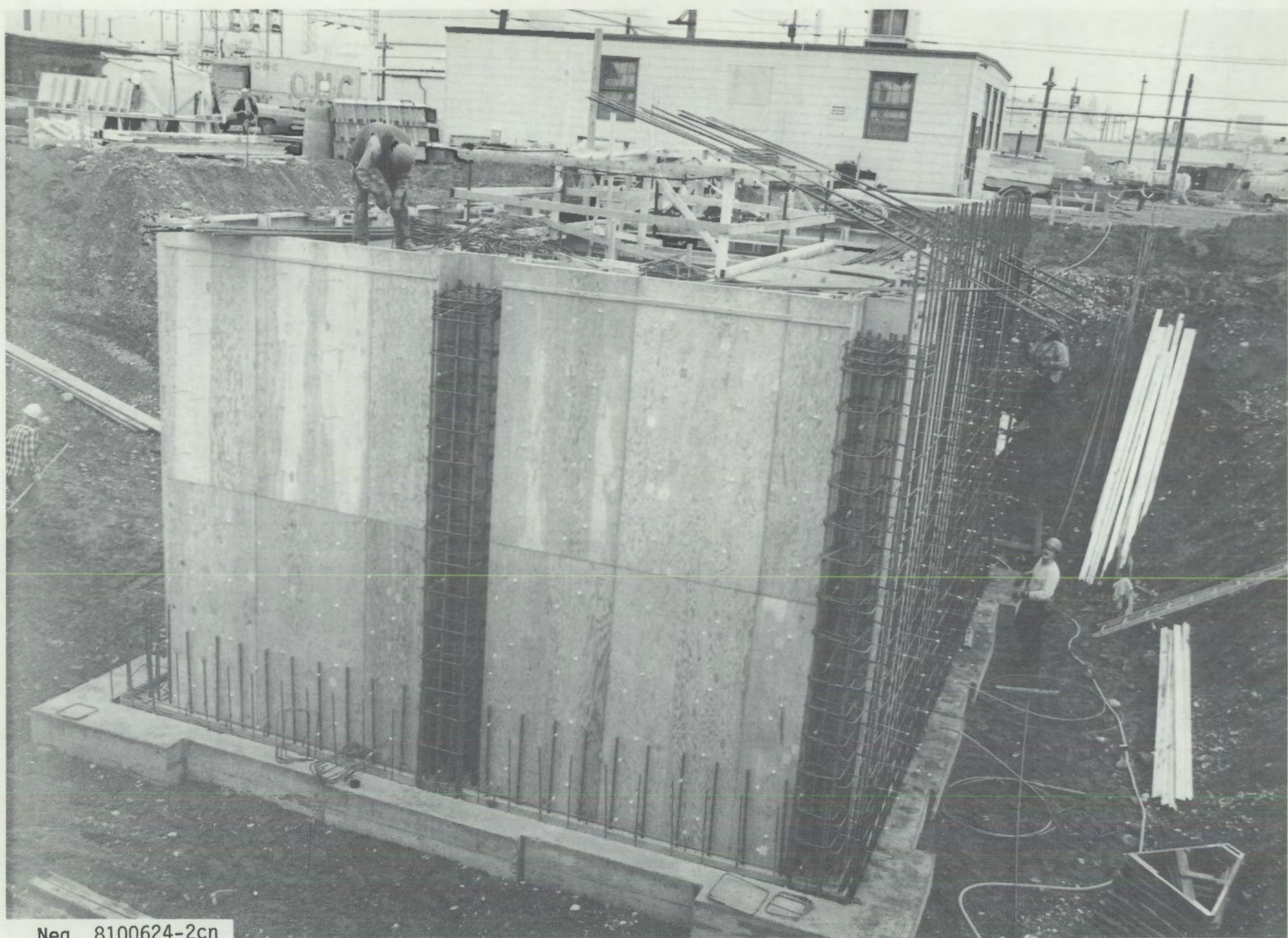

FIGURE 2. Excavation for SGEF 


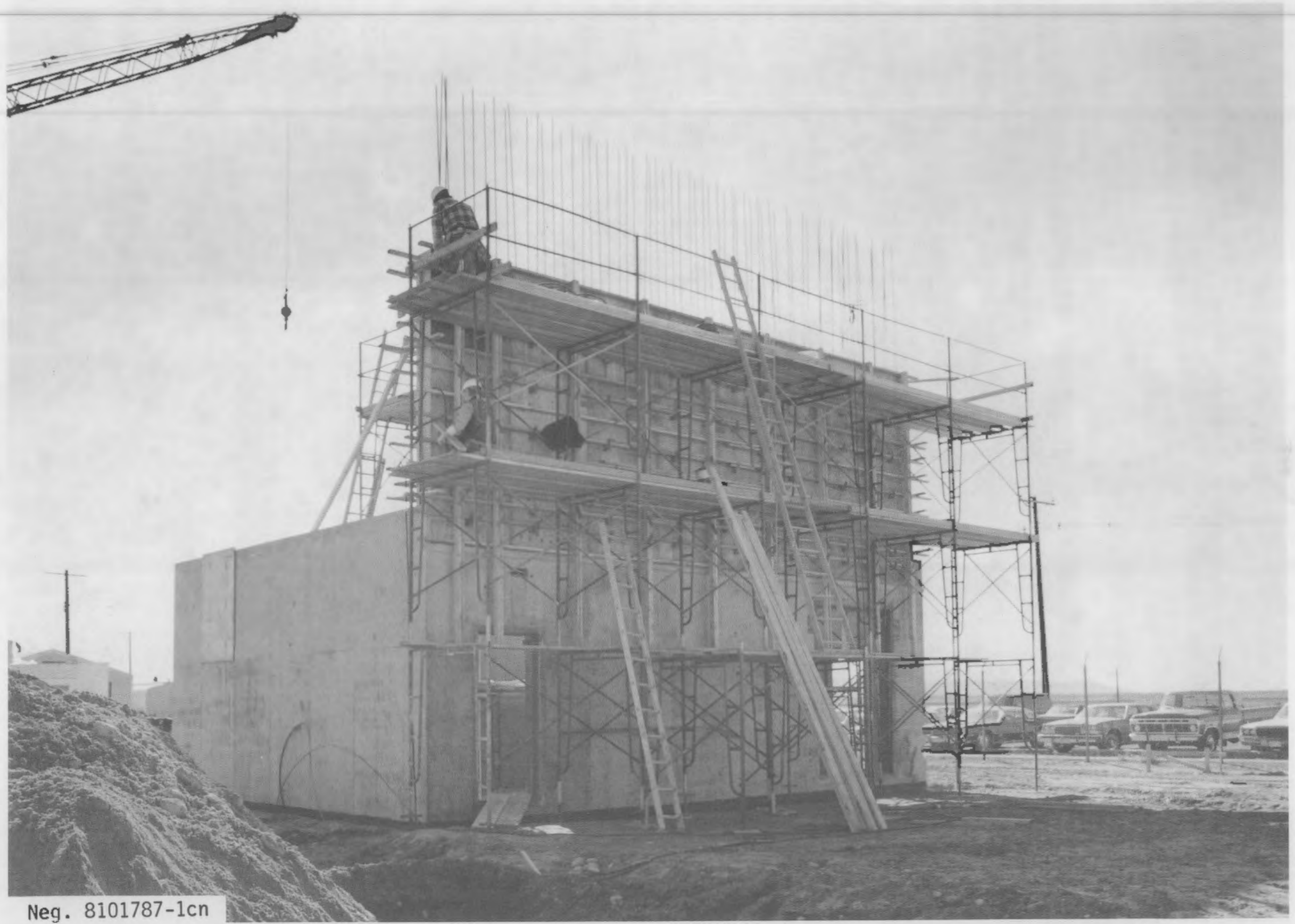

FIGURE 3. Casting SGEF Shielding Walls 


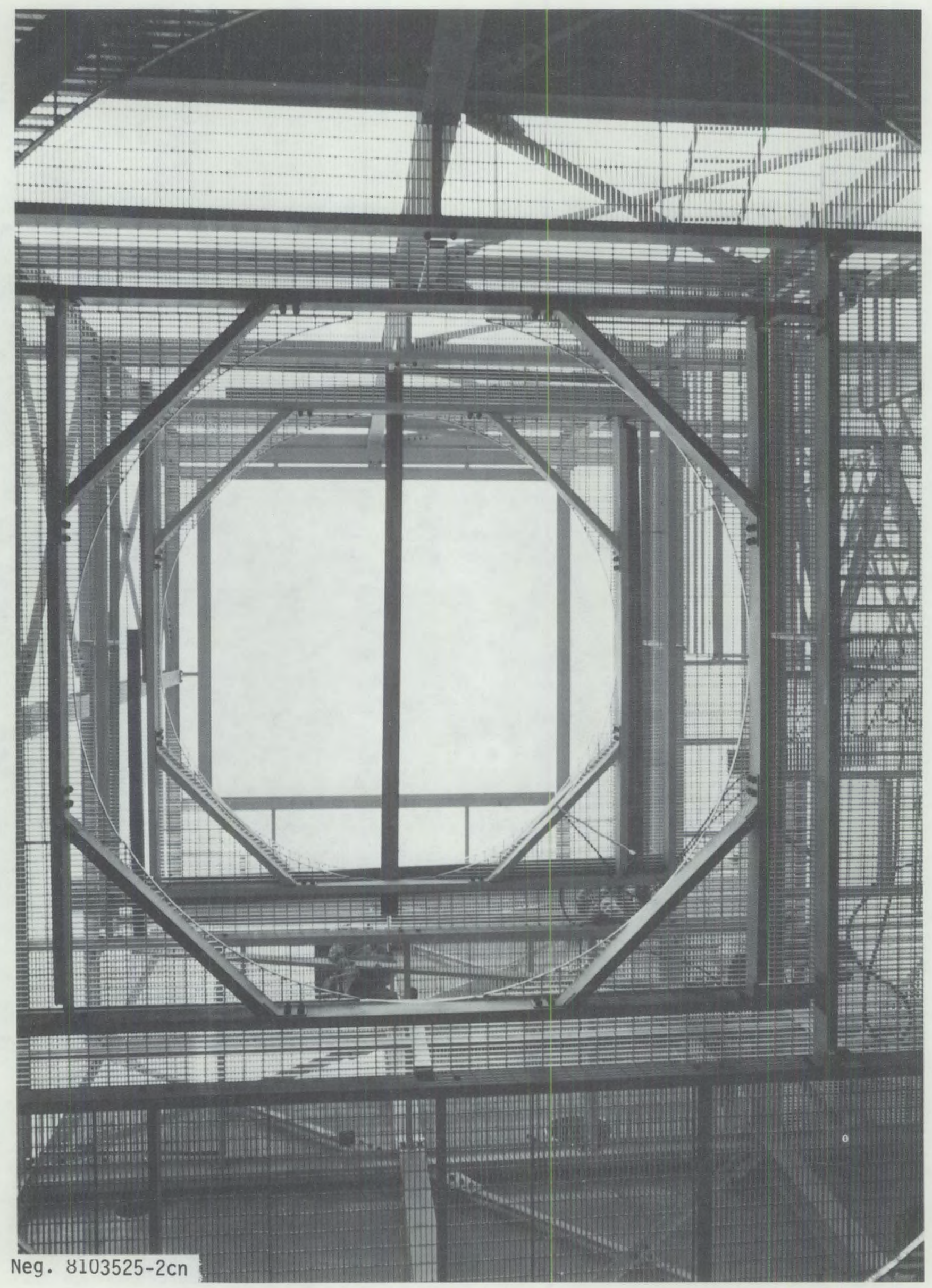

FIGURE 4. SGEF Framework 


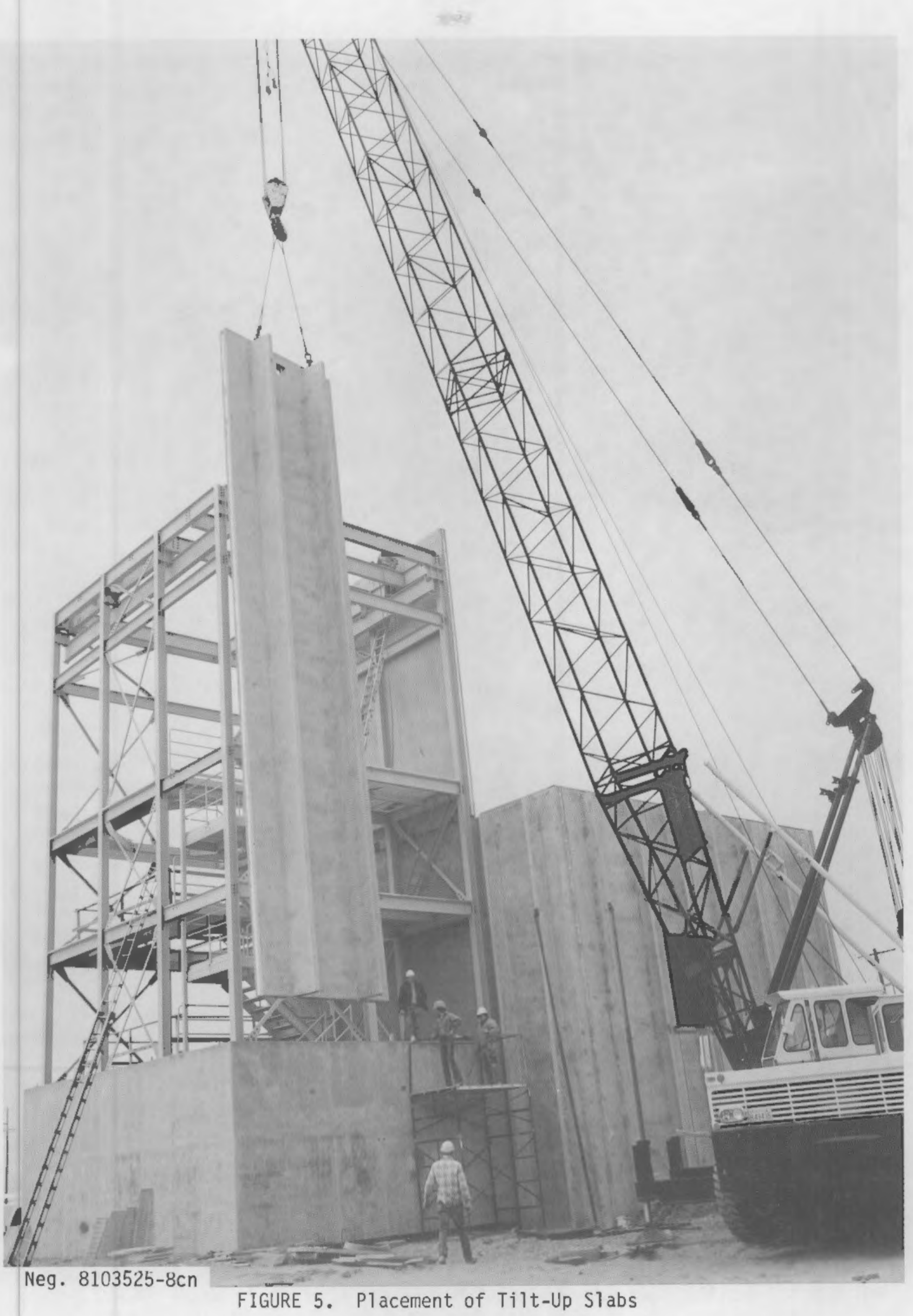




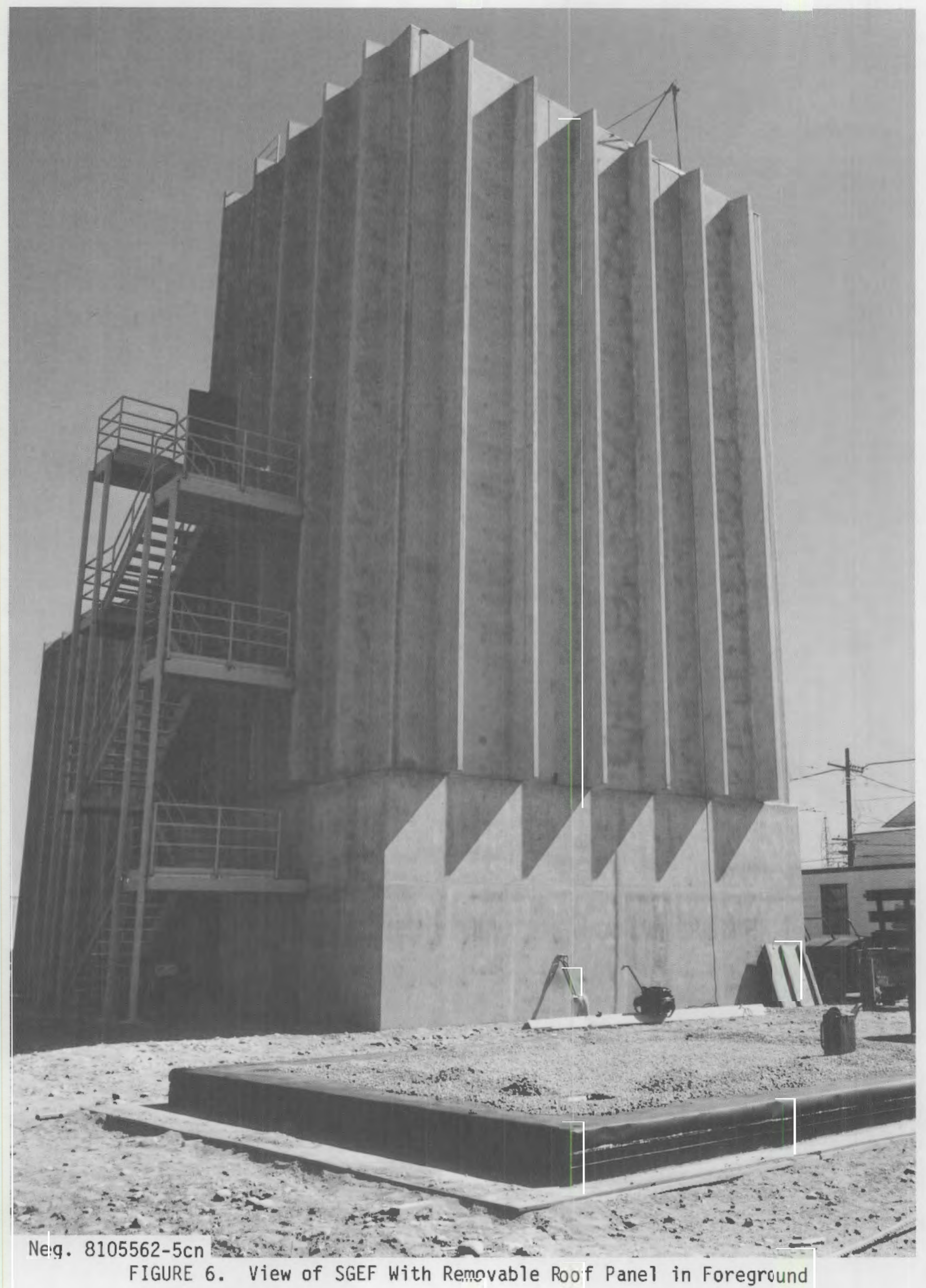




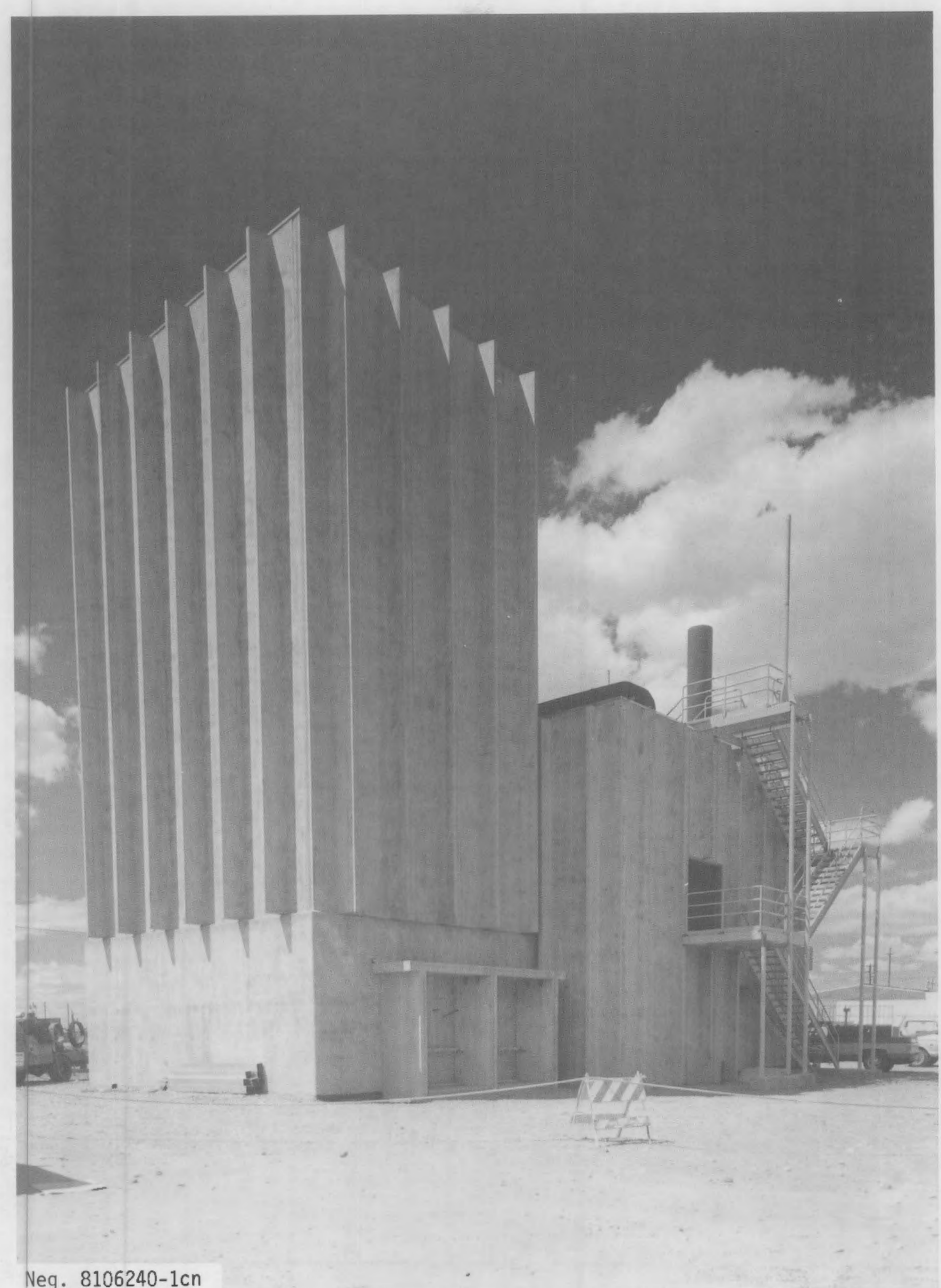

FIGURE 7. View of SGEF 


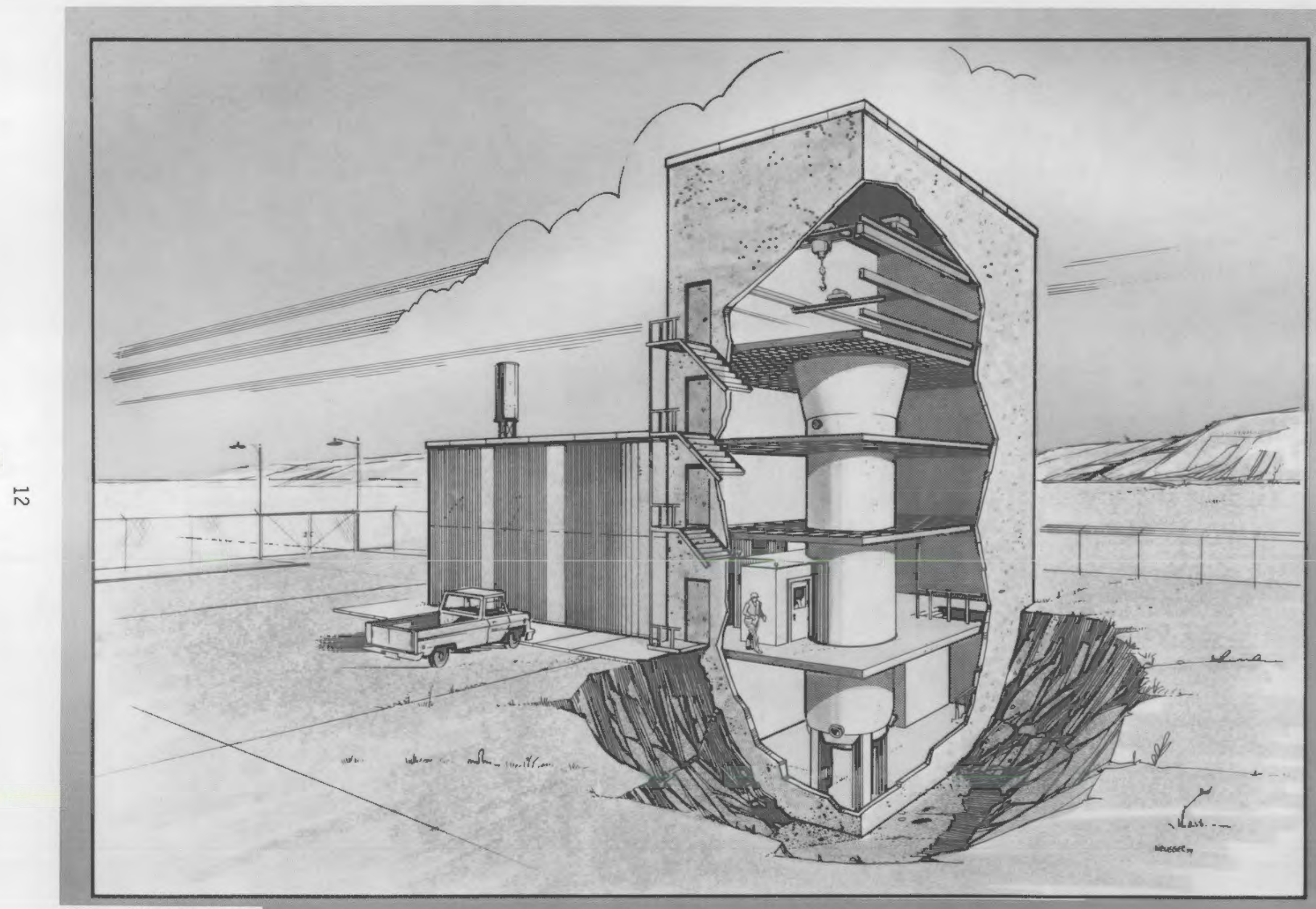

Neq. 80D920-1cn

FIGURE 8. Cut-Away of SGEF Showing Position of Steam Generator 


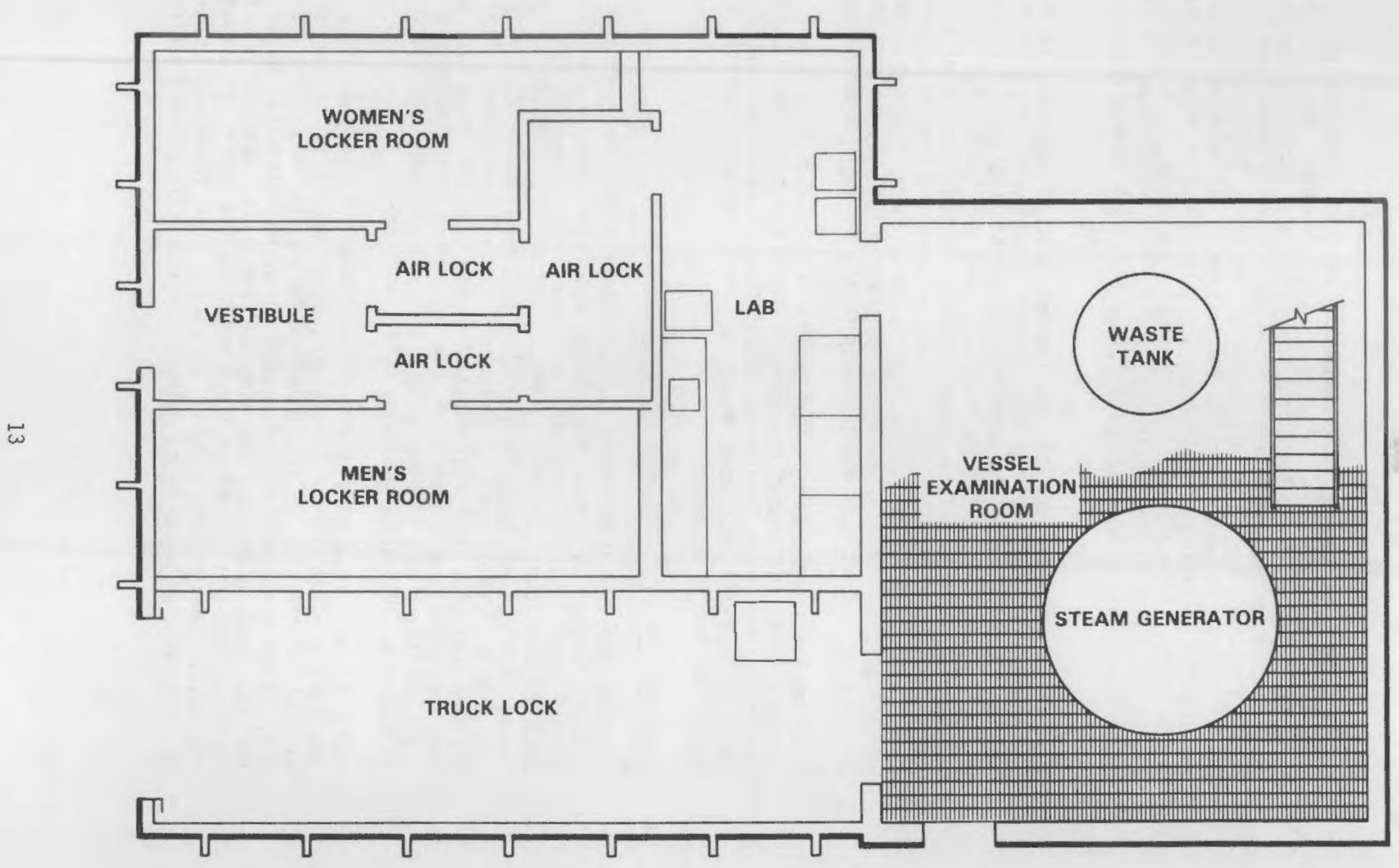

FIGURE 9. Plan Drawing of SGEF Main Floor Neq. 8206911-13 
entire tower is double HEPA filtered and the greenhouses are independently triple HEPA filtered. In the basement of the tower is a 2000 gallon fiberglass tank for storing liquid radioactive waste. Also in the basement, is a $50 \mathrm{gpm}$ stainless steel pump and piping for transferring liquid waste to the truck lock. Figure 10 shows the SGEF tower including the cranes. The roof panel for placing the generator is visible. Figure 11 is a view of the triple HEPA filtered hoods in the support laboratory. Figures 12 and 13 are views in the Equipment Room on the second floor of the Support Building showing the HEPA filter bank and the breathing air system.

The SGEF is located in its own fenced compound adjacent to the Hanford 300 Area. This permits easier access for subcontractor personnel and for non-U.S. participant representatives. In addition to the SGEF itself, three trailers have been positioned in the compound to provide office space, storage, a staff training area, and a computer facility. These trailers were acquired from existing Hanford inventories at no cost to the project. Also adjacent to the SGEF, is a diesel emergency generator that is wired to keep all necessary electrical equipment operating during a power outage.

Prior to loading the Surry steam generator into the SGEF, a set of Standard Operating Procedures were prepared and approved. A full Operational Readiness Review was conducted by a specially appointed board of Battelle facilities managers, health physics experts, and industrial safety personnel.

\section{Position Generator into SGEF (Task 2)}

A competitive bid subcontract was negotiated with Lampson Universal Rigging Company to move the Surry generator from a temporary storage site $\sim 2 \mathrm{~km}$ to the SGEF and place it inside the SGEF. A detailed procedure for the entire operation was prepared by the subcontractor (see Appendix A). It included stress calculations for the equipment used, safety and security measures, health physics controls, and qualification tests for all rigging. All work was done consistent with the intent of the Department of Energy Hoisting and Rigging Manual. It was reviewed and approved by Battelle, DOE, and J.A. Jones safety personnel.

Owing to the fact that the P-4 preshipment inspection port is immediately above one of the lifting trunnions, a stress analysis was made of the area to assure safety during the lift. The analysis, shown in Appendix B, indicated adequate strength. Owing to the low temperature at the time of the lift, about $20^{\circ} \mathrm{F}$, the trunnion, and all of the adjacent metal of the shell, were heated for several hours with a torch to assure that there was no possibility of that metal being below its nil-ductility temperature. 


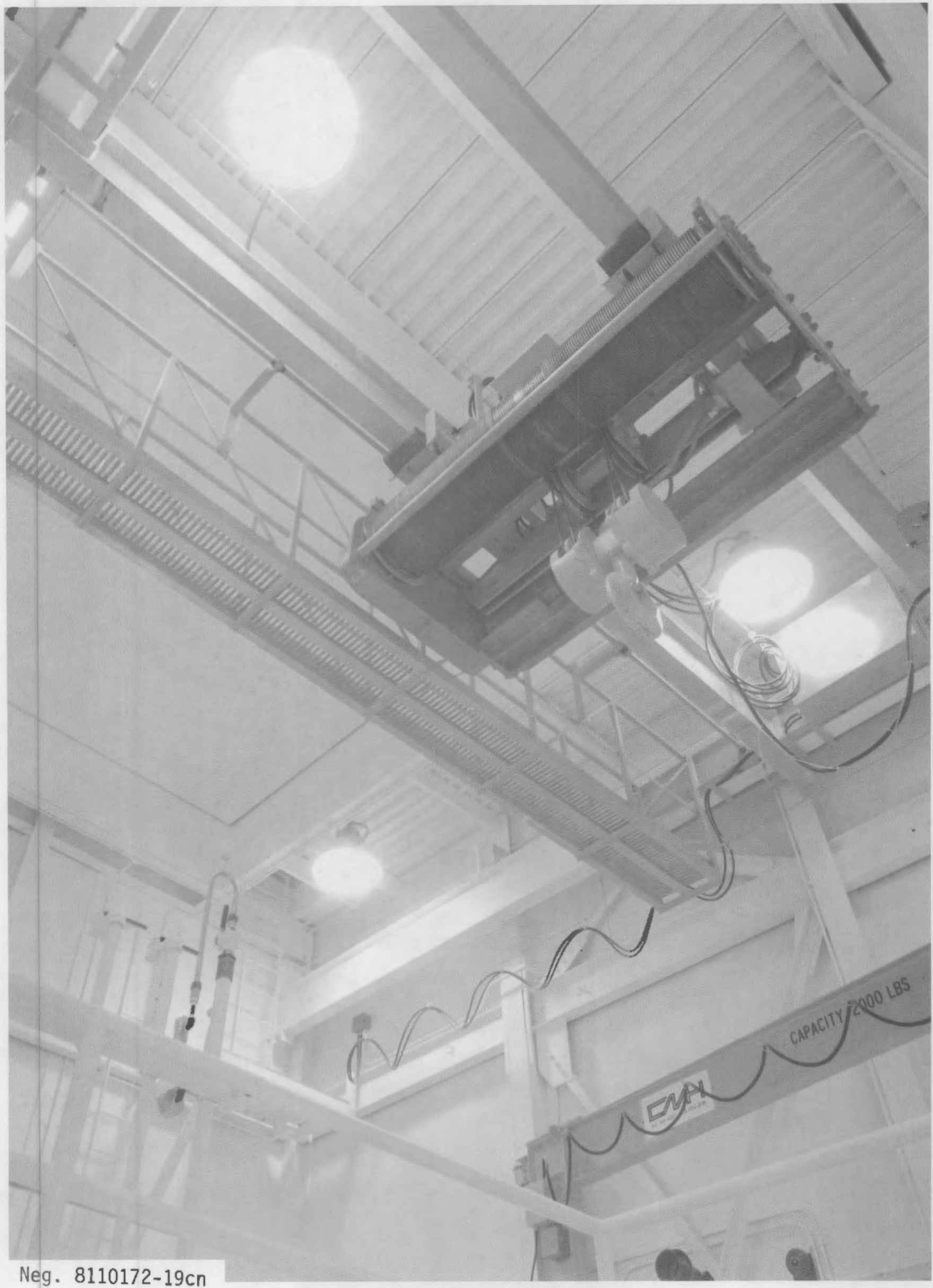

FIGURE 10, View of SGEF Cranes 


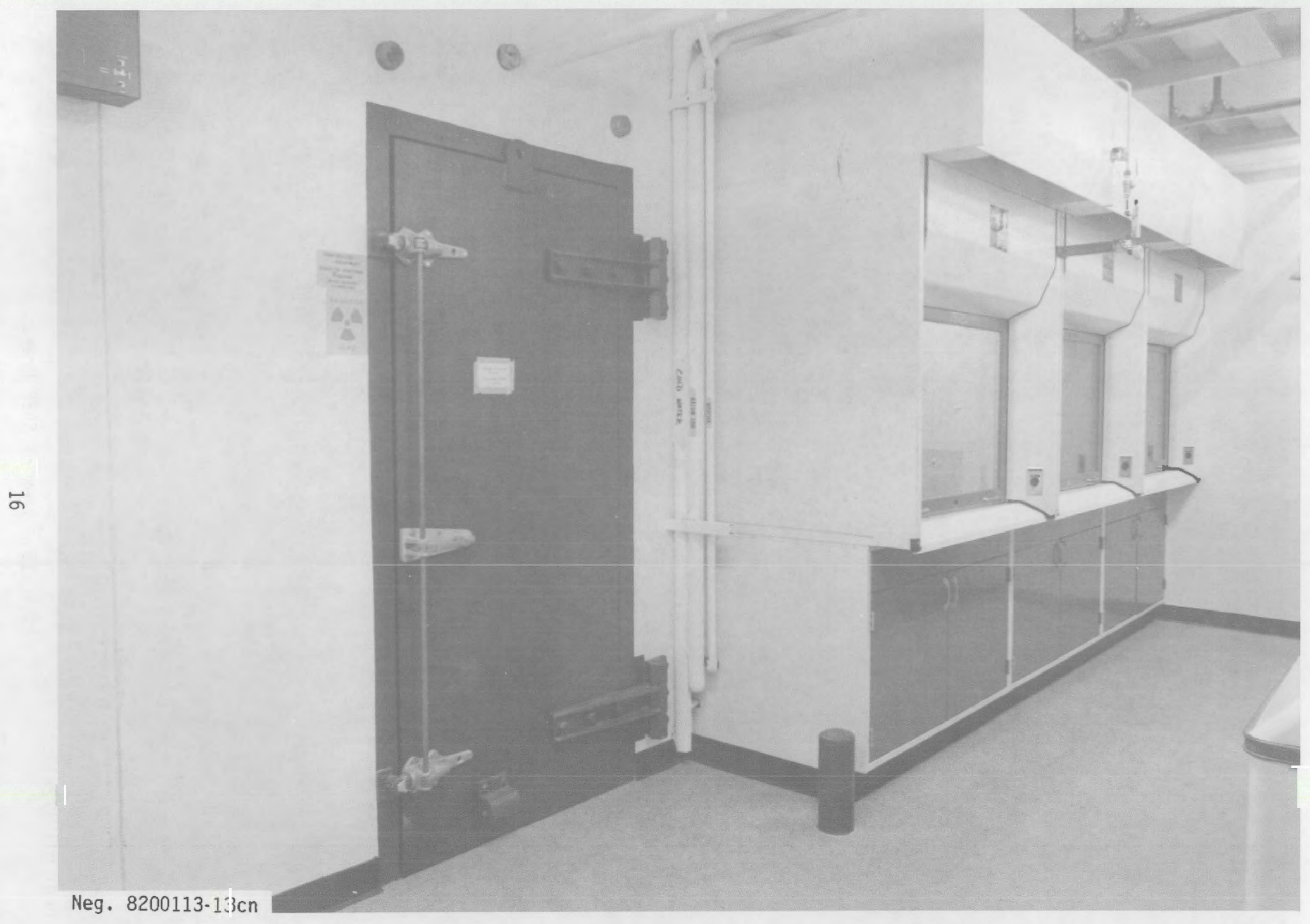

FIGURE 11. HEPA-Filtered Laboratory Hoods, Access Door to Tower 


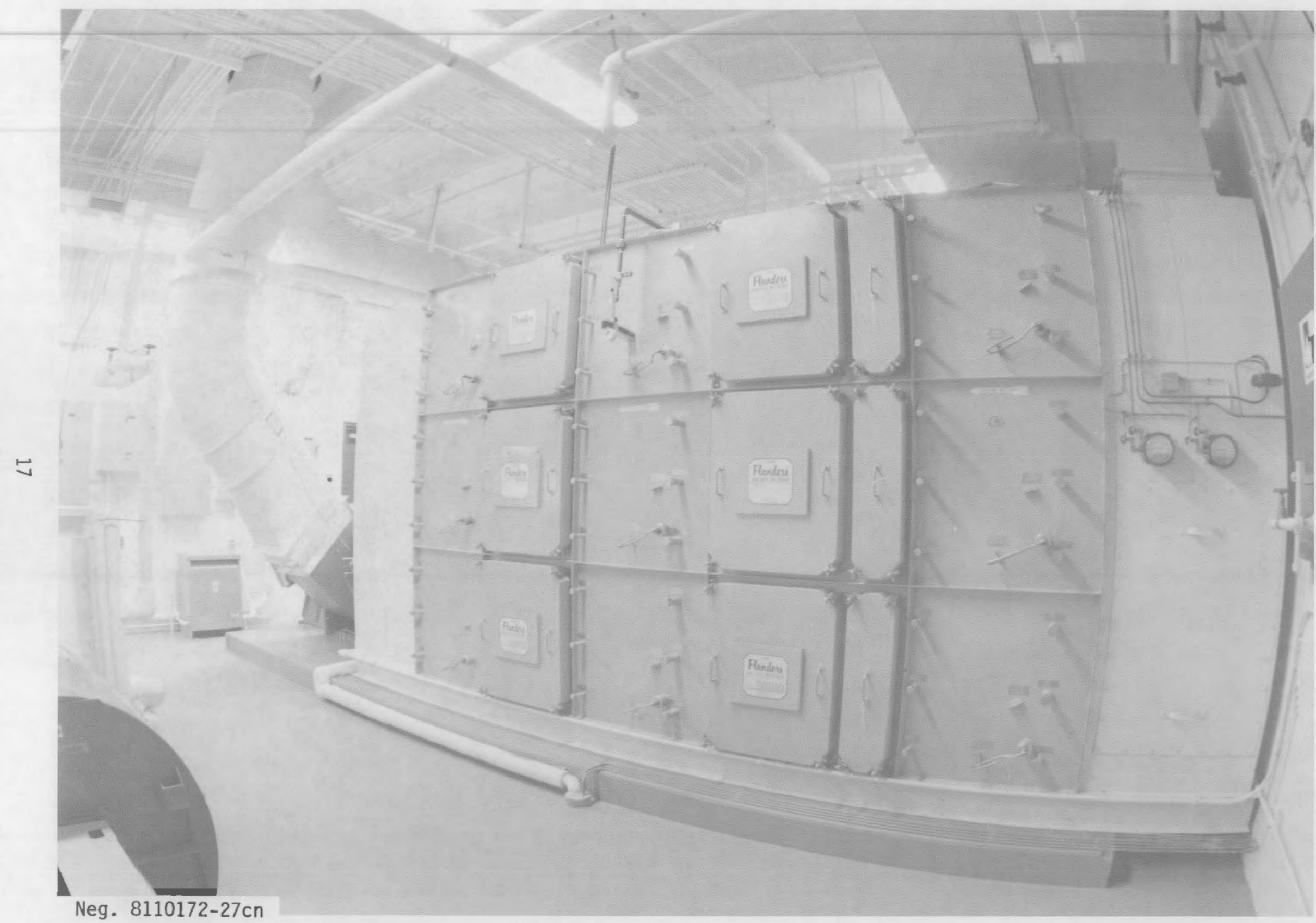

FIGURE 12. HEPA Filter Bank in Equipment Room 


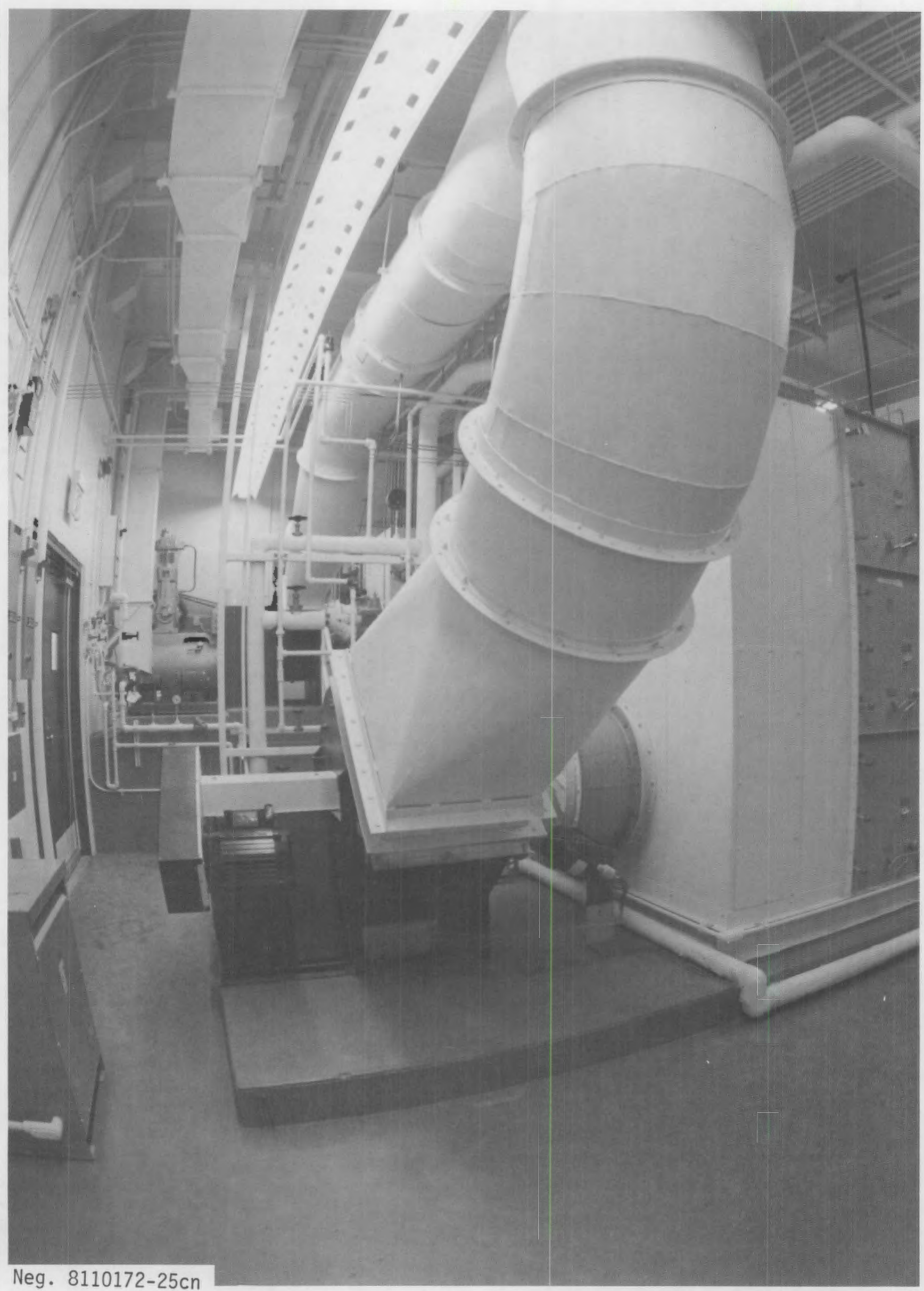


The fit-up between the bottom of the steam generator and the support structure was tested by removing the support structure from the SGEF and bolting it to the generator in the field. The bowl of the generator was found to interfere with one of the transverse members of the support structure. Four 8 " thick shims were fabricated and attached to the generator support pads to eliminate this interference. The changed height of the generator relative to each level in the SGEF tower was deemed acceptable.

The Manitowoc Model 4100 Ringer Crane, shown in Figure 14, was assembled and tested at the temporary storage site. It was used to load the generator onto a special rubber-tired trailer, which was then moved to the SGEF site (Figures 15 and 16). The crane was disassembled and moved to the SGEF site also, where it was reassembled. A pit filled with sand bags was dug under the steam generator bowl to serve as a pivot during the upending (Figure 17). On January 11, 1982, the 220-ton steam generator was then lifted, lowered through a removable roof panel into the SGEF tower (Figures 18 through 21), and bolted in place.

Health Physics (Task 3)

The health physics task provides procedures for personnel exposure monitoring, control, training, and documentation. An automated training program with slides illustrating all of the SGEF safety features was assembled and narrated. All personnel working in the building view this training program. Research activities include radiologic mapping, determination of decontamination effectiveness, and evaluation of waste and waste disposal problems associated with various operations. A specific accomplishment was the exposure control for moving the steam generator into the SGEF. Radiation control procedures were prepared and reviewed for reopening the preshipment shell penetrations (Task 5), and for entering the primary side through the channel head manways in preparation for Tasks $6,7,8$, and 9 . Once the generator was positioned in the SGEF, the first order of business was to develop radiation field maps of the generator itself and of work areas in the SGEF tower (Ref. 2). Figures 22 and 23 show radiation levels at contact and at three feet from the external surface of the generator. Figures 24 through 28 are maps of radiation levels around the generator, at each working level of the SGEF tower. These maps aid in planning work procedures to minimize personnel exposure. Table 2 shows radiation levels inside the tube bundle. These measurements were taken from the secondary side by positioning thermoluminescent dosimeter (TLD) trains through existing shell penetrations. A radiation level sampling system was established at various perimeter locations surrounding the SGEF (see Figure 29). Table 3 provides quarterly results. Dose rate information enhanced the planning of subsequent tasks to provide for ALARA personnel exposures. Steel plate shielding was placed on studs spot welded to the shell at strategic work locations, cutting exposure rates in half. Steel was far less expensive than lead, and much easier to handle. 


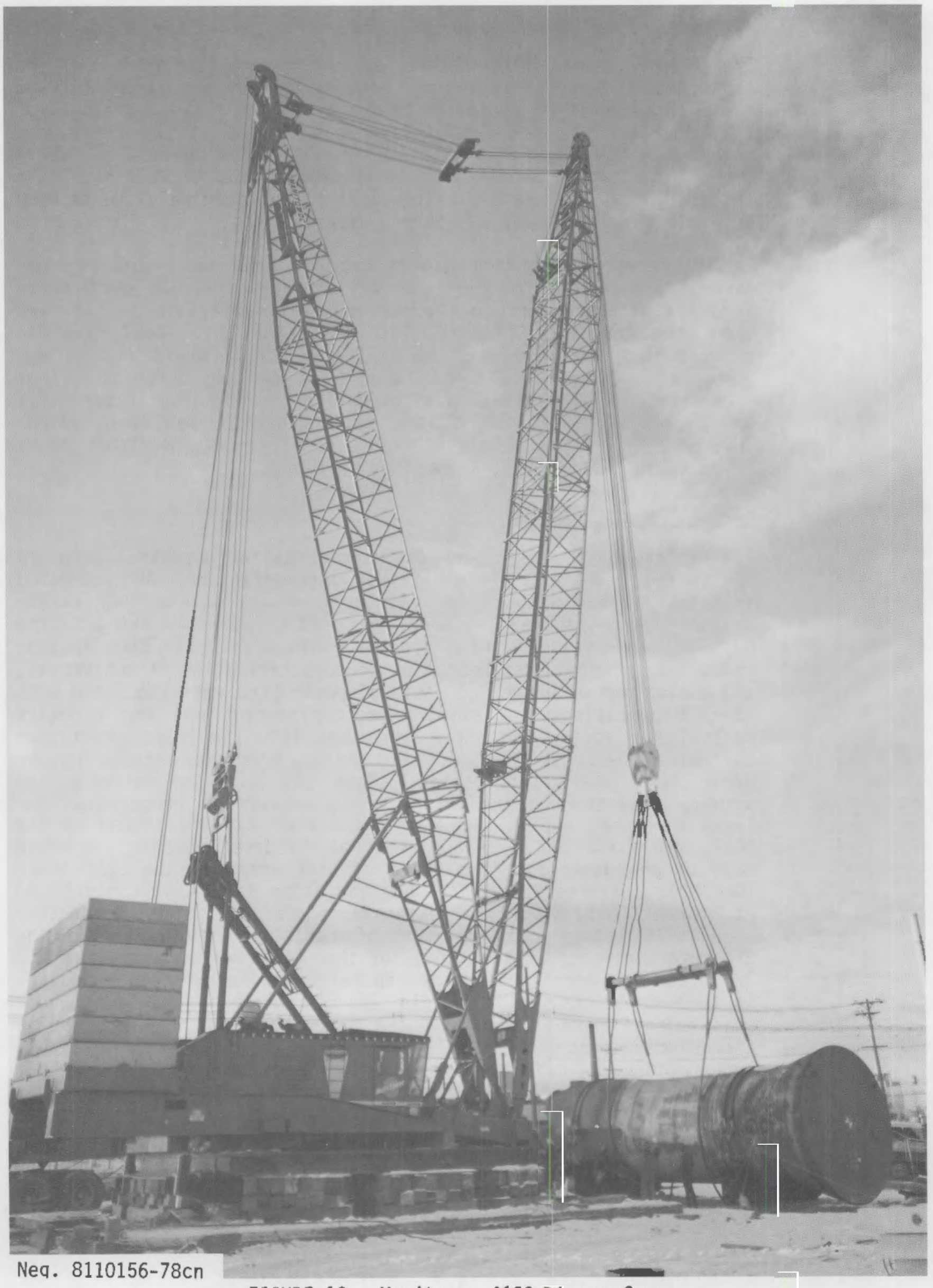

FIGURE 13. Manitowoc 4100 Ringer Crane 


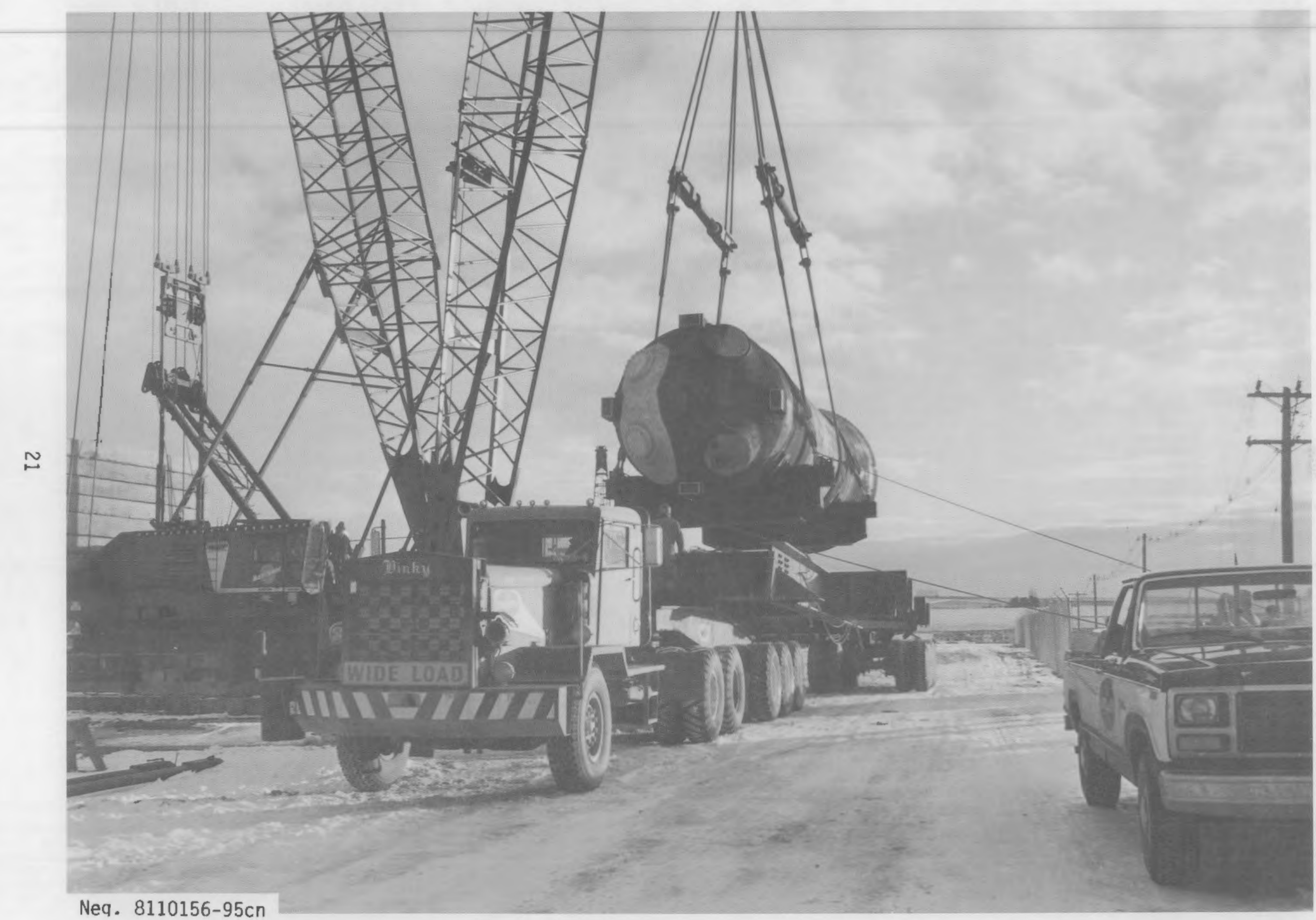

FIGURE 15. Lifting Generator Onto Trailer 


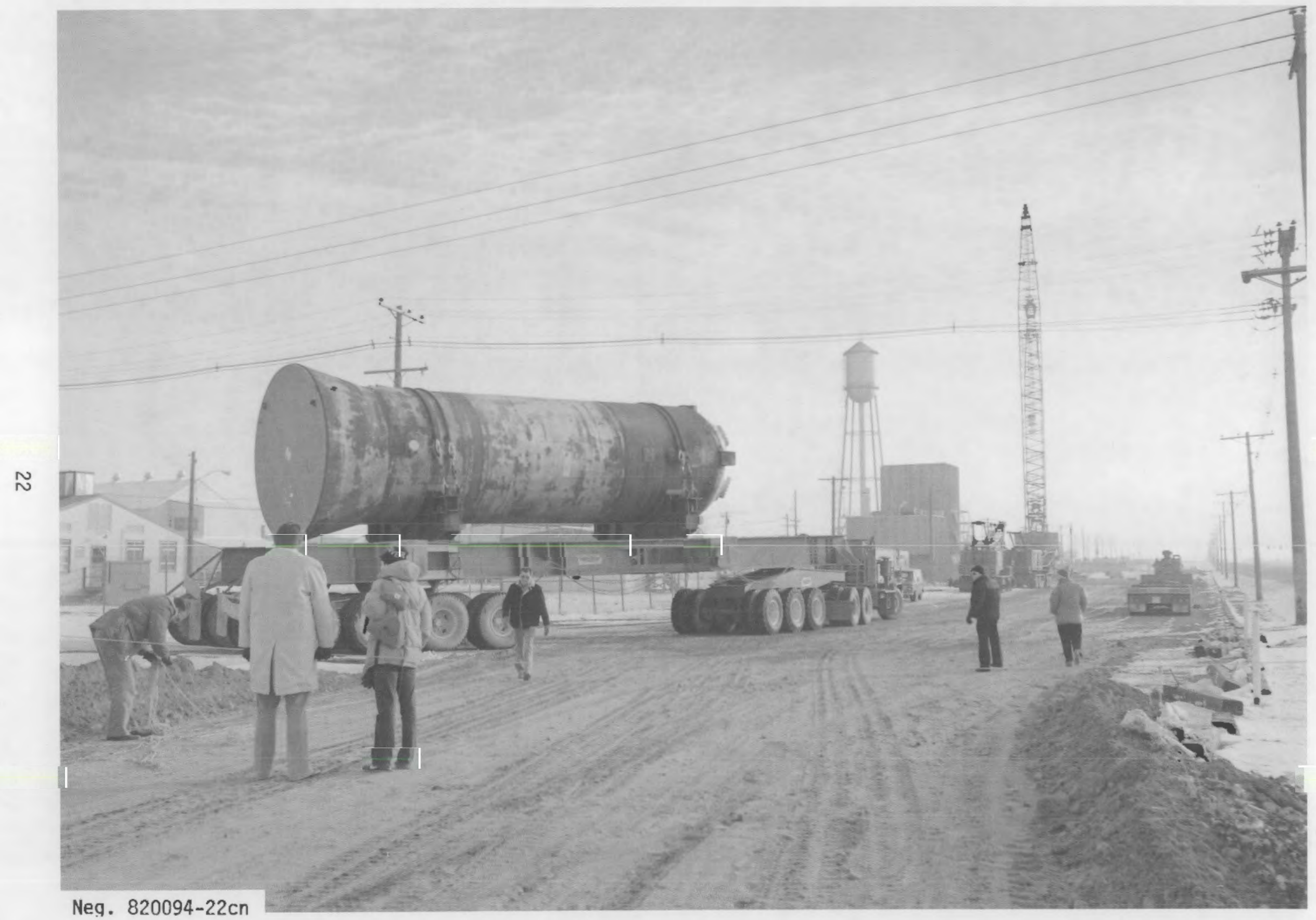

FIGURE 16. Moving Generator to SGEF Site 


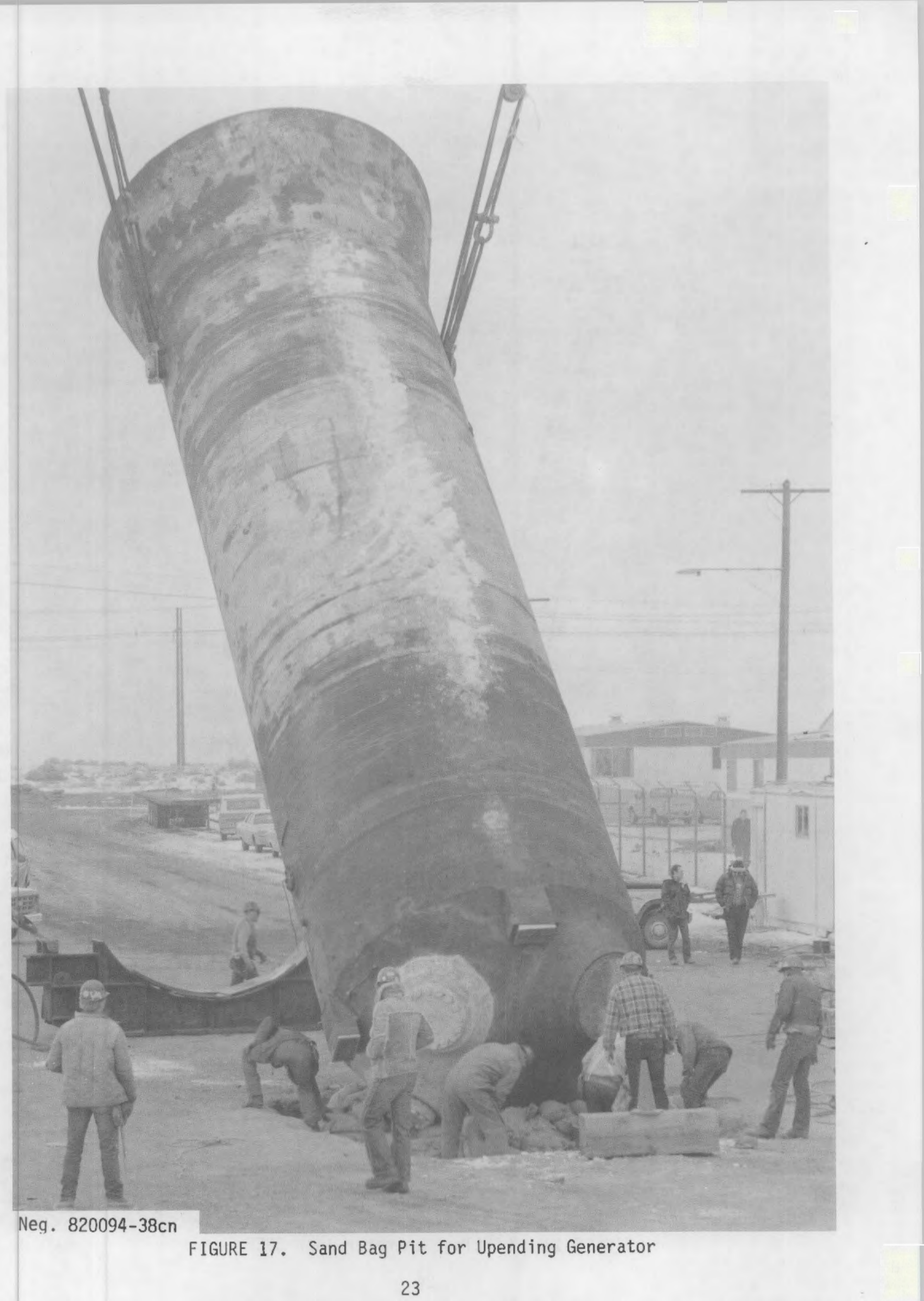




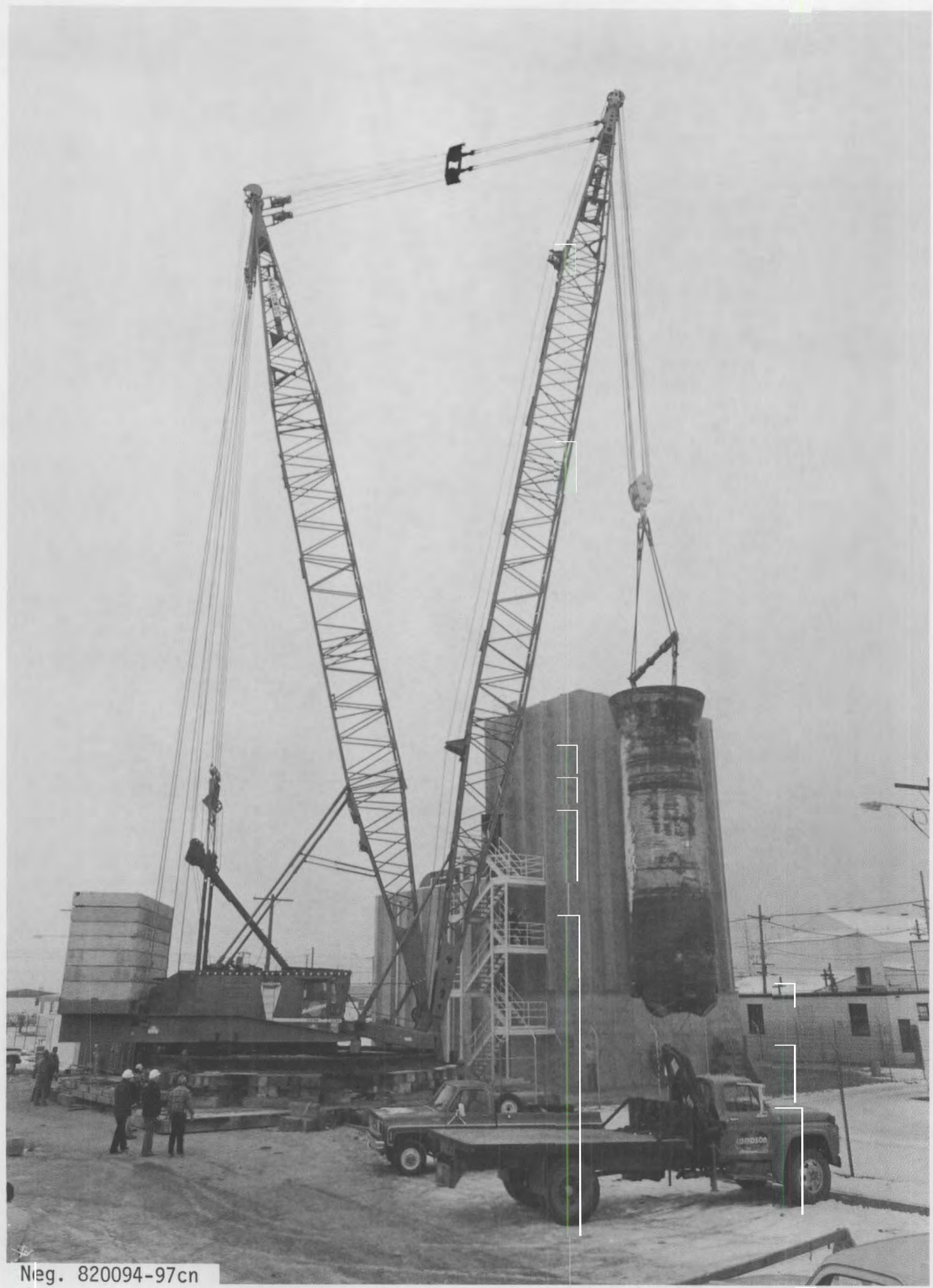

FIGURE 18. Lifting Generator Into SGEF 


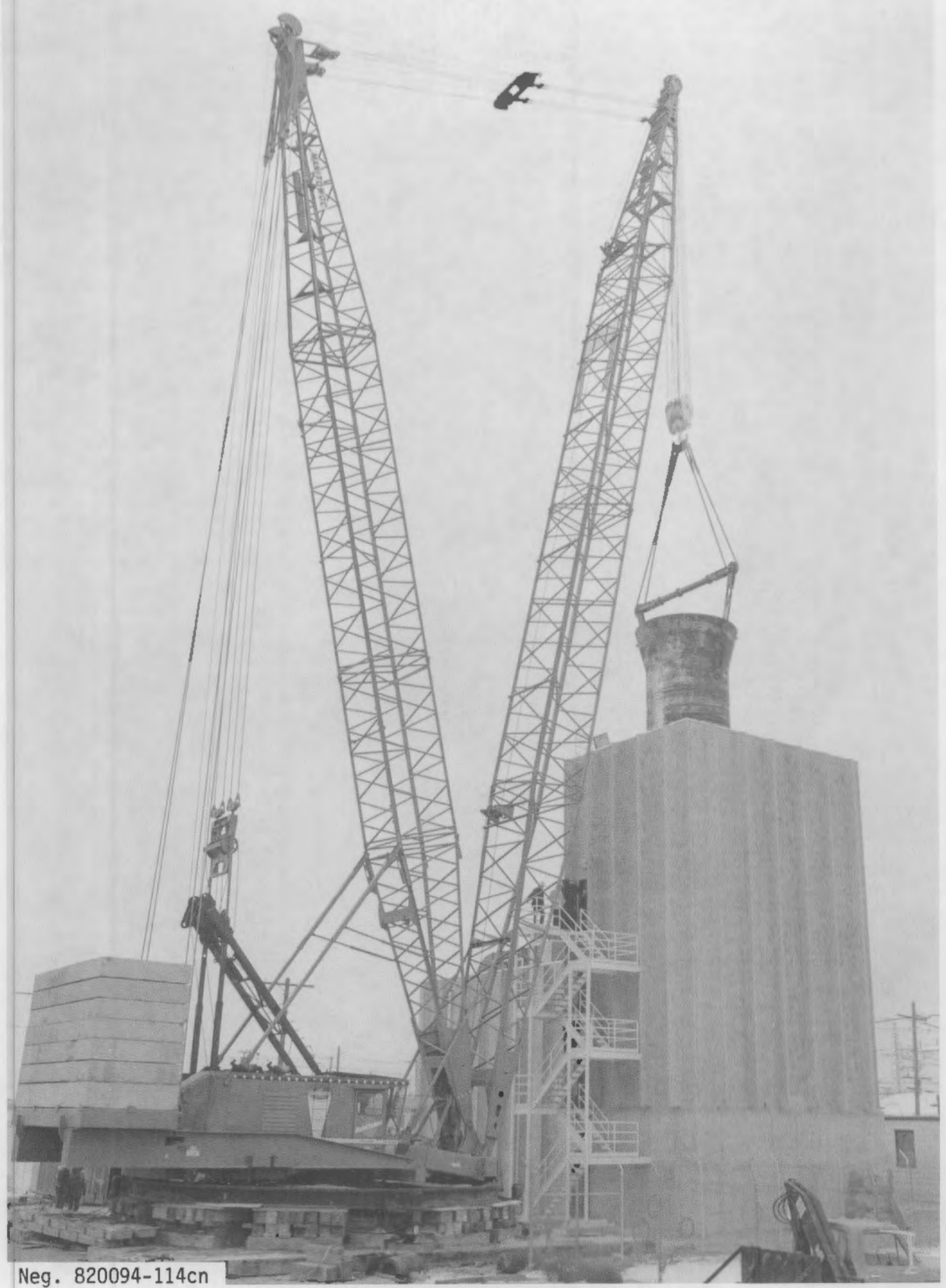

FIGURE 19. Lifting Generator Into SGEF 


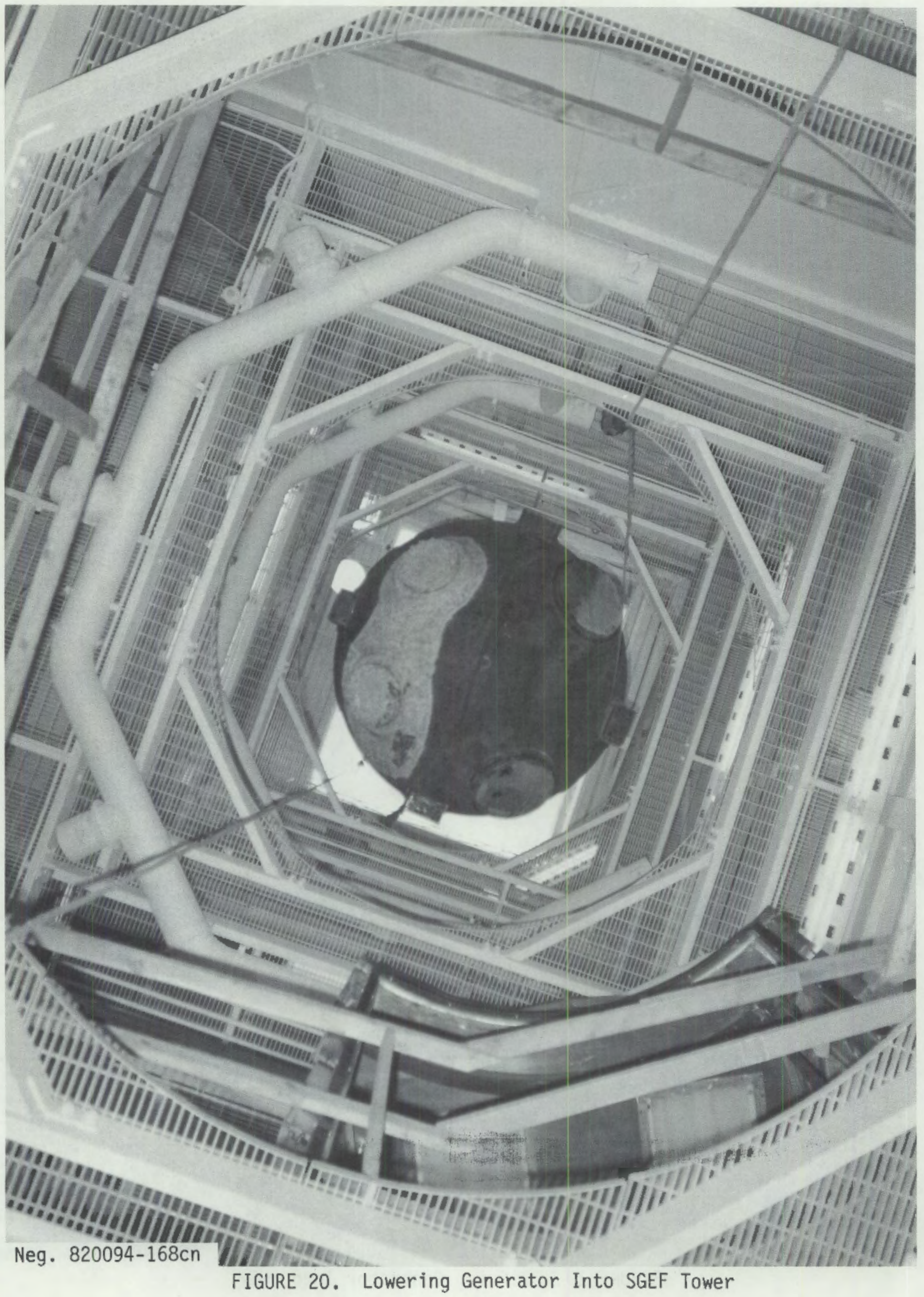




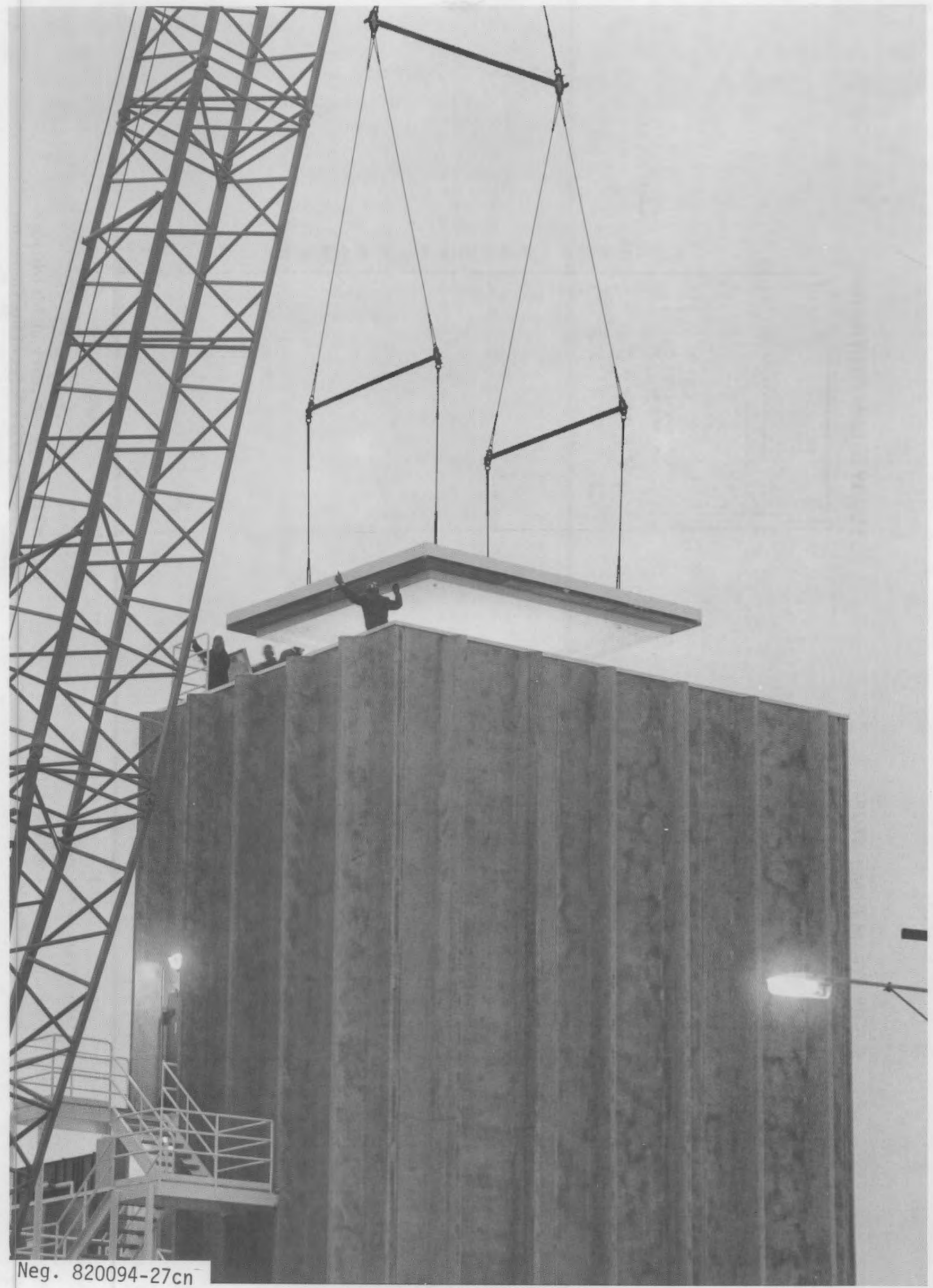

FIGURE 21. Replacing Roof Panel on SGEF 
SURRY STEAM GENERATOR

\section{SURRY STEAM GENERATOR}

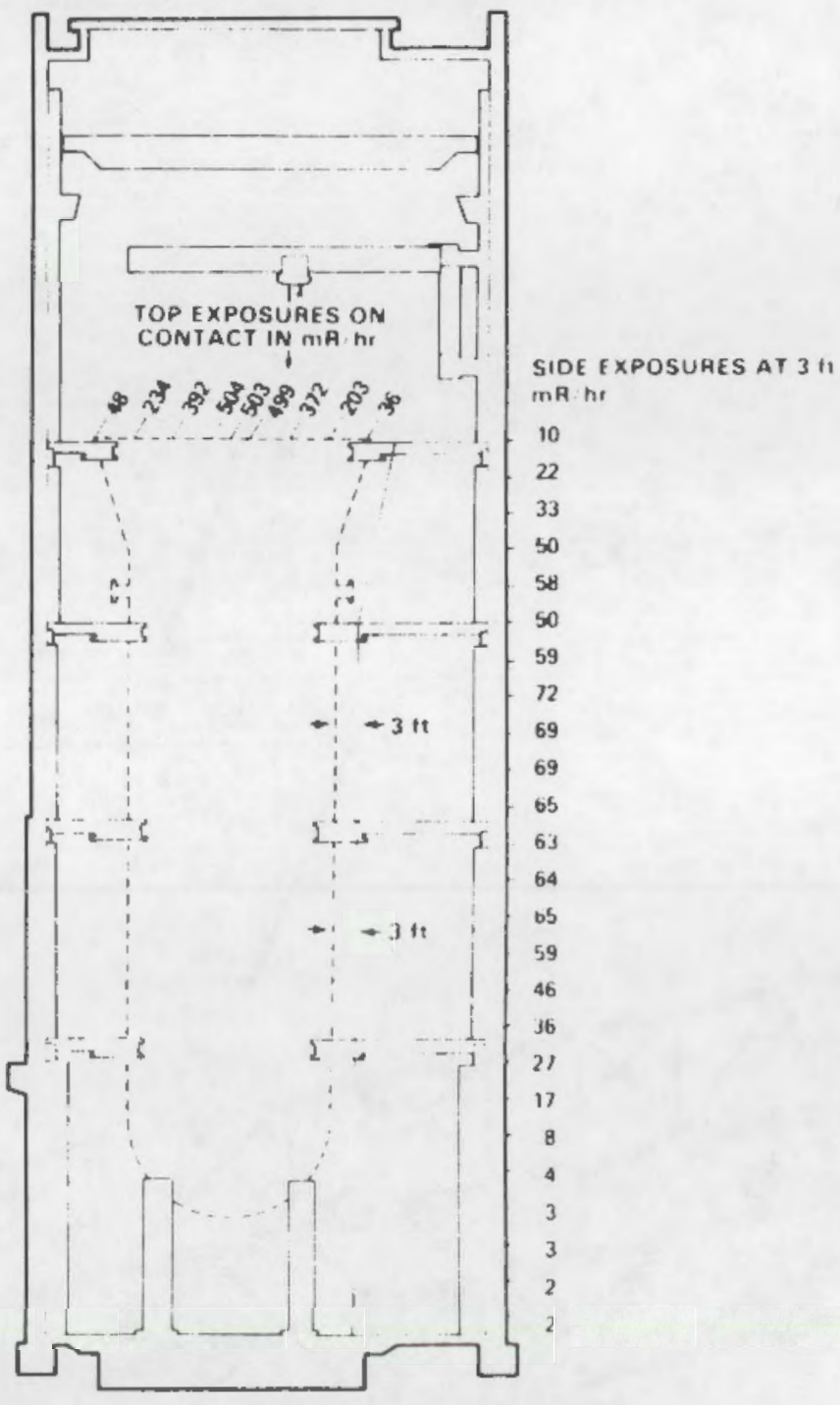

Figure 23. Radiation Levels at 3-ft Distance from the Sides of the Generator
Figure 22. Radiation Levels at Contact of the Generator in the SGEF 


\section{RADIOLOGICAL SURVEY DOSE PROFILE}

OF SURRY STEAM GENERATOR

\section{LEVEL - 1st FLOOR}

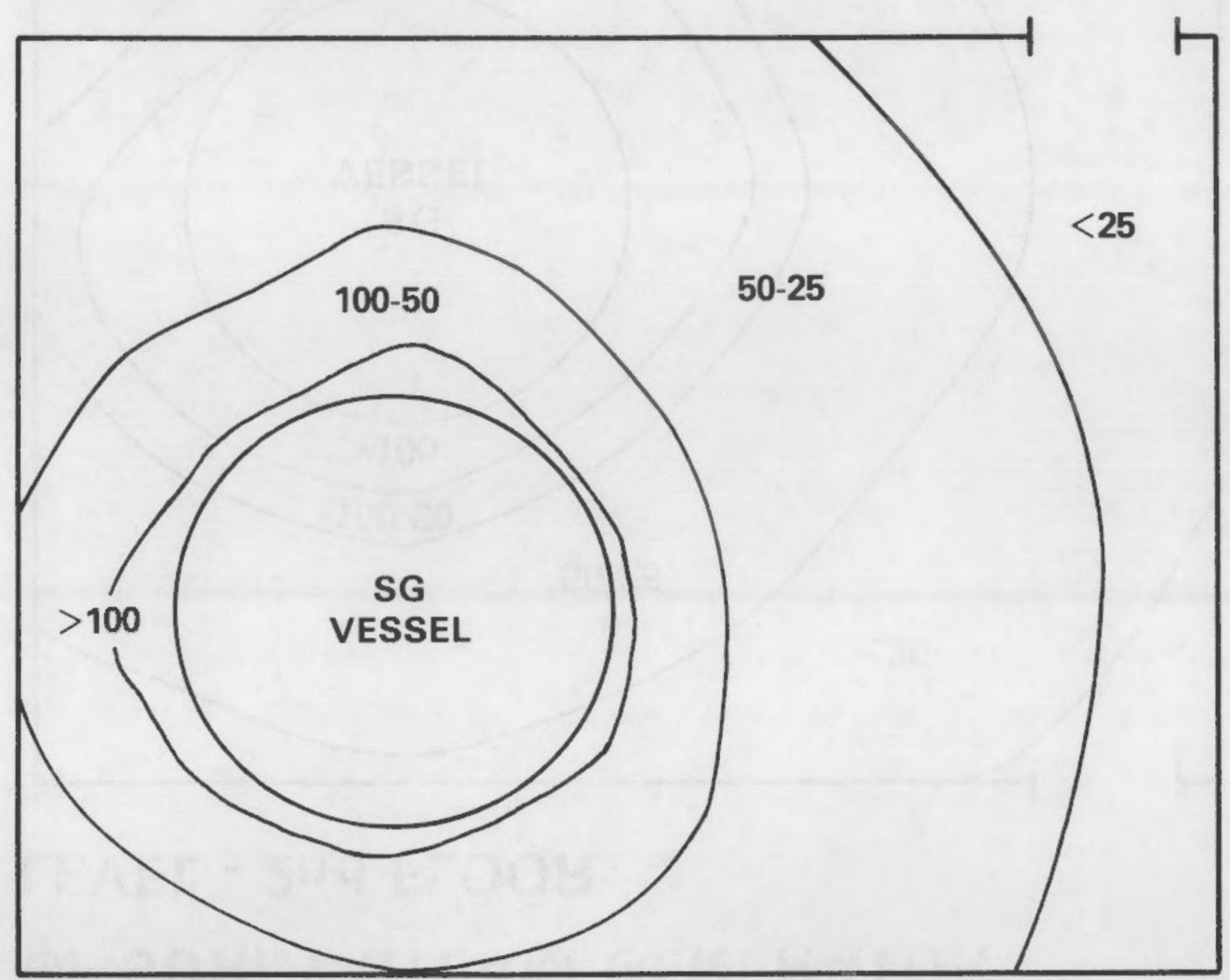

*DOSE RATES ARE IN mR/hr

FIGURE 24. Radiological Map - 1st Floor Level 


\section{RADIOLOGICAL SURVEY DOSE PROFILE OF SURRY STEAM GENERATOR}

\section{LEVEL - 2nd FLOOR}

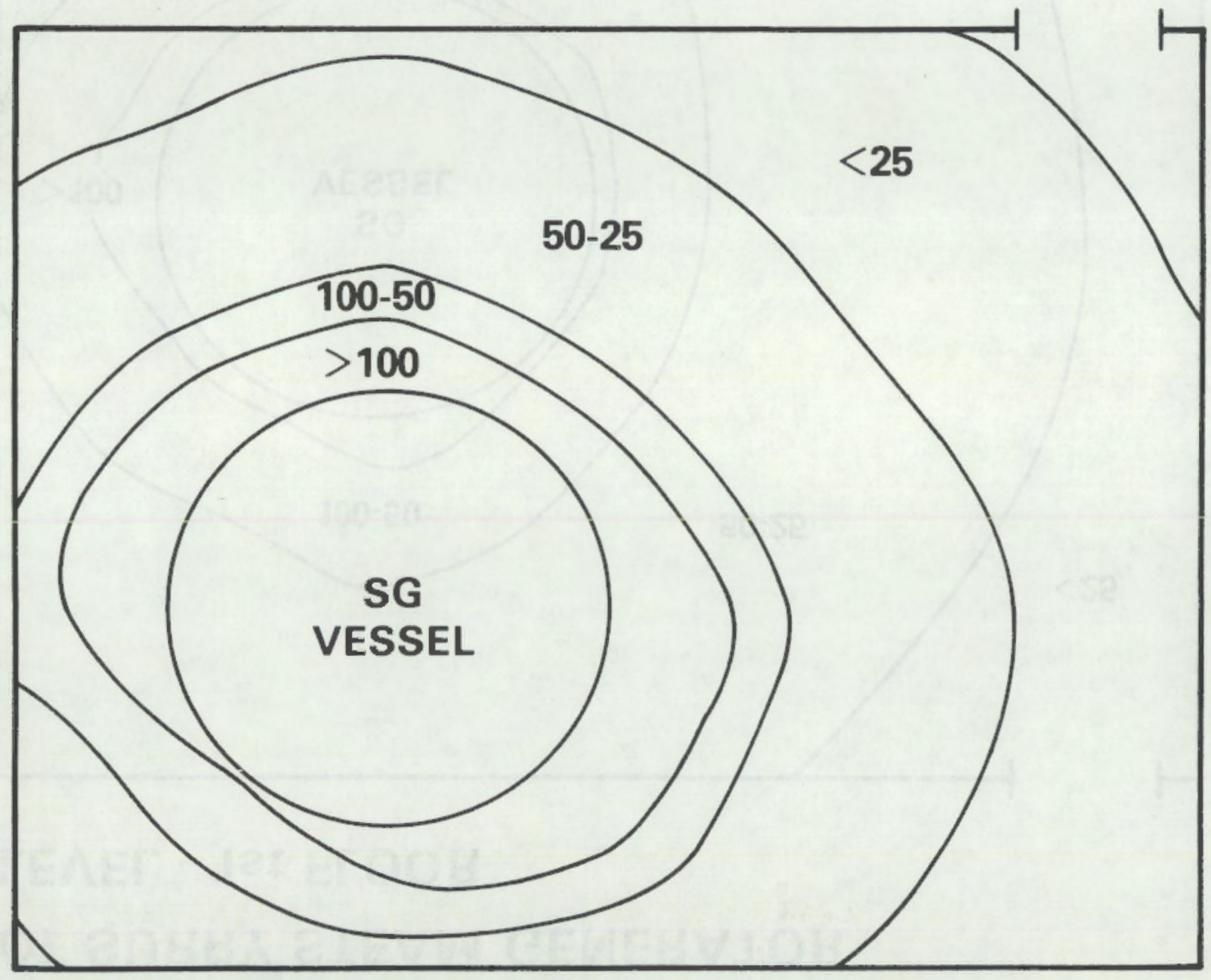

*DOSE RATES ARE IN mR/hr

FIGURE 25. Radiological Map - 2nd Floor Level 


\section{RADIOLOGICAL SURVEY DOSE PROFILE OF SURRY STEAM GENERATOR}

\section{LEVEL - 3rd FLOOR}

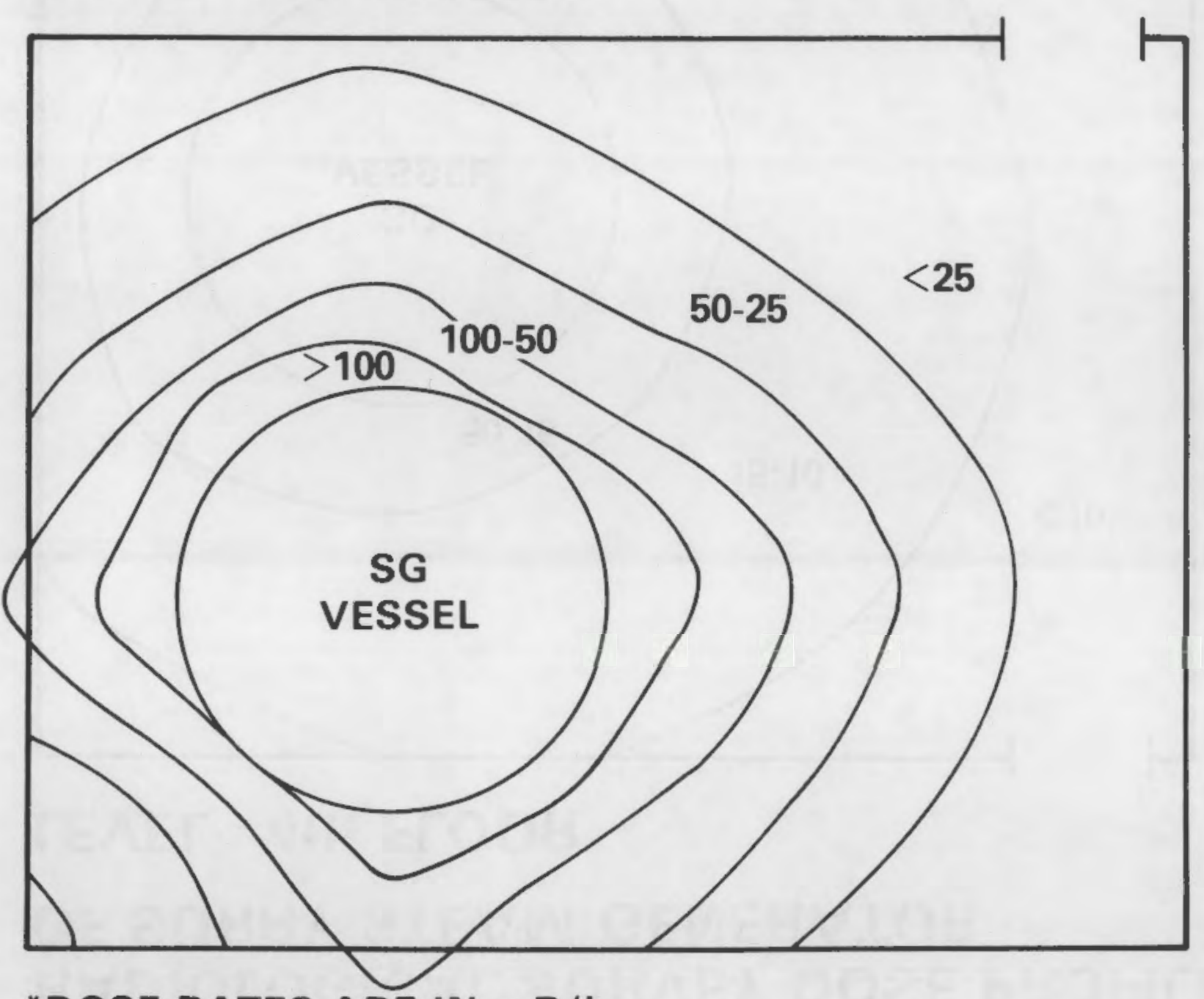

*DOSE RATES ARE IN mR/hr

FIGURE 26. Radiological Map - 3rd Floor Level 


\section{RADIOLOGICAL SURVEY DOSE PROFILE OF SURRY STEAM GENERATOR}

\section{LEVEL - 4th FLOOR}

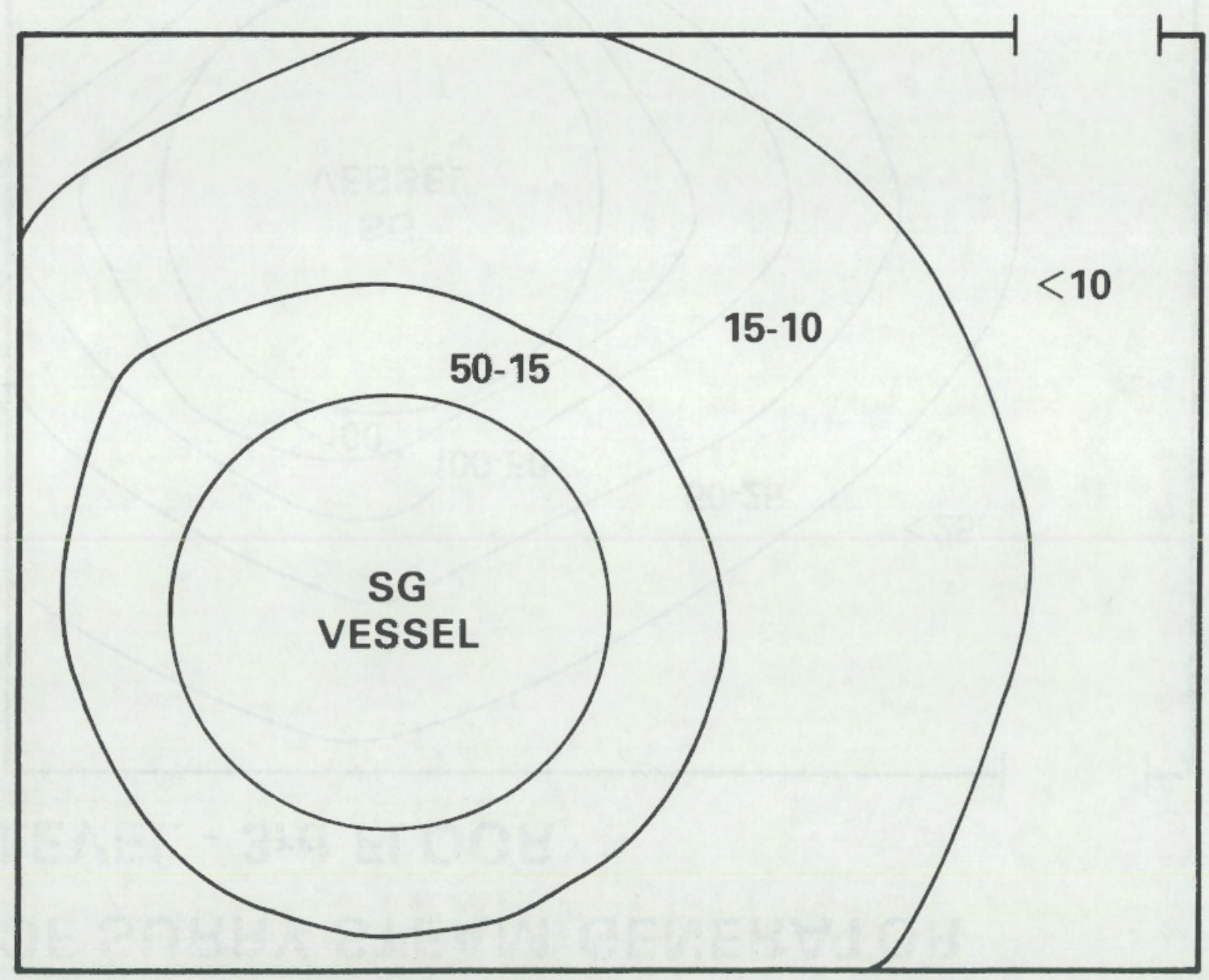

*DOSE RATES ARE IN $\mathrm{mR} / \mathrm{hr}$ 


\section{RADIOLOGICAL SURVEY DOSE PROFILE OF SURRY STEAM GENERATOR}

\section{LEVEL - BASEMENT}

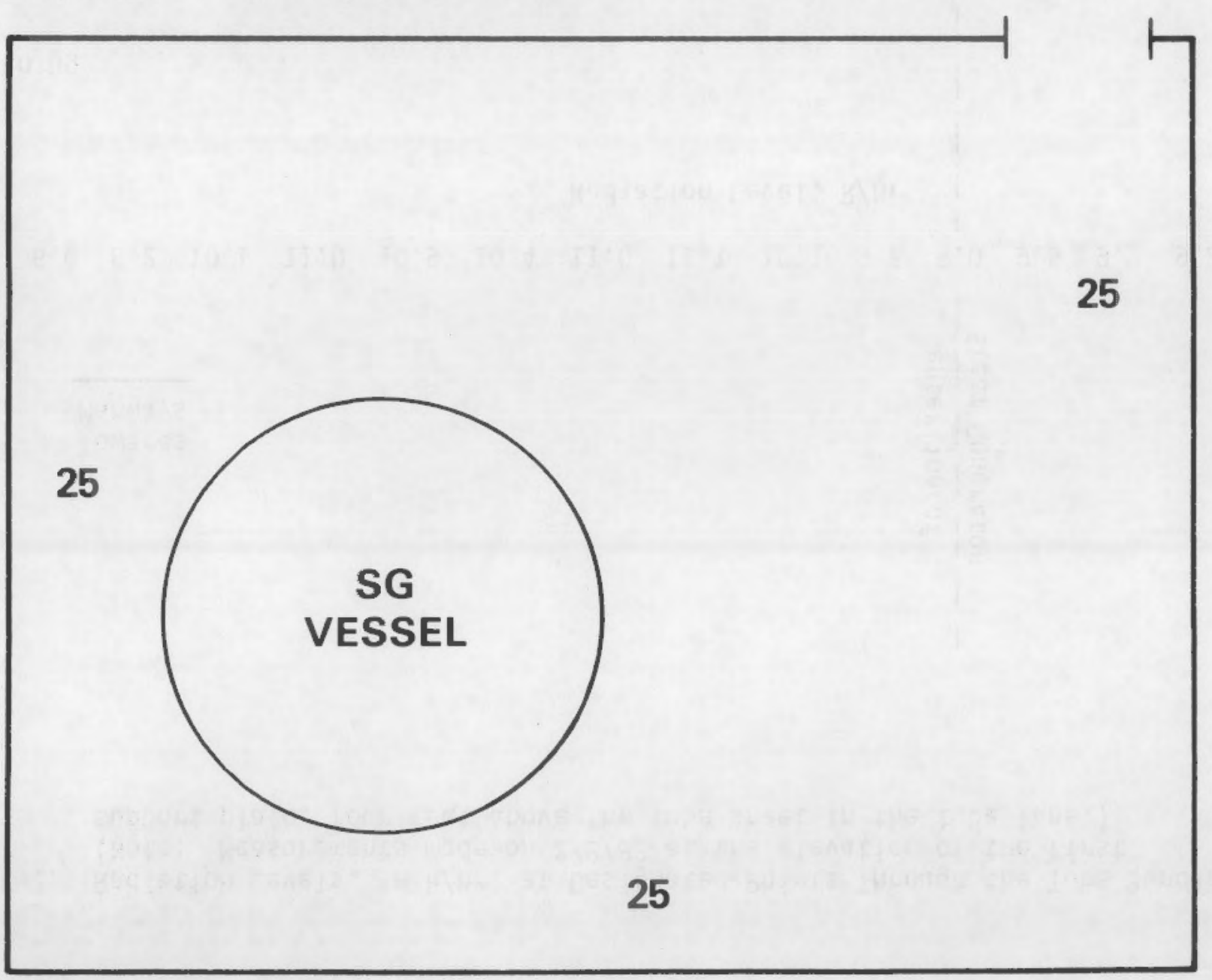

*DOSE RATES ARE IN mR/hr

FIGURE 28. Radiological Map - Basement Level 
TABLE 2. Radiation Levels, in $R / h r$, at Designated Points Through the Tube Bundle. (Note: Measurements made on $2 / 8 / 82$ at the elevation of the first

support plate, four feet above the tube sheet in the tube lane.)

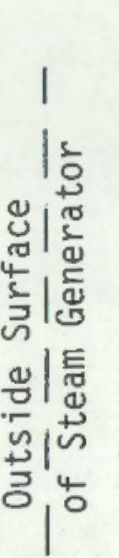

Towards

Manways

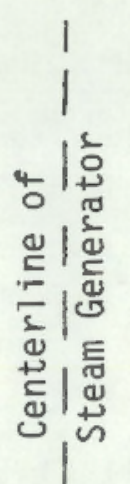

Towards

Nozzles

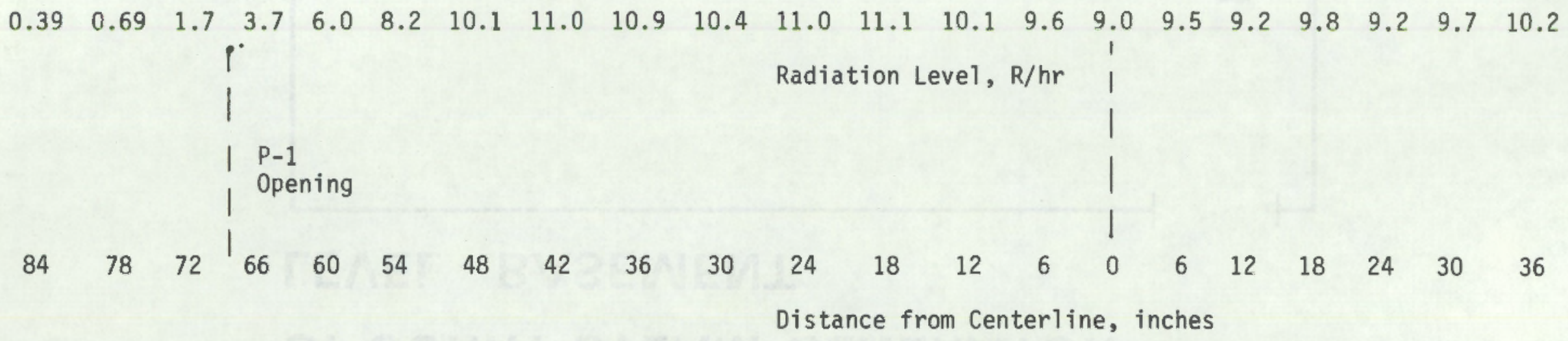




\section{STEVENS DRIVE}
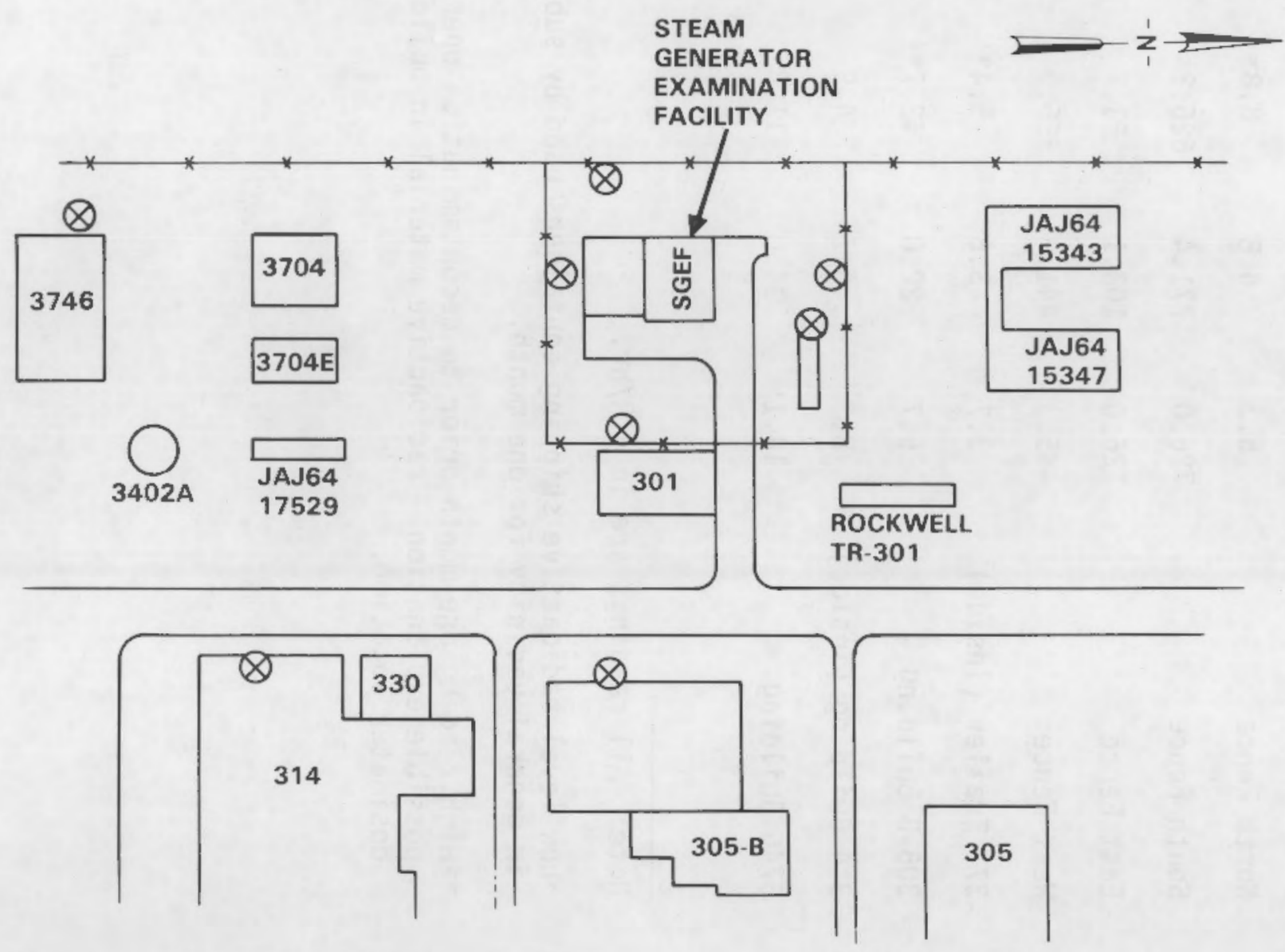

environmental dosimeter locations

FIGURE 29. Radiation Monitoring Locations in the SGEF Vicinity 
TABLE 3. Exposure Dose Rate as Determined by Environmental TLD Dosimeters Located Near the Steam Generator Examination Facility (Quarterly Average)

$\begin{array}{lrrrr} & \text { Q2/82 } & \underline{Q 3 / 82} & \underline{Q 4 / 82} & \underline{Q 1 / 83} \\ \text { North Fence } & 5.3 & 4.8 & 8.8^{\star} & 31.5^{\star} \\ \text { South Fence } & 726.0 & 771.4 & 626.2 & 761.0 \\ \text { East Fence } & 126.0 & 103.1 & 83.7 & 106.0 \\ \text { West Fence } & 485.3 & 441.8 & 356.9 & 437.0 \\ 377 \text { Trailer (inside) } & 3.7 & 3.6 & 5.4^{*} & 9.1^{*} \\ 305-B \text { Building } & 25.7 & 22.0 & 42.7^{\star *} & 22.9 \\ 314 \text { Building (inside) } & 8.3 & 6.7 & 4.9 & 7.7 \\ 3746 \text { Building } & 14.1 & 14.8 & 11.8 & 13.9\end{array}$

Note: All readings are in $\mu \mathrm{R} / \mathrm{hr}$.

*Low level radioactive shipping containers used by sub-contractor in general vacinity for one month.

**High reading one month prior to decontamination operation possible explanation - radioactive material in building near dosimeter location. 
Personnel radiation exposures are tabulated in Table 4 for the groups of people who have been working on the project. The major activities at the SGEF during each quarter are shown in the footnotes to the table. A correlation may be made with the exposures shown.

During the decontamination of both sides of the channel head, detailed measurements were made of radiation levels before, during and after each operation. Several measurement methods were utilized. These included (a) external monitoring of the channel head with shielded $\mathrm{NaI}$ and hand-held Ge detectors, (b) gamma spectroscopy of contaminated corrosion specimens with a GeL $i$ detector, and (c) exposure rate measurements on the inside of the channel head with both shielded and unshielded TLD's. Numerical results using method (c) are shown in Figures 30 through 35. The plastic rods (actually tubes) containing the unshielded TLD's were placed in two positions, as indicated: (1) hanging $8 \mathrm{~cm}$ below the tube sheet and parallel to it, and (2) extending through the manways to the far corners of the channel head. These latter TLD's were at differing elevations. These measurements were the primary basis for evaluating the effectiveness of the two decontamination operations. The post-decontamination (final) readings were all taken after both sides of the channel head had been decontaminated. Before the hot leg side was decontaminated, the readings on the cold leg side were double those shown in Figure 31 . This illustrates that there is significant "shine" from one side of the channel head to the other. Examination of the data shows that volumetric decontamination factors (DF's) of 6 to 7 were achieved by both processes, except close to the tube sheet where they are only about 4 . The steam generator tubes were intentionally not decontaminated to avoid any further degradation by the chemical solutions; also, to avoid seepage of solutions through existing cracks and flaws in the tubing into the crevice between the tubing and the tube sheet. Such seepage, besides attacking the tubing further, would contaminate the crevice deposits which it is planned to analyze at a future date. There is still significant "shine" from the tubes, which strongly influences the volumetric radiation levels in the channel head. On the other hand, the dosimeters that were placed against the channel head inner surfaces and shielded by four inches of lead, showed very low radiation levels after decontamination, corresponding to DF's greater than 30 to 50 .

The radiation levels shown in Figures 31 and 34 were confirmed by TLD's attached to a worker who later entered the channel head to place equipment for a profilometry experiment. TLD's attached to his head and wrists showed exposure rates of 615 to $681 \mathrm{mR} / \mathrm{hr}$. Much of the time he was working to place templates on the tube sheet above his head. On the other hand, TLD's attached to his torso and ankles showed rates at those points of 394 to $418 \mathrm{mR} / \mathrm{hr}$. 
TABLE 4. 1982 Personnel Radiation Exposures of Groups Working on the Steam Generator

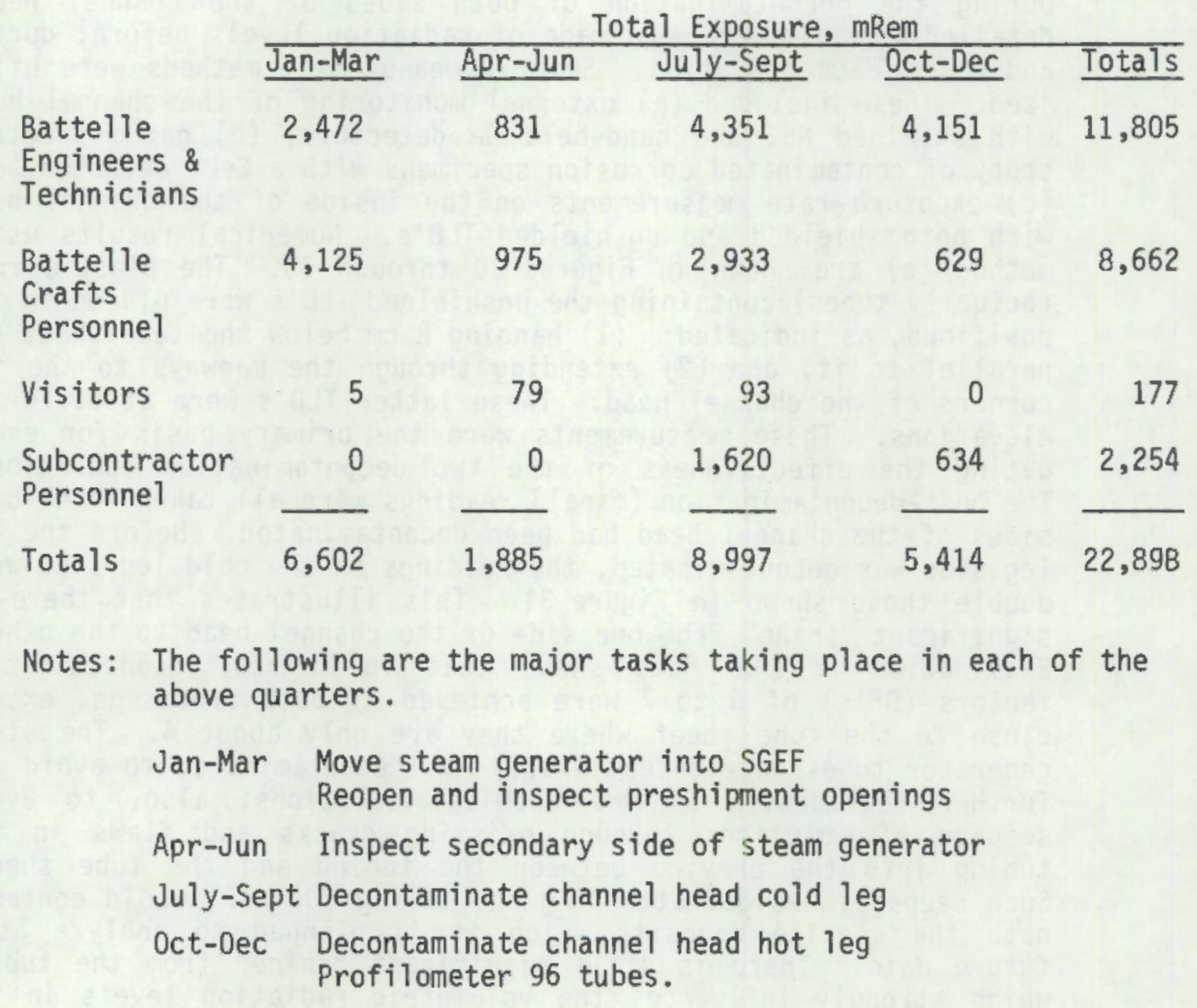




\section{INITIAL RADIATION READINGS}

\section{(COLD LEG - R/h)}

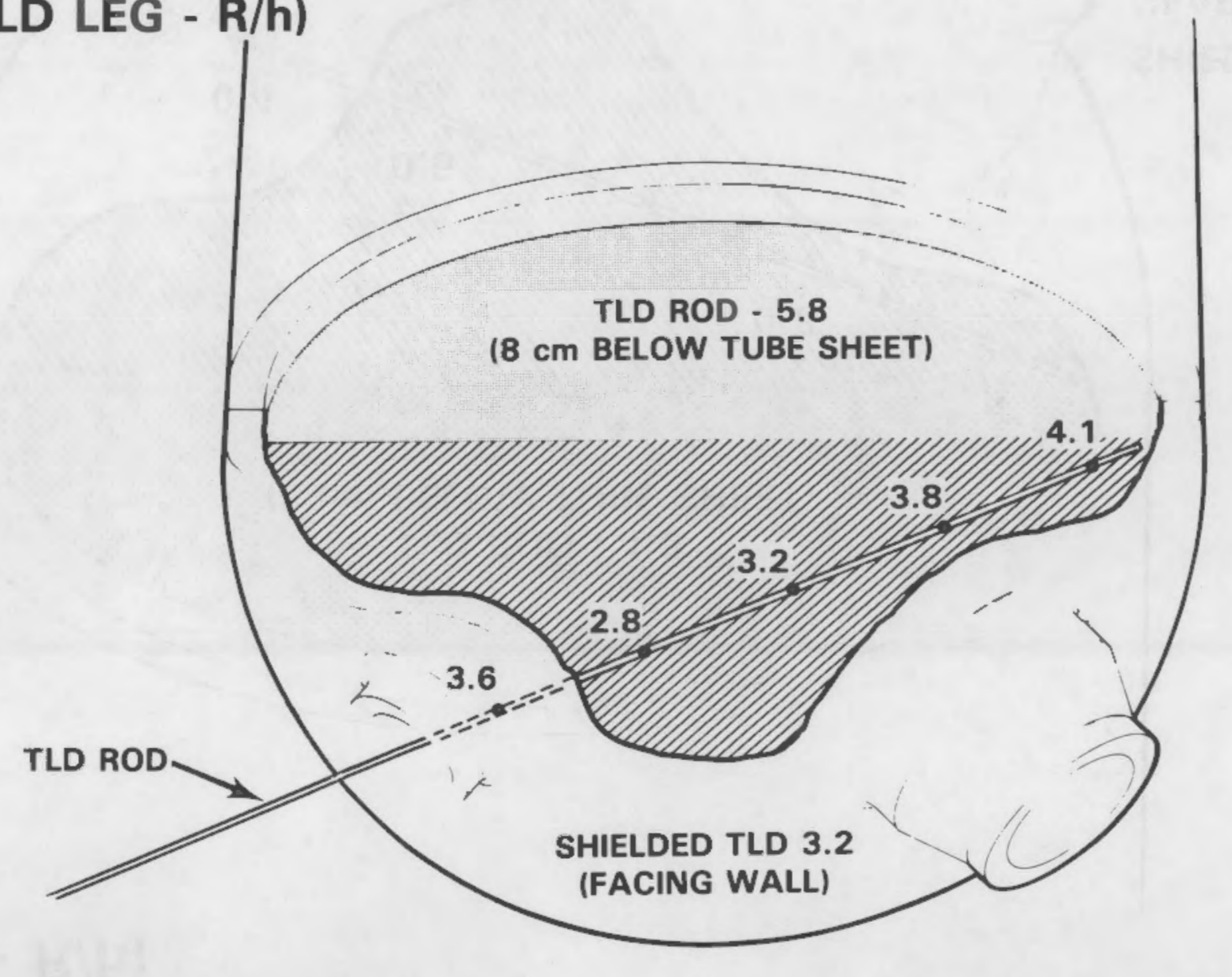

FIGURE 30 . 


\section{IINAL RADIATION READINGS}

\section{COLD LEG - R/h)}

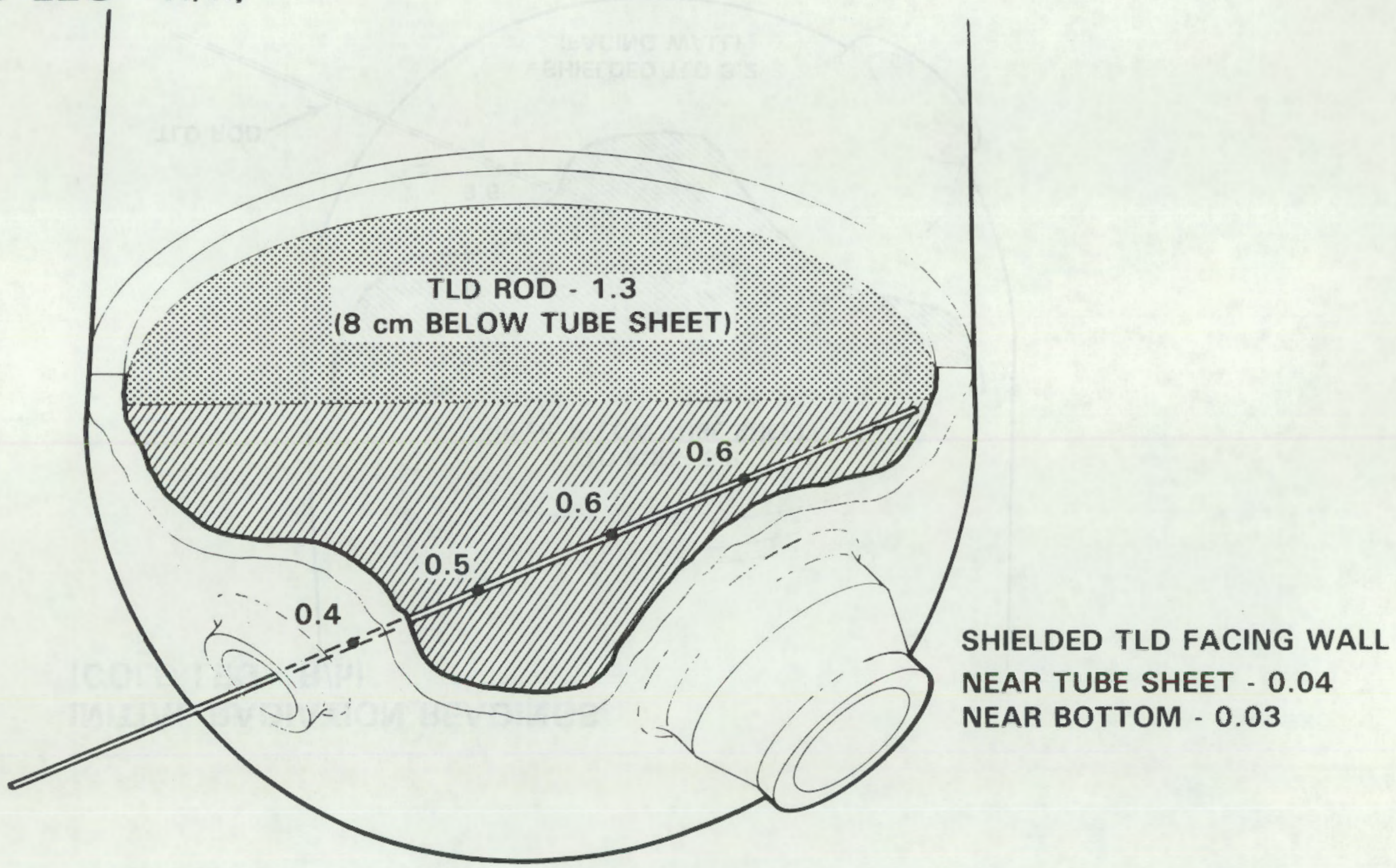

FIGURE 31. 


\section{RADIATION READING CHANGE}

(COLD LEG - R/h)

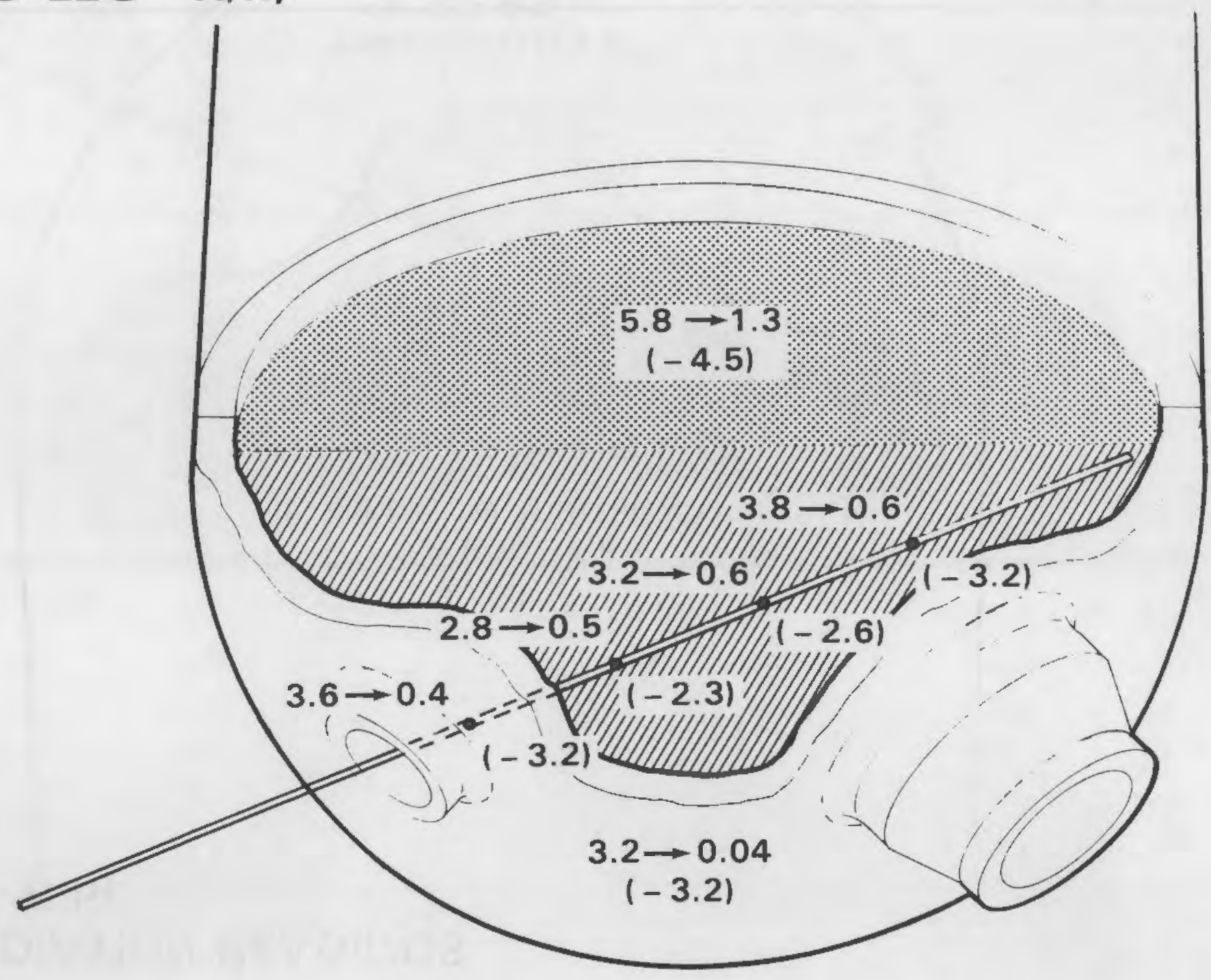

FIGURE 32. 


\section{INITIAL RADIATION READINGS (HOT LEG - R/h)}

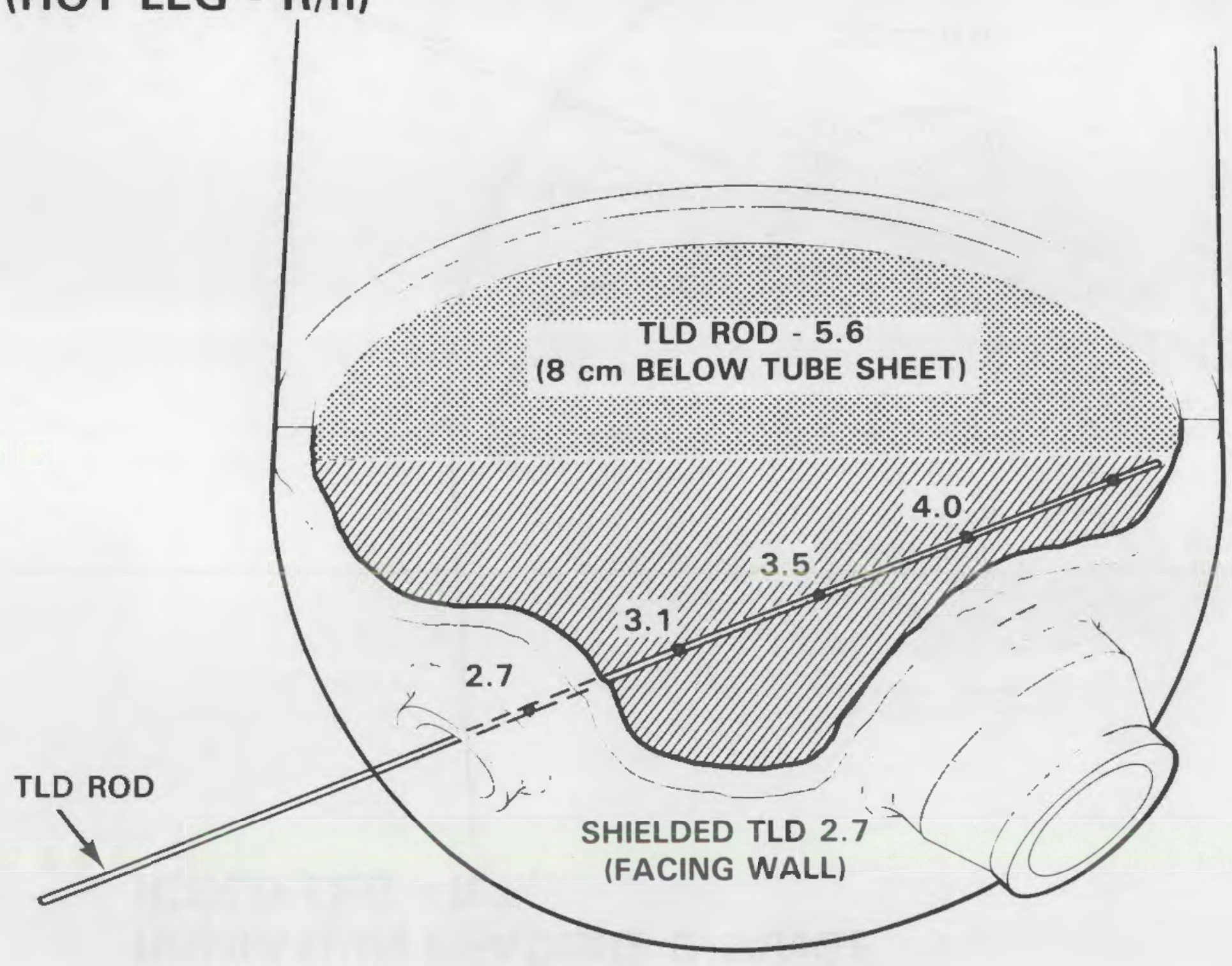




\section{FINAL RADIATION READINGS}

\section{(HOT LEG - R/h)}

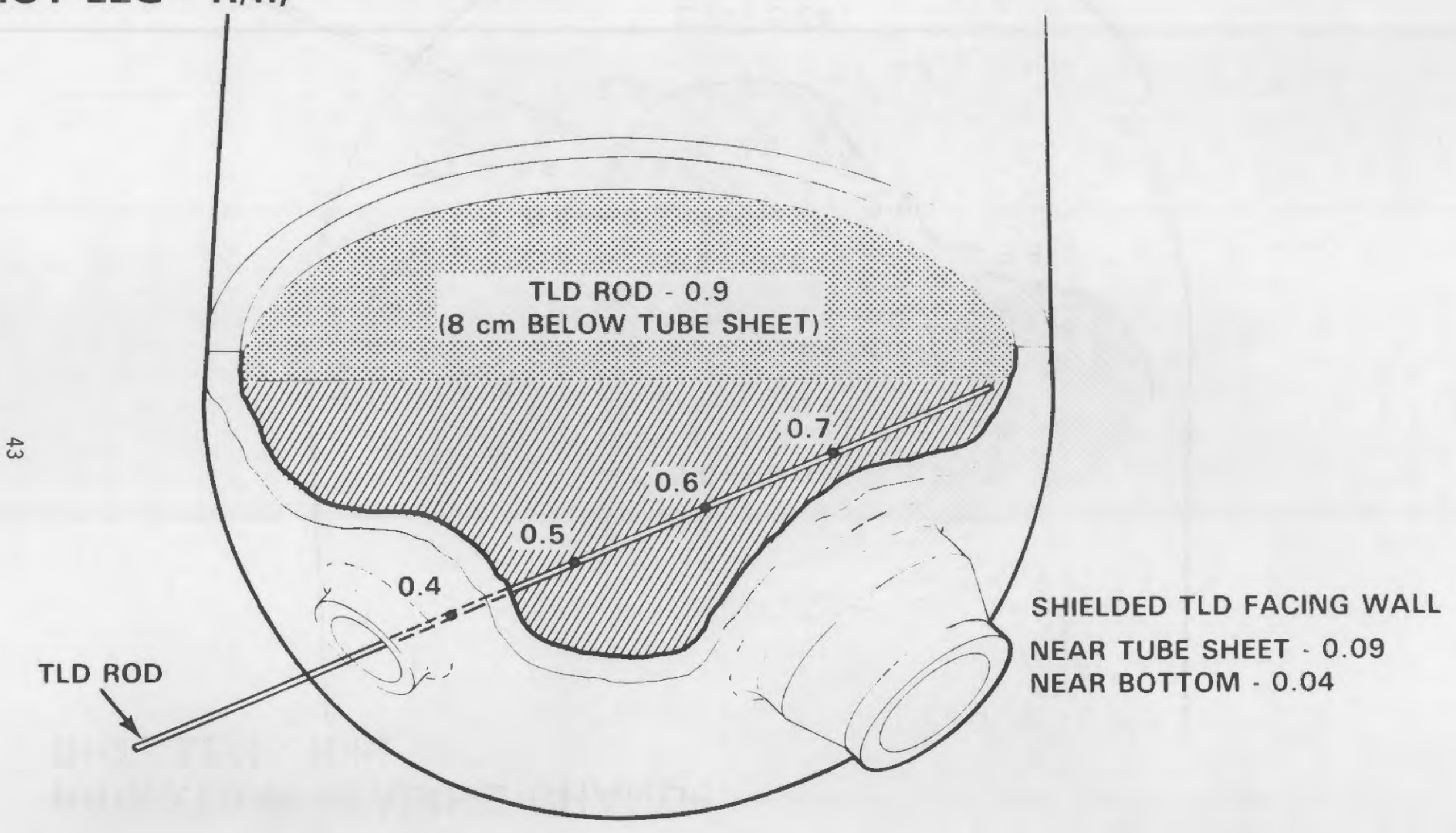




\section{RADIATION READING CHANGE}

(HOT LEG - R/h)

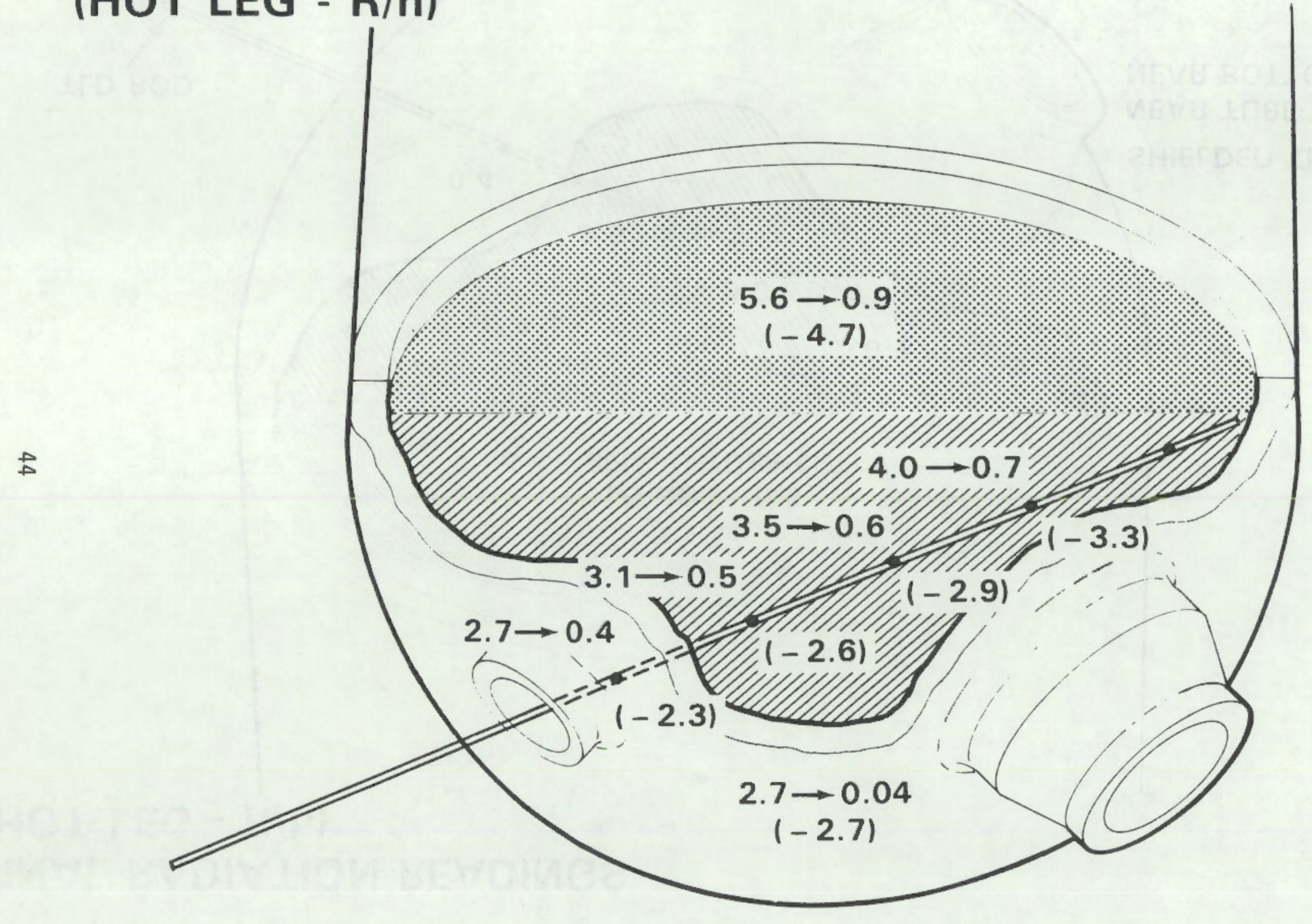

FIGURE 35 . 


\section{- Data Storage Retrieval System/Statistical Analysis (Task 4)}

The nondestructive and destructive examinations being conducted on the service degraded generator are expected to yield an enormous amount of data. Specifically there are $3388 \mathrm{U}$-bend tubes in the generator each with 14 support plate and 2 tube sheet intersections. At least three eddy current measurements will be taken through the entire length of almost all these tubes. In addition numerous repeat measurements will be made on selected tubes with different NDT instrumentation and operating teams. Secondary side examinations will characterize conditions throughout the generator with optical observations and corrosion product/scale samples and analyses.

To track this database, the use of two computer systems was obtained and appropriate software was developed (Ref. 3). Figure 36 depicts the PDP $11 / 44$ system which will digitize analog NDT signals in real time and store information on discs as well as tape. This system also contains software to operate and control the NDT probe pusher-puller. The controller and a device that automatically inputs NDT probe position to the computer, along with data signals, were developed under this program. This puts data in a form where it can be located and readily manipulated in a computer. In addition to controlling the NDT equipment and automatically recording/processing NDT data, the PDP $11 / 44$ system will also allow discrete entries to input data from the secondary side examinations, or destructive assay of removed specimens. Data analysis and statistical modeling will involve use of a VAX 11/780 computer system. This system has the necessary capacity and software for handling large data sets, and uses the PDP $11 / 44$ generated data discs.

Another activity under this task during the year was the accumulation and analysis of historical data on the research generator. A map of the plugged tubes with the reasons for plugging is shown in Figure 37. A massive amount of data has been provided to the project by Virginia Electric Power Company (VEPCO), operators of the Surry Plant. These included a complete set of inspection reports, which supplement the Westinghouse database obtained earlier. Together they provide a complete record of inspection data for the $2 \mathrm{~A}$ steam generator. Copies of previous eddy current examination analog tapes were obtained, to provide a basis for sample selection and comparison with future examinations. Historical data on operating water chemistry analysis, tube plugging dates, criteria and reason were also obtained and entered into the computer files. Data on any specimen is accessible by tube row, column, and height above the tube sheet. Graphics capability allows plotting of defects at specific steam generator cross sections as well as maps of a specific defect occurrence throughout the generator. 


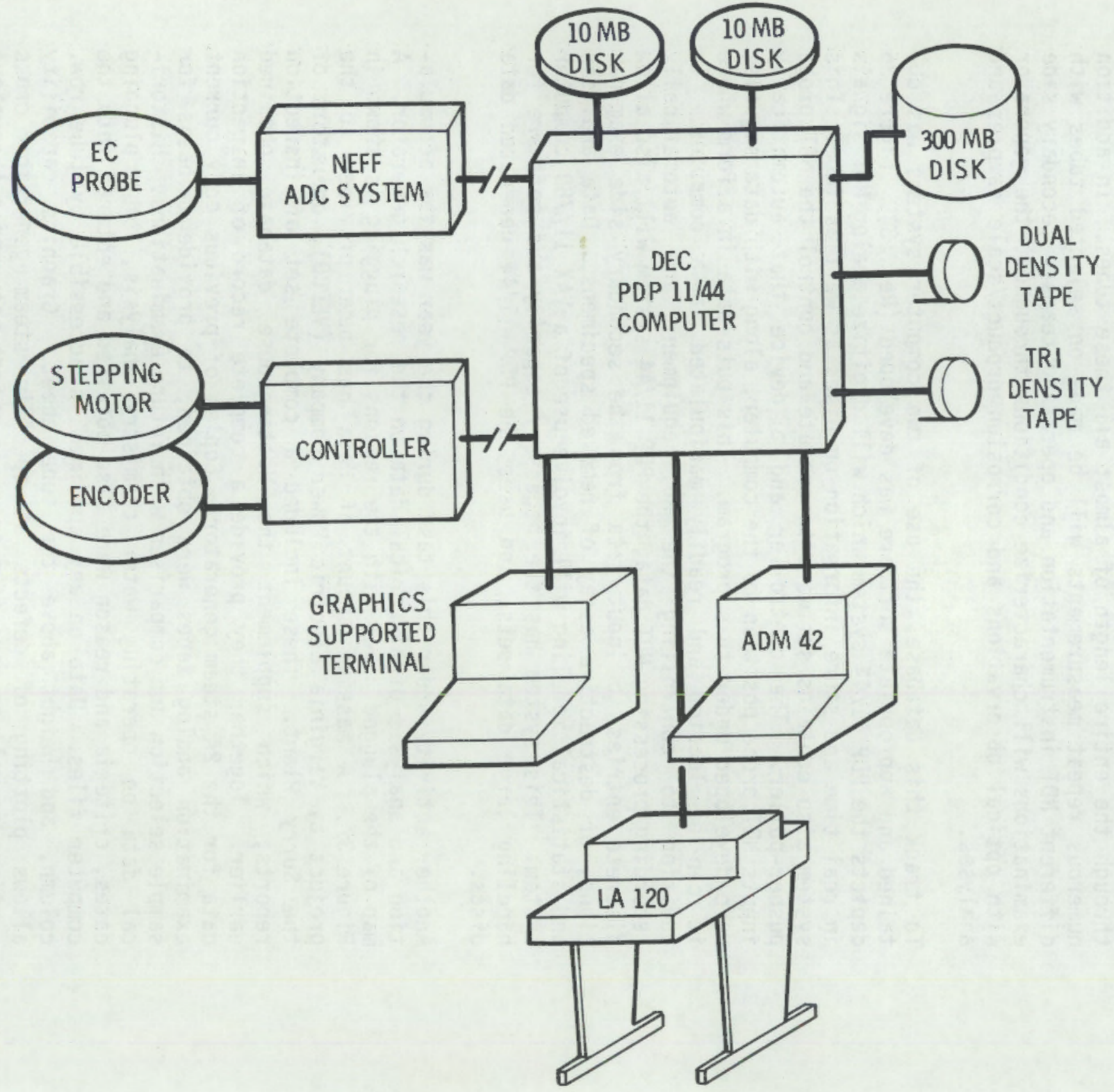

FIGURE 36. Computer System for NDT Probe Control and Data Aquisition/Digitization 
SURRY 2A STEAM GENERATOR

TUBE PLUGGING MAP AS OF $8 / 8 / 78$

ALL PLUGS REMOVED $\nleftarrow$ O SELECTIVE UNPLUGGING

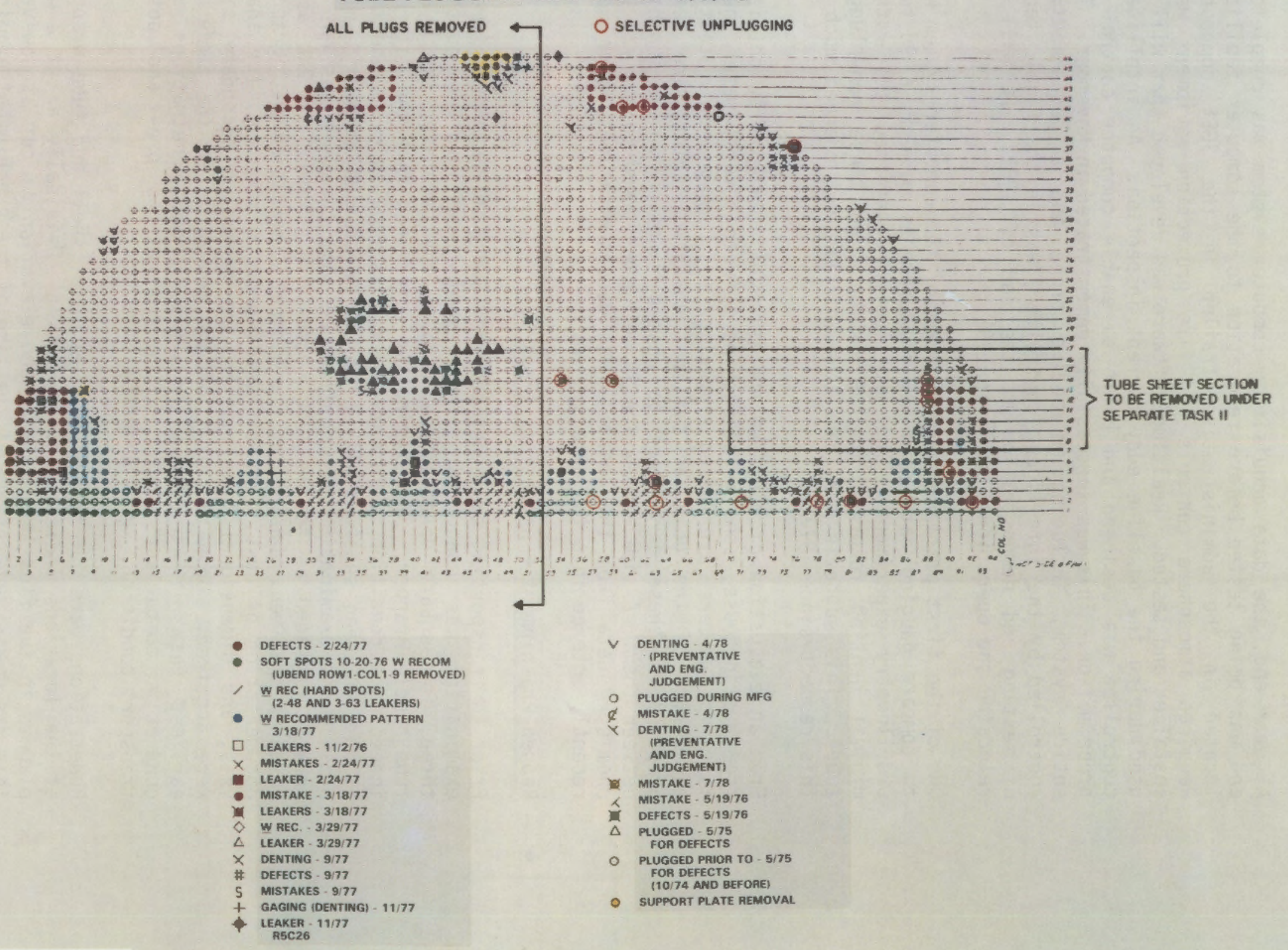

Neg. 8206747-1cn 
At year end, the data acquisition computer system was completed, and was being tested before relocation to the computer facility, located in the administrative trailer in the SGEF compound. Required atmosphere controls and fire protection equipment were installed and tested. Realtime software was developed that will be used during the baseline eddy current inspection. An intelligent controller was designed and built to enable computer control of probe motion. This was successfully demonstrated in November. The entire system, including an active probe and a pusher-puller controlled by the intelligent controller, was in the final stages of testing and demonstration at the end of 1982. It will be relocated and operational early in 1983.

One of the first practical applications of the computer system was to compare gauging data with new measurements made in a 96-tube profilometry experiment. The profilometry confirmed the rather minimal denting recorded in the database on these non-plugged tubes. This suggests that the generator has not changed much in this respect since 1977 .

From an evaluation of blowdown chemistry data originally obtained from Westinghouse, some relationships between several water chemistry parameters are being investigated through the plotting capability of the computer system. Analytical plots are being prepared of these parameters to assess functional relationships between them. A similar service is being performed to analyze the chemistry data from the channel head decontaminations which were recently entered into the data system.

\section{Reopen Preshipment Penetrations (Task 5)}

Prior to transporting the generator from Surry to PNL a preshipment examination was conducted. This examination involved cutting three, foot-square penetrations through the generator shell and tube bundle wrapper. The examination determined that the unit was indeed in a condition representative of its final service and that it had not been substantially affected by storage at Surry. The preshipment examination also determined that the unit was not so service degraded as to preclude successful shipment to PNL as a research specimen. During the preshipment examination photographic documentation of condition, corrosion product scrapings for analysis, and dimensional baselines on the generator secondary side were acquired. Upon placement of the generator in the SGEF the earliest task was to reopen the preshipment penetrations and conduct a comparison study of the generator's pre- and posttransport condition (Refs. 4 and 5).

Penetrations were cut through the generator shell and tube wrapper at the locations indicated in Figure 38. Originally a cut 2 was planned in the flow lane at the same elevation as cut 3 ; however, this was deemed unnecessary at the time of the preshipment examination. After the preshipment examination the penetrations were resealed by welding the original shell material back into position, 


\section{CUT LOCATION}
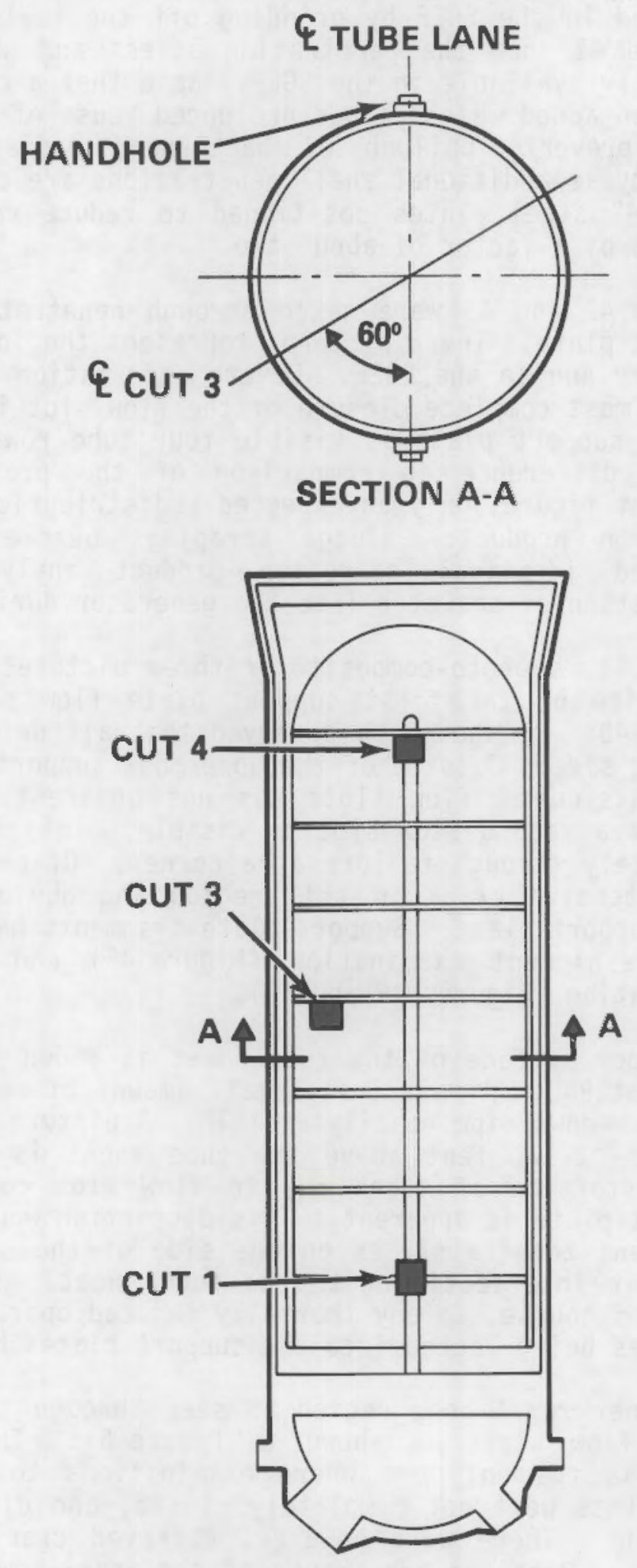

FIGURE 38. Location of Inspection Penetrations 
plus applying a further welded patch. The penetrations were reopened in the SGEF by grinding off the seal welds. Figures 39 , 40 , and 41 show the penetration access and shielding arrangement typically available in the SGEF. Note that a closeable shield door has been added which allows prolonged reuse of each penetration and which prevents buildup of background radiation levels in the facility as additional shell penetrations are completed. Note also the $3 / 4^{\prime \prime}$ steel plates positioned to reduce radiation exposure to workers by a factor of about two.

Figures 42 and 43 were taken through penetration 1, at the first support plate. These pictures represent the identical region taken at Surry and in the SGEF. Severe deformation in the support plate with almost complete closure of the flow slot is apparent. A crack in the support plate is visible four tube rows in. Note there is little difference in comparison of the preshipment with postshipment figure, only an expected redistribution of loose scale and corrosion product. Sludge scrapings before and after transit produced identical corrosion product analysis, indicating no penetration of seawater into the generator during transport.

Figure 44, a photo-composite of three pictures shows a more extensive view of the first support plate flow slot closure seen in Figure 43. It should be observed that all deformation is from the hot leg side. Outside of the uppermost support plate the classical hourglassing of flow slots was not apparent. Also in Figure 44 part of a second flow slot is visible. This flow slot has closed completely through failure at a corner. Of particular interest is the extensive crack in this region and obvious missing piece of tube support plate. Support plate fragments have been found during the preshipment examination (Figure 45) and during the current examination (Figures 46 and 47 ).

The upper surface of the tube sheet is shown in Figures 48 and 49 taken at PNL. A relatively small amount of debris is present with the blow-down pipe readily visible. A picture through the handhole located $-1-1 / 2$ feet above the tube sheet is shown in Figure 50 . The distortion of tubes due to flow slot collapse in the first support plate is apparent. This distortion would appear to place a permanent tensile stress on one side of the steam generator tubes at their intersection with the tube sheet. This stress is additive, of course, to any thermally induced operating stresses caused by tubes being locked into the support plates by corrosion product.

The inner row U-bend region as seen through the uppermost support plate flow slots is shown in Figure 51. The uppermost support plate is the only one where examinations to date have indicated flow slots were not completely closed, and did in fact show hourglassing. There were however, observed cracks at the flow slot corners. Detailed appearance of the inner-row U-bends at Surry is shown in Figure 52 and at PNL in Figure 53. A direct location correlation is possible by comparing the shiny (nonoxidized) region 


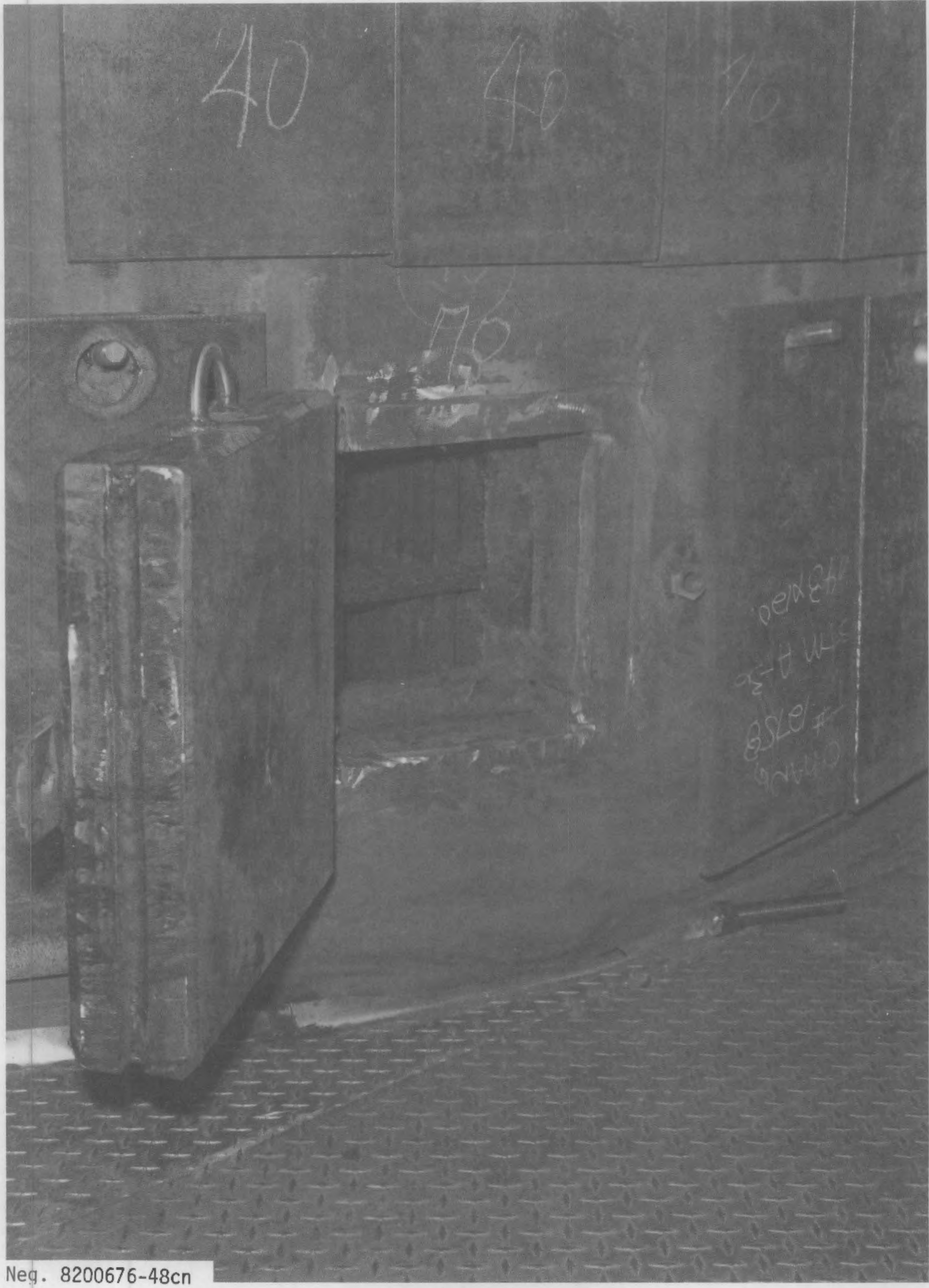

FIGURE 39. Penetration Access in SGEF at Cut 1 


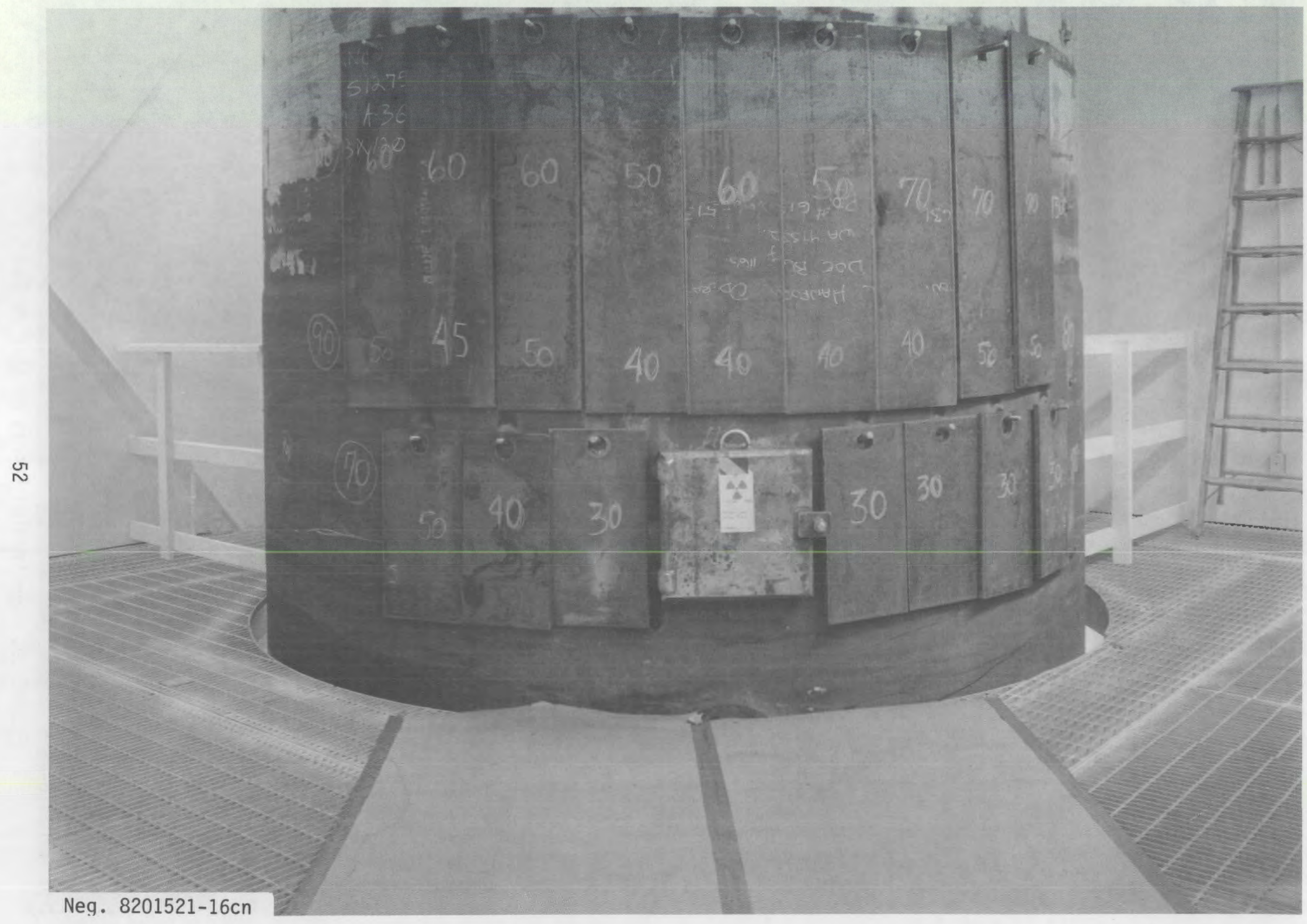

FIGURE 40. Shielding Arrangement in SGEF at Cut 1 


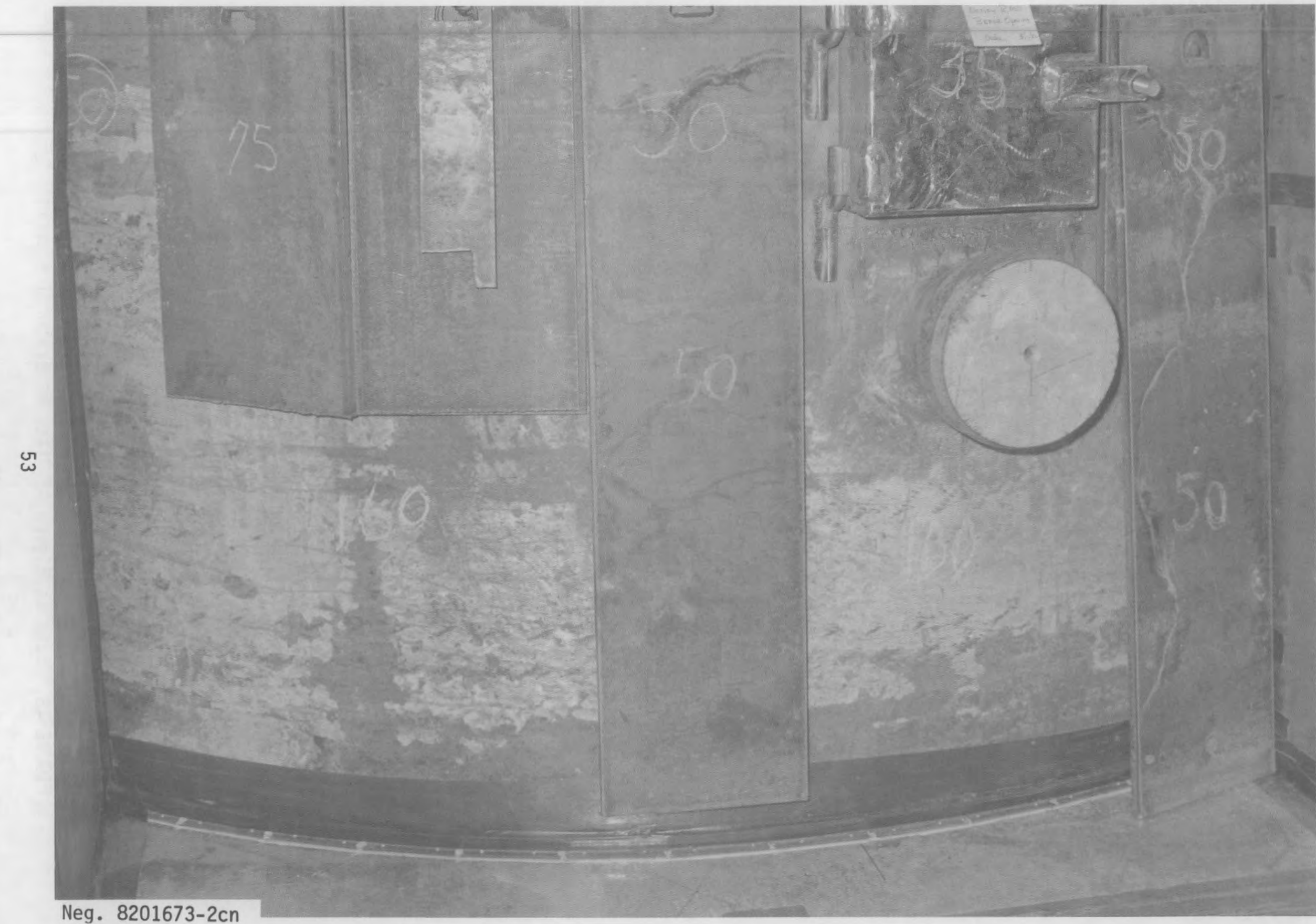

Neg. $8201673-2 c n$

FIGURE 41. Penetration Access in SGEF at Cut 4 


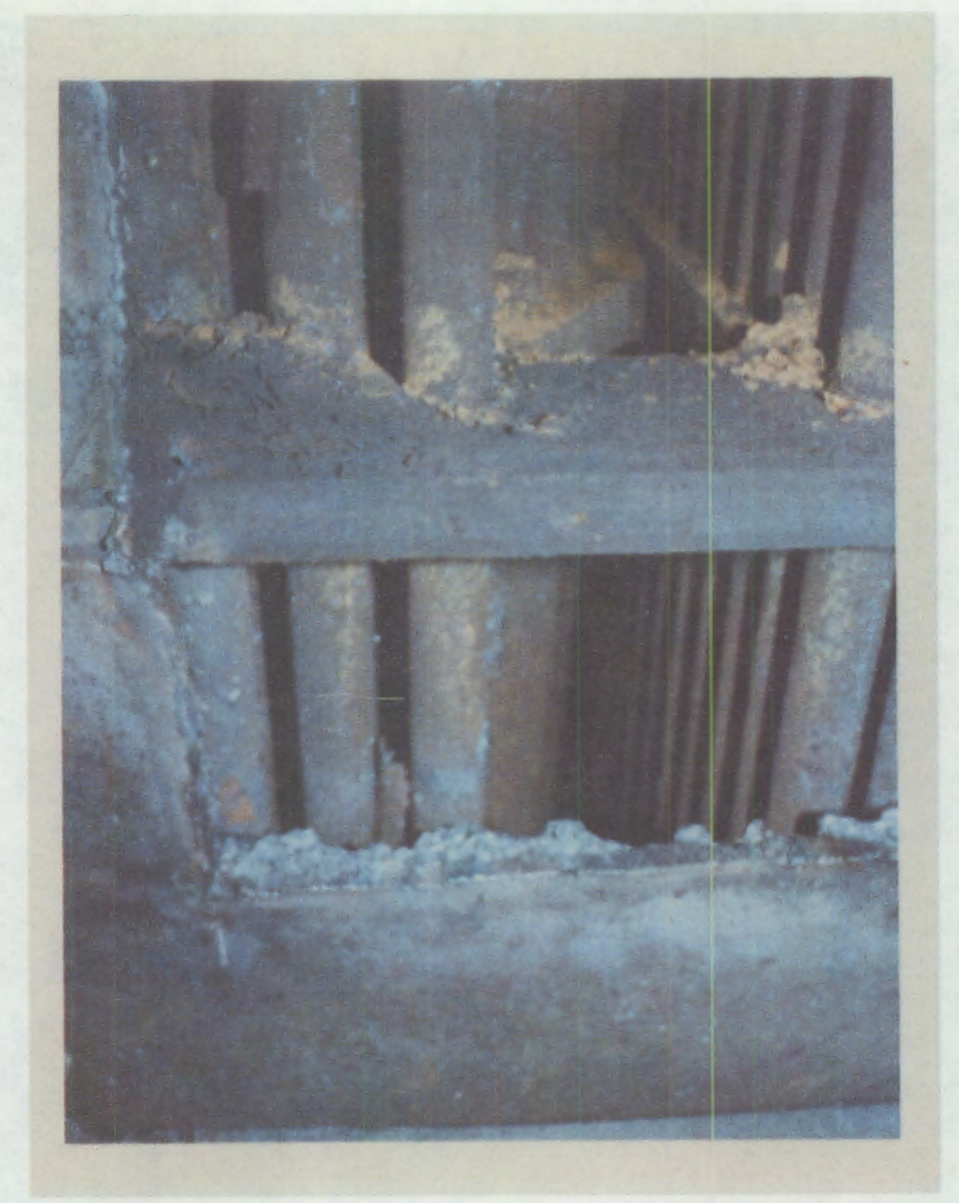

FIGURE 42. Condition of First Support Plate at Penetration 1 Before Shipment

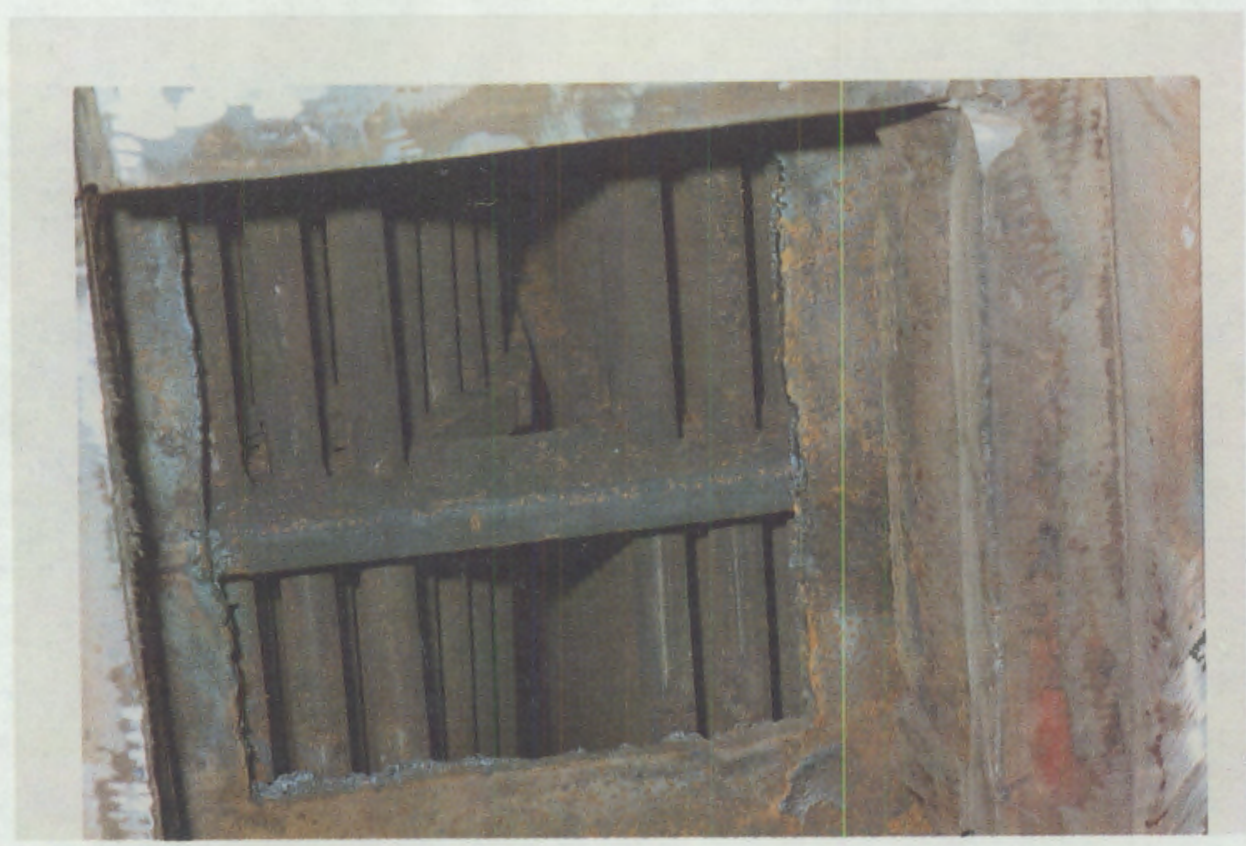

Neq. $8200722-2 c n$

FIGURE 43. Same as Figure 42 After Generator Transport 


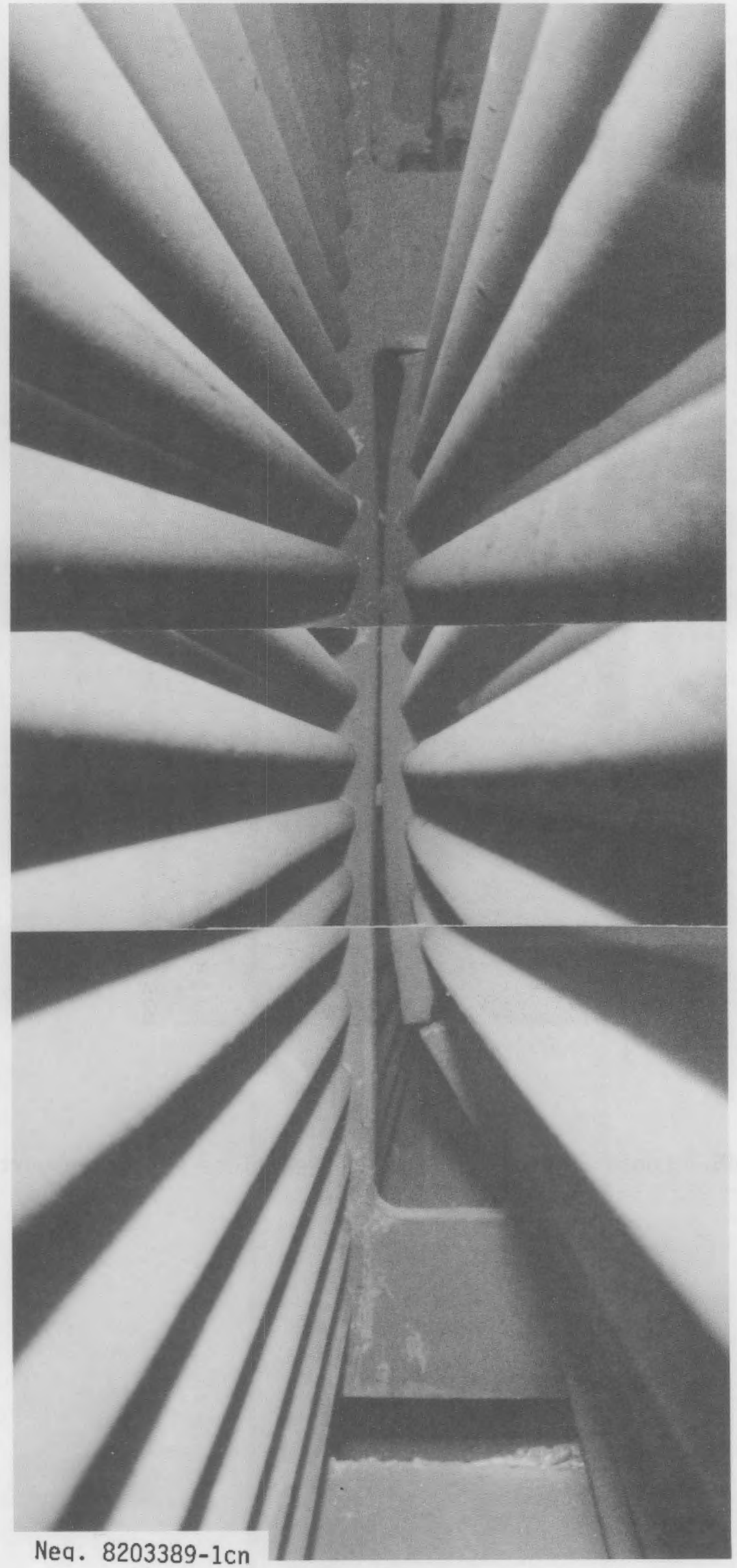

FIGURE 44. Bottom Surface of First Support Plate Viewed Upward from Handhole (Composite Photograph) 


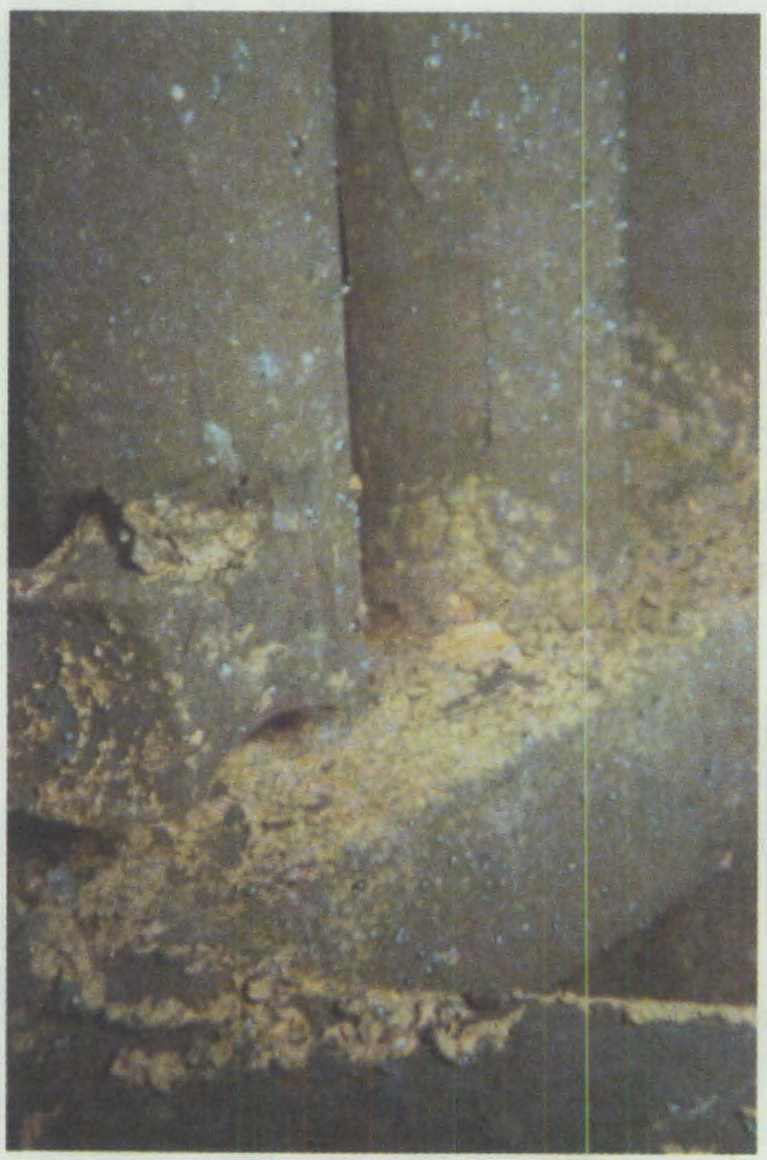

Neg. $8006520-15 \mathrm{cn}$

FIGURE 45. Loose Support Plate Piece Near Tube - Tube Support Junction 


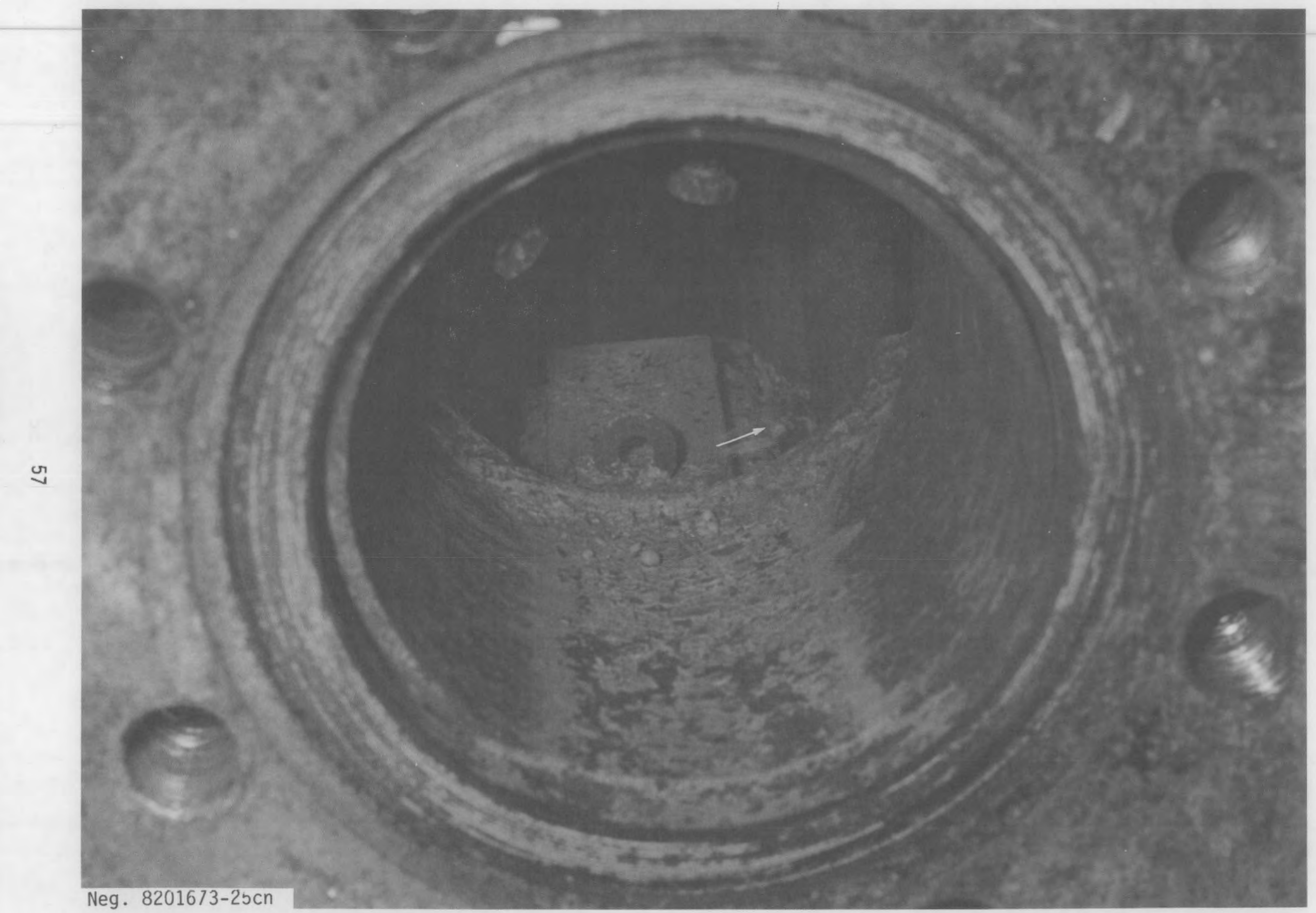

FIGURE 46. Separated Support Plate Piece at Lower Handhole 


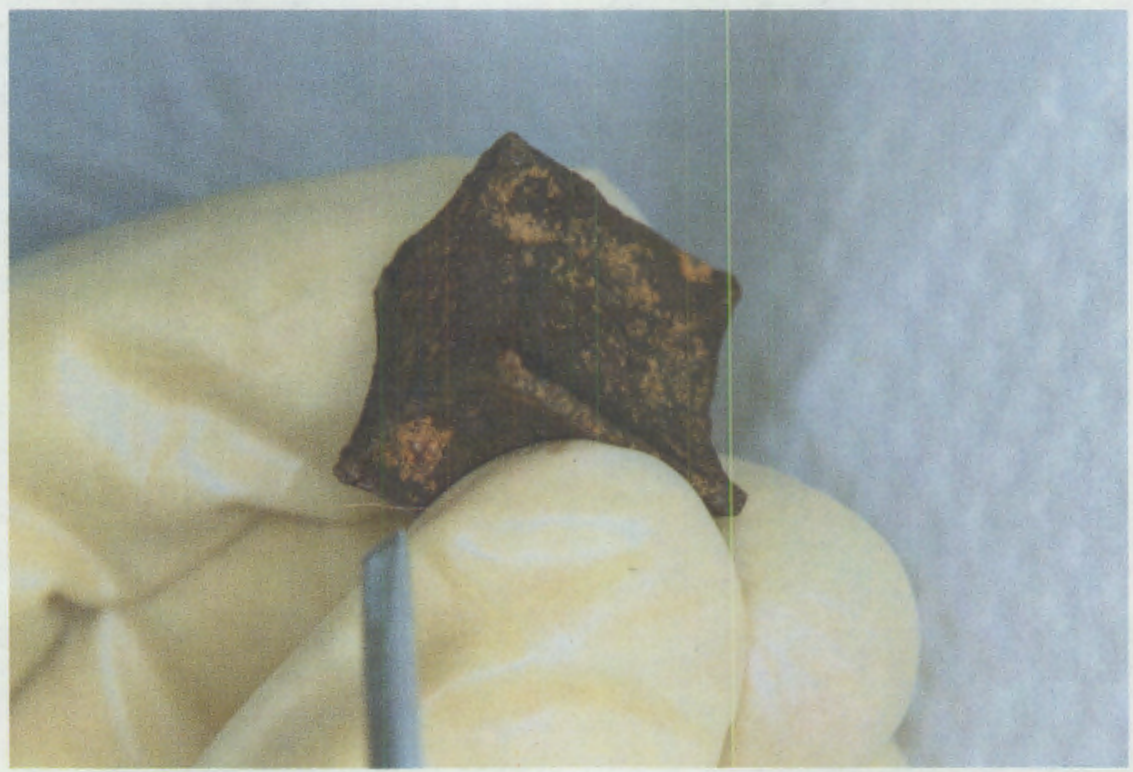

Neg. $8202972-5 c n$

FIGURE 47. Piece of Support Plate from Figure 46

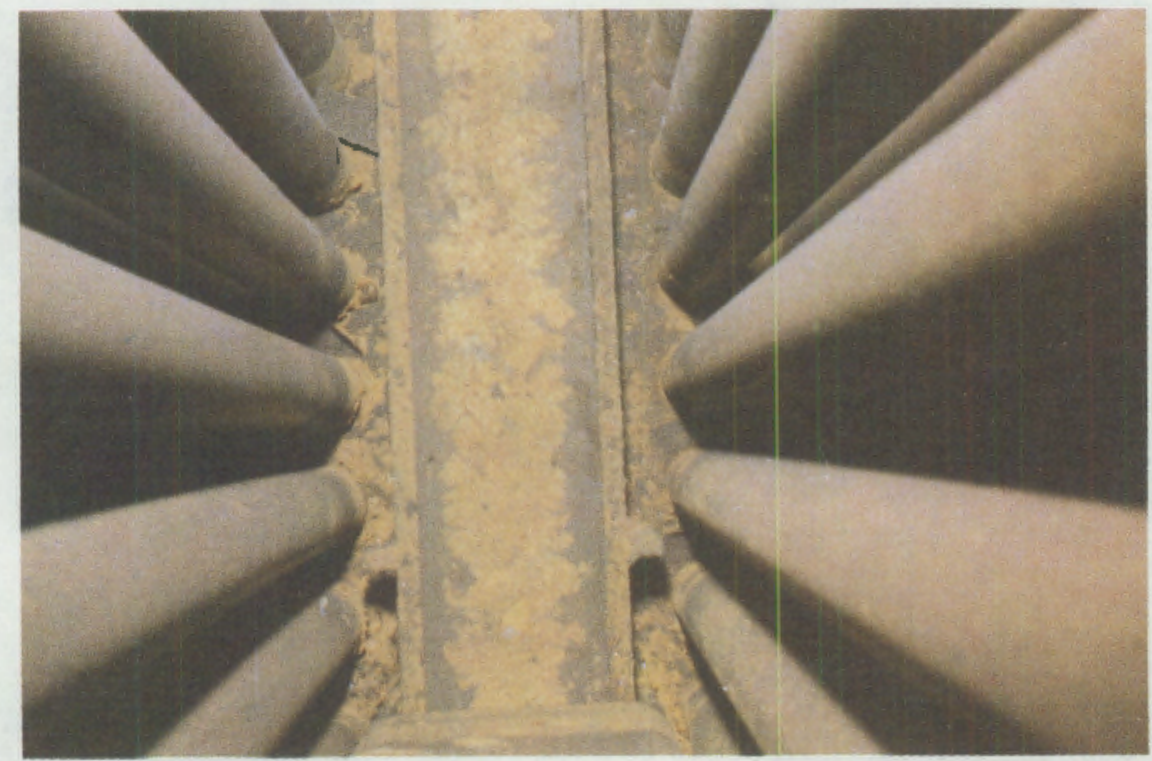

Neg. $8202105-4 c n$

FIGURE 48. Blowdown Piping and Top of Tube Sheet in Tube Lane 


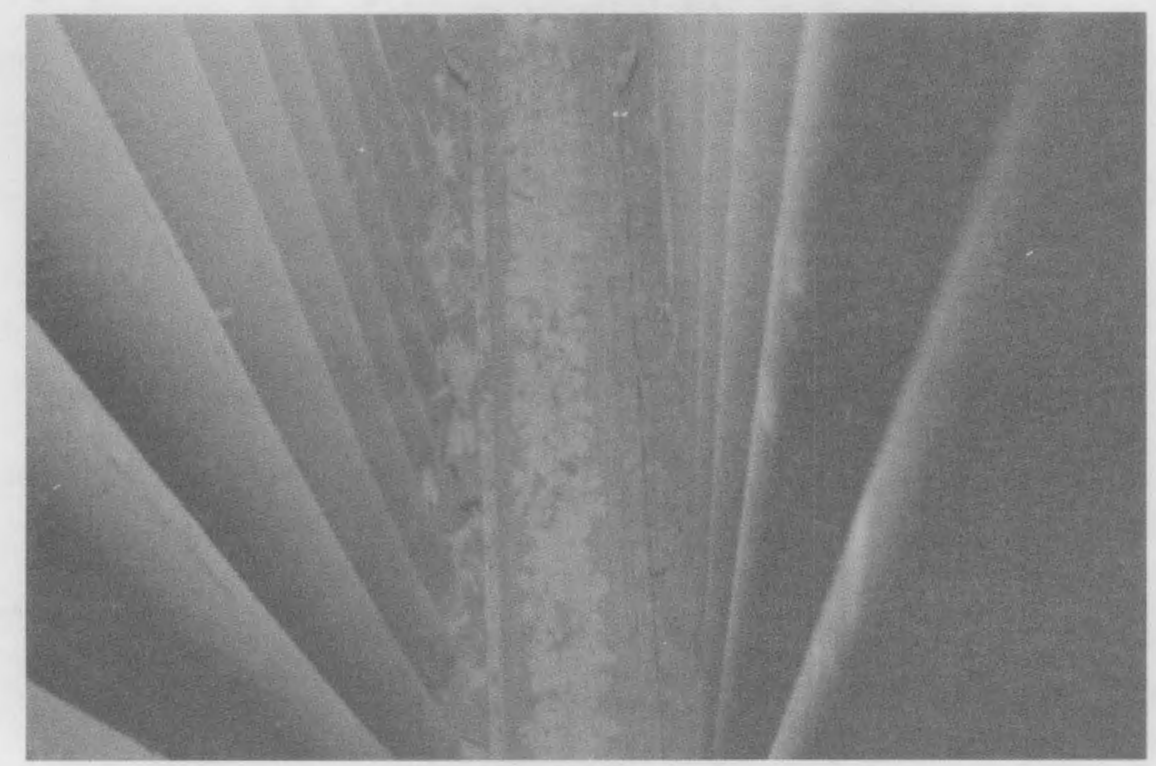

Neg. 8202105-1cn

FIGURE 49. Blowdown Piping and Top of Tube Sheet Further in Along Tube Lane

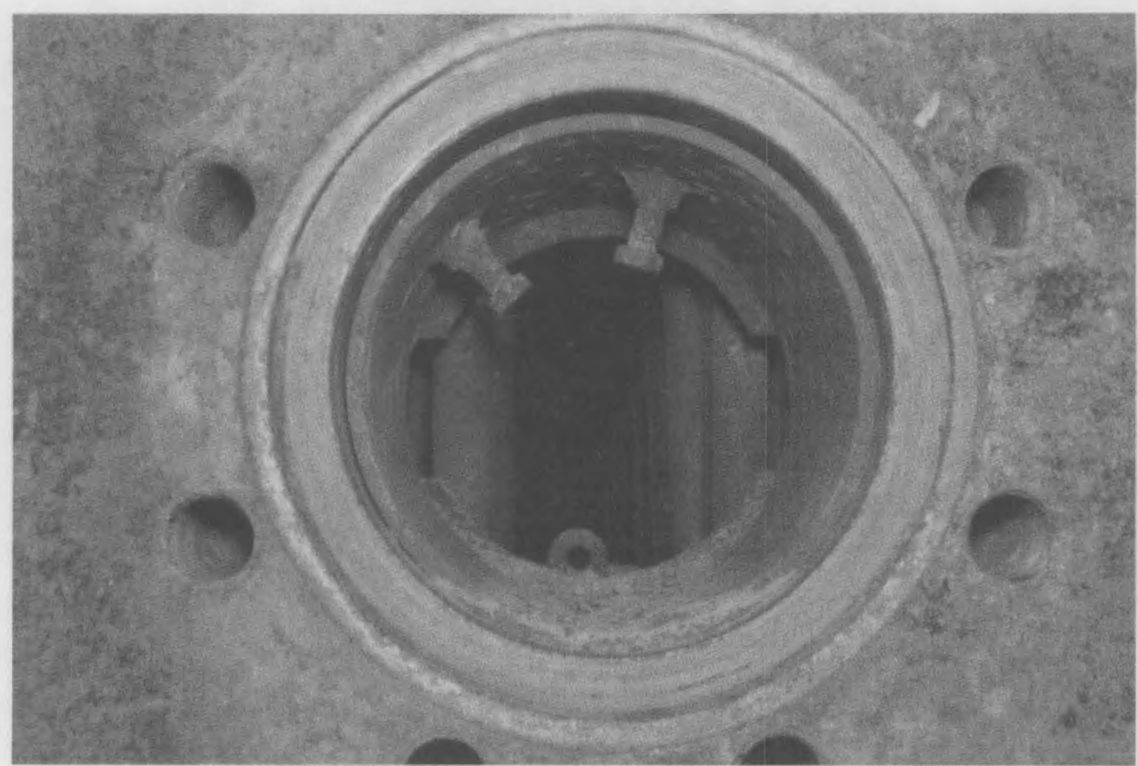

Neg. $8201673-24 c n$

FIGURE 50. View in Handhole 


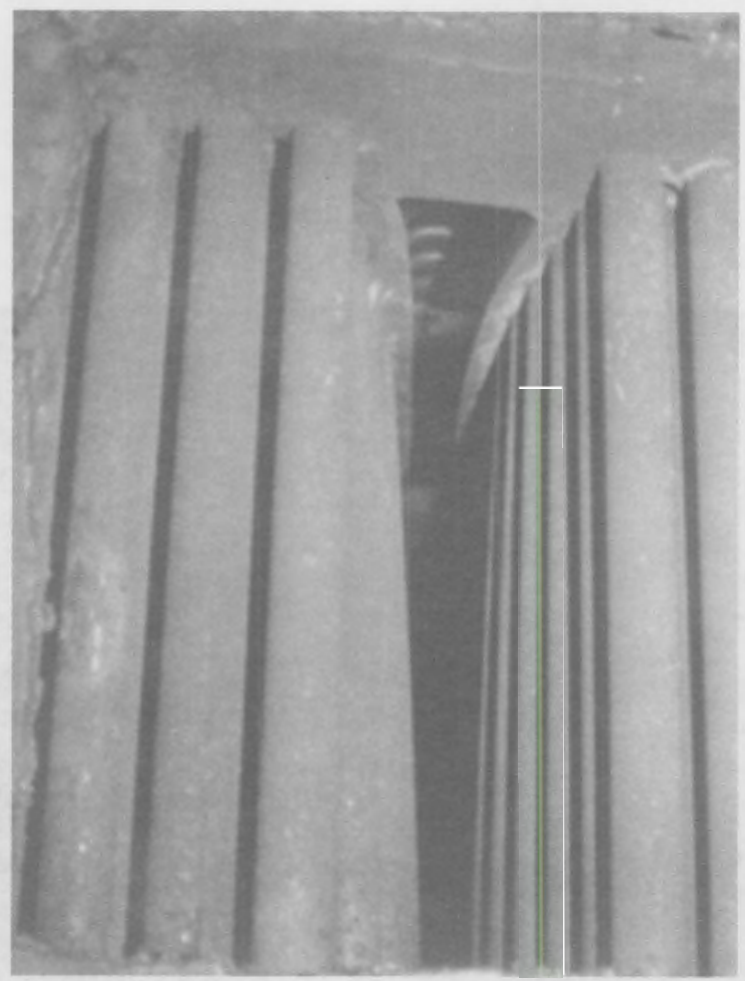

Nea. $8006520-38 \mathrm{cn}$

FIGURE 51. Flow Slot Deformation

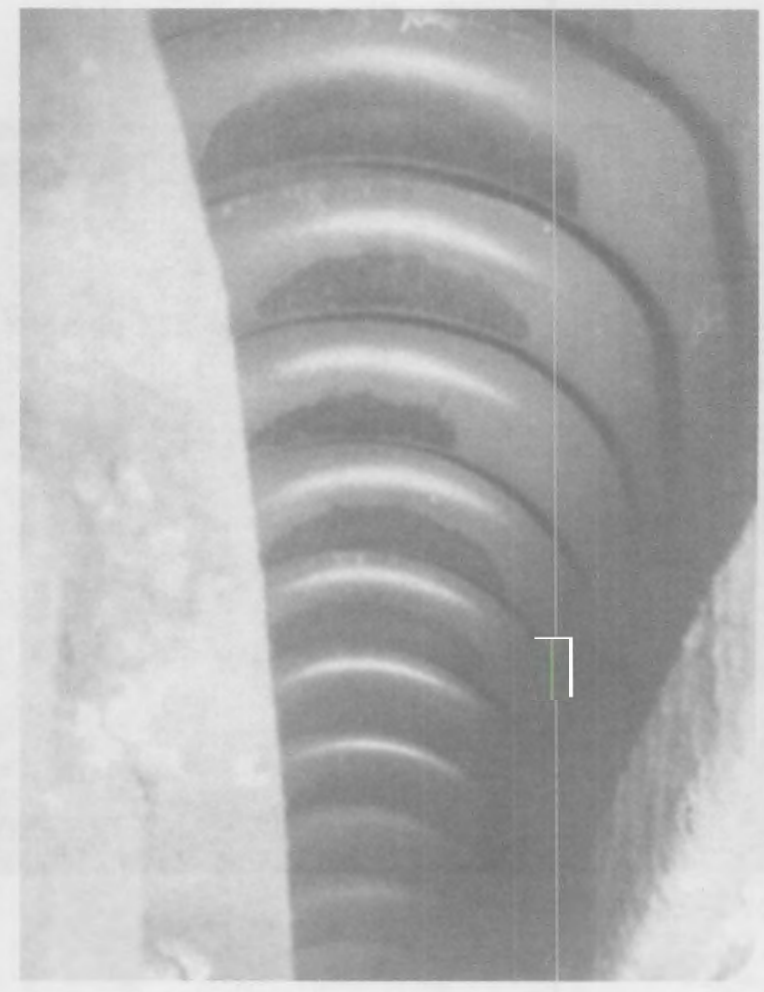

Neg. $8006520-34 c n$

FIGURE 52. Detail of Inner Row U-Bends at Surry 


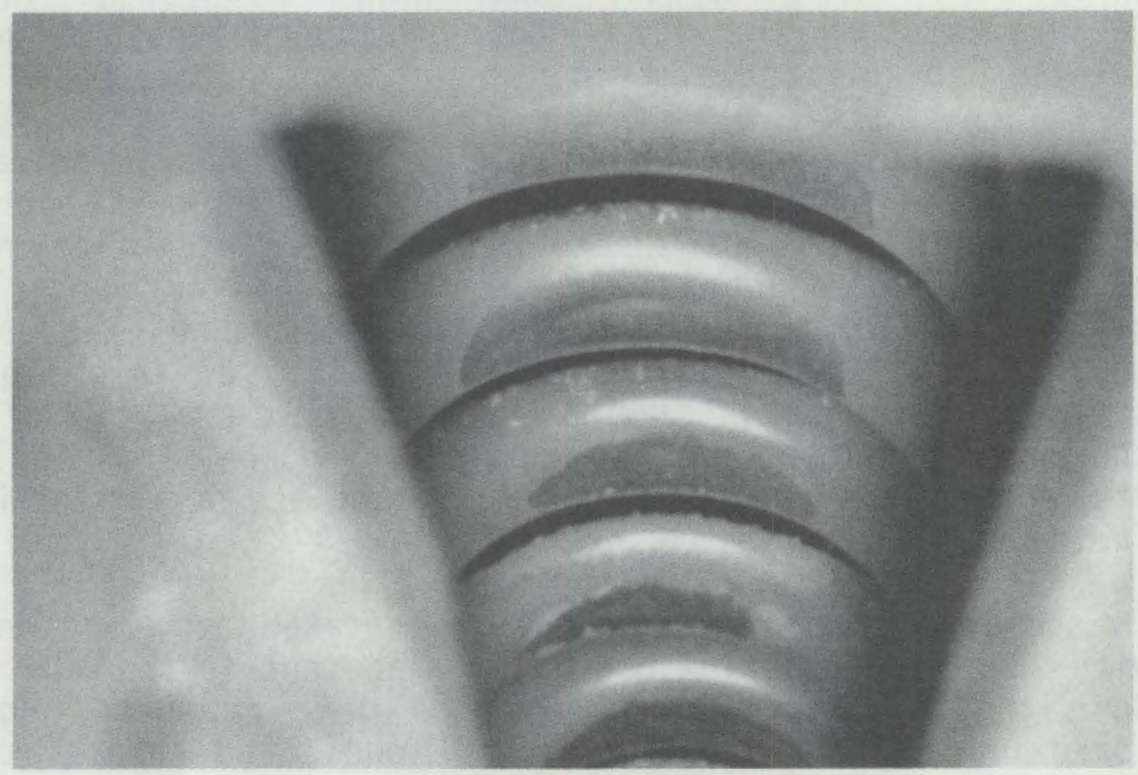

Neg. $8201673-17 c n$

Figure 53. Inner Row U-bend Detail After Transport

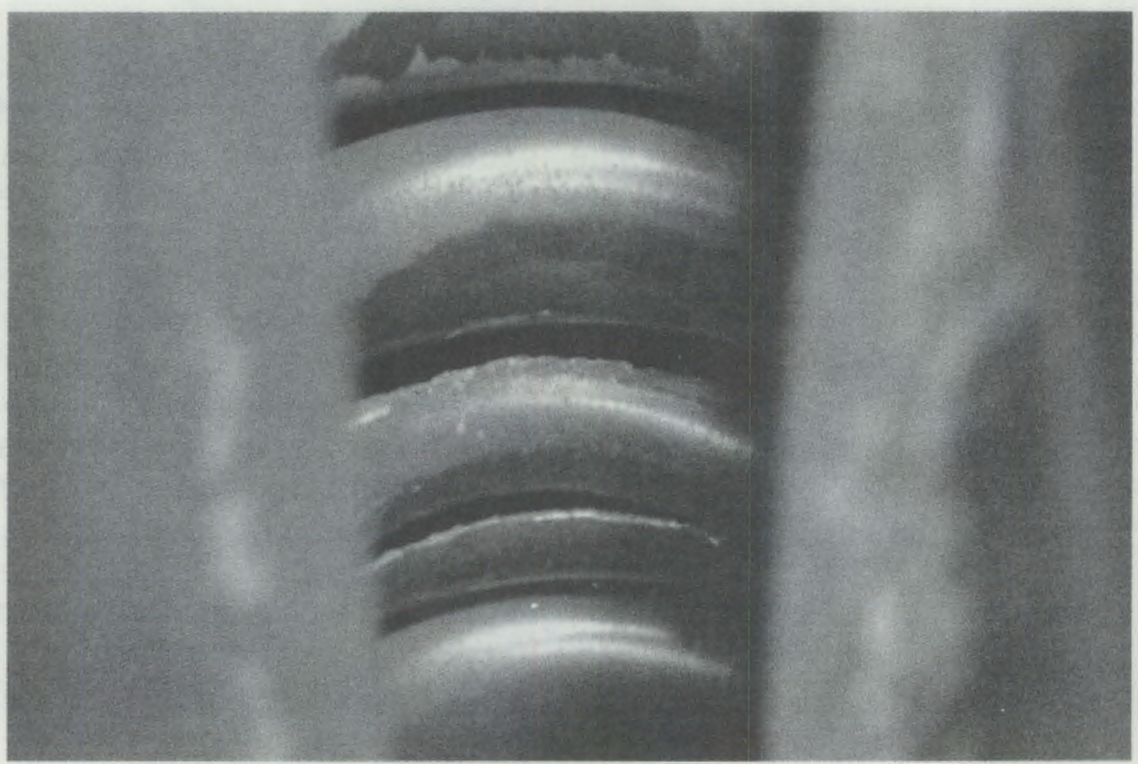

Neg. $8201718-4 c n$

FIGURE 54. Large Longitudinal Failure 
on each tube. At Surry, tube striations were visible and could be felt. At PNL some tubes had fishmouthed open at the previous striation locations (Figure 54). In addition, a separation of an upper tube half from the lower half is apparent in Figure 54. Measurements of the flow slot closure dimensions were however identical before and after generator transport to PNL.

The other region on which we have initiated characterization is the primary side of the tube sheet. Figure 55 shows a portion of the underside of the tube sheet, with a clear visibility of the tube plugging. Also leakage at certain plugs is apparent. Three gallons of liquid were removed from the channel head after placement of the generator into the SGEF. All of this liquid is presumed to have leaked from plugged tubes. Analysis of the liquid showed that it contained $135 \mathrm{ppm}$ chloride ion, thus indicating that its source was not seawater. A complete analysis is shown in Table 5 .

In summary, preshipment observations taken at Surry were compared with identical observations after placement in the SGEF at Hanford. No significant dimensional changes were measured, no change in corrosion product composition was found, and general condition of the steam generator remained unchanged. The only exception was that inner row U-bend crack indications at Surry have opened up in a couple of instances. Extension of the initial visual examinations has documented secondary structure condition through further regions of the generator confirming severe support plate damage. Primary side examinations have begun with the initial observation that numerous tube plugs are leaking under gravity conditions.

- $\quad$ Channel Head Decontamination (Task 6)

The initial intended purpose of decontaminating the channel head was to reduce exposure during subsequent experiments requiring primary side access to the steam generator tubes. A competitive bid procedure resulted in an opportunity to utilize two dilute chemical reagent techniques, one on either side of the channel head. The use of these dilute reagent techniques had several research aspects relevant to possible use in the future. First they were basically ready for field application, had been laboratory tested, but needed a successful demonstration to allay fears associated with use of chemical reagents within a steam generator. Second the techniques offered an opportunity for lower radiation exposure during application than abrasive decontamination methods since they do not require positioning a device inside the channel head and could potentially generate less secondary radwaste. Also there was need to evaluate the types and quantity of secondary waste generated. Demonstration of these techniques may result in advancement of the current state of technology. 


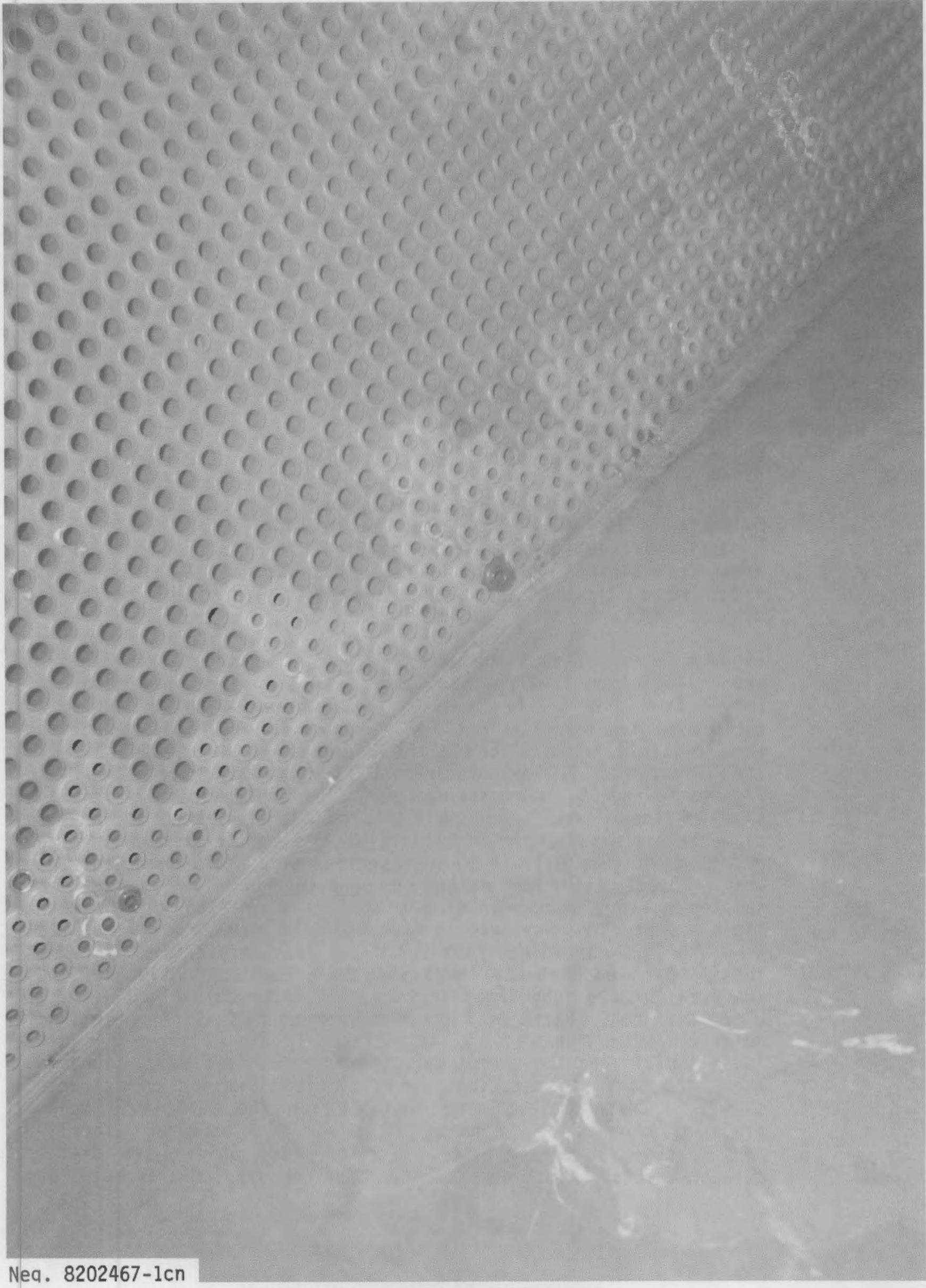


TABLE 5. Analysis of Water Removed from Steam Generator Primary Side After Transport to Hanford

\begin{tabular}{|c|c|c|}
\hline Radiation: & $\mathrm{Co}-60$ & $3.0 \times 10^{7} \mathrm{~d} / \mathrm{m} / \mathrm{ml}$ \\
\hline & $M n-54$ & $3.3 \times 10^{5} \mathrm{~d} / \mathrm{m} / \mathrm{ml}$ \\
\hline Chemical: & $M n$ & $0.4 \mathrm{~g} / 1$ \\
\hline & $\mathrm{Fe}$ & $0.5 \mathrm{~g} / 1$ \\
\hline & $2 n$ & $1.4 \mathrm{~g} / 1$ \\
\hline & $\mathrm{Ni}$ & $7.4 \mathrm{~g} / 1$ \\
\hline & $\mathrm{Cl}^{-}$ & 135 ppm \\
\hline & $\mathrm{pH}$ & 1.5 \\
\hline
\end{tabular}

London Nuclear Services, Inc. applied the Canadian-developed CANDECON process to the cold leg side. Following that, Quadrex Corporation applied a British-developed process, LOMI (for Low Oxidation state Metal Ion), to the hot leg side. Quadrex aTso demonstrated electropolisshing as a final step to produce a shiny, smear-free surface in local areas. This was useful in the manway areas where frequent entries are made by personnel performing project tasks.

Figures 56 and 57 show the materials and dimensions of the channel head. Radiation levels inside each half of the channel head bowl ranged from 3 to $6 \mathrm{R} / \mathrm{hr}$, as shown in Figures 30 and 33. Prior to performing the decontamination, a number of preparatory actions were required in addition to the radiation measurements shown in the figures. Pre-decontamination photographs are shown in Figures 58 and 59. Core samples were drilled (Figure 60) from each side of the channel head wall that contained about a one-inch diameter circular sample of the stainless steel inner cladding from each side (Figure 61). A 10-inch section of a steam generator tube was removed, also for reference purposes and for use as test samples during decontamination. Samples were also cut from the stainless steel manway inserts that had been removed from the steam generator. A one-square-foot stainless steel protective plate was installed on each channel head side to prevent decontamination of two areas of the tube sheet surface, for later comparison with the clean surfaces. Racks of corrosion specimens of all the pertinent materials were prepared and installed. Figure 62 shows the protective plate and the corrosion specimen racks in place. Figure 63 shows the corrosion specimens which included welded and stressed samples. Corrosometers were installed in the substitute manway plates (Figure 64). A number of minor but necessary facility modifications were completed. For example, holes were drilled between the truck lock and the tower for hoses to deliver solutions 


\section{CHANNEL HEAD COMPONENTS AND MATERIALS}

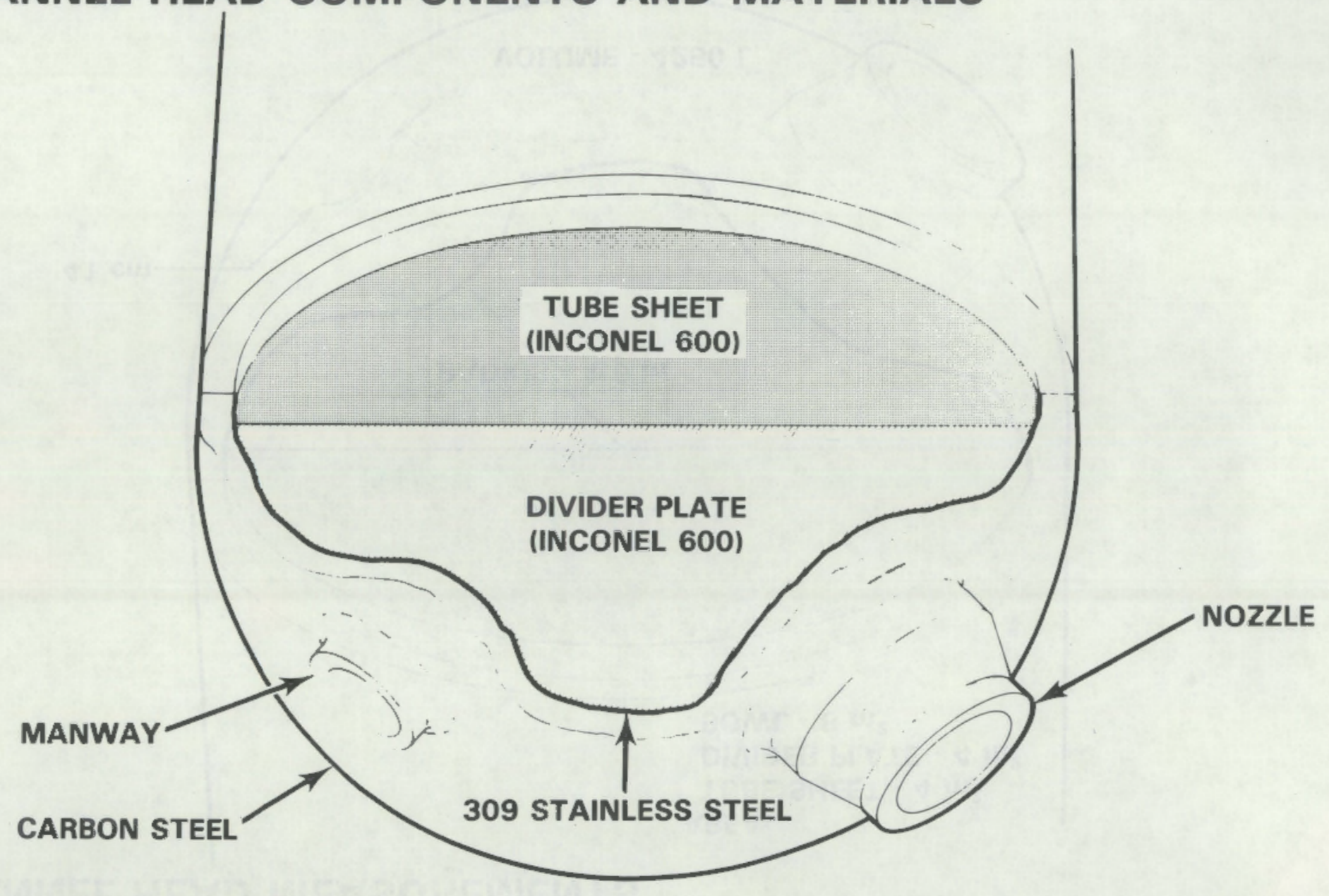




\section{CHANNEL HEAD MEASUREMENTS}

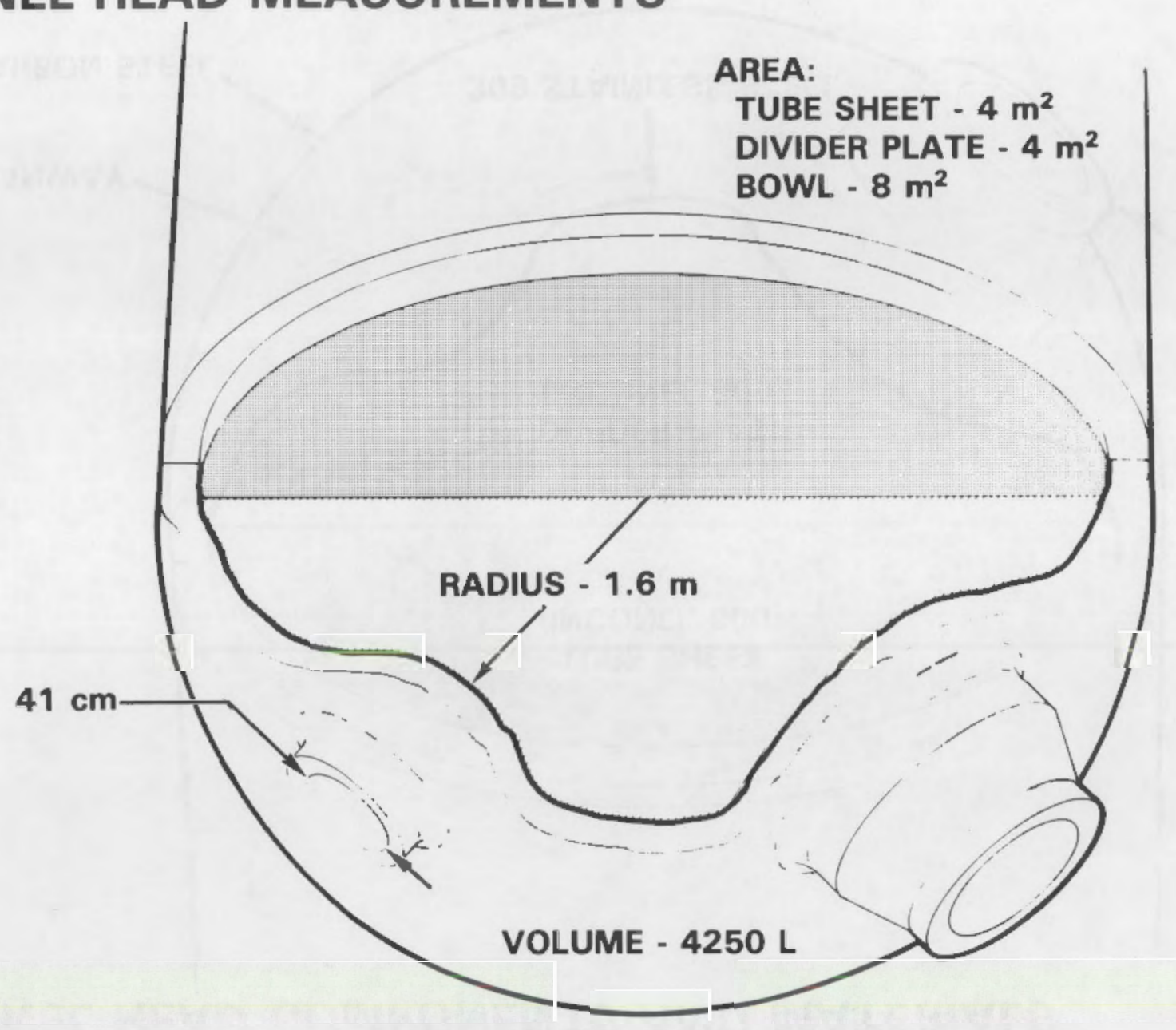


$100000000000 \%$

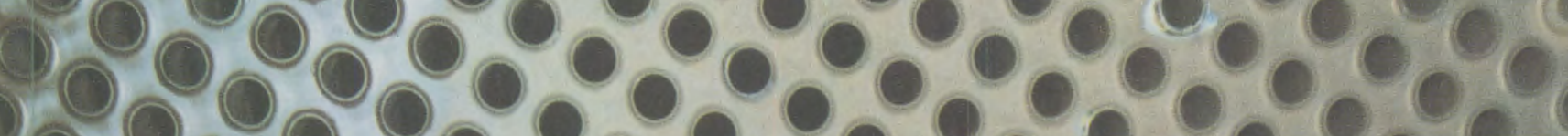

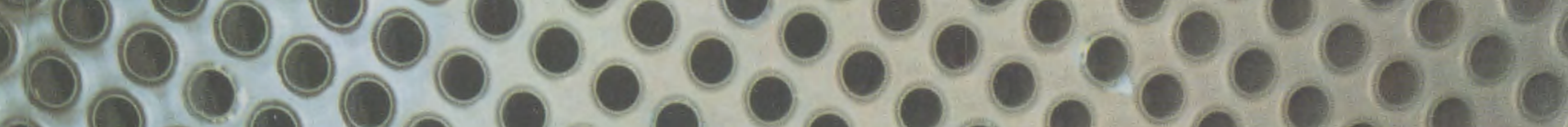

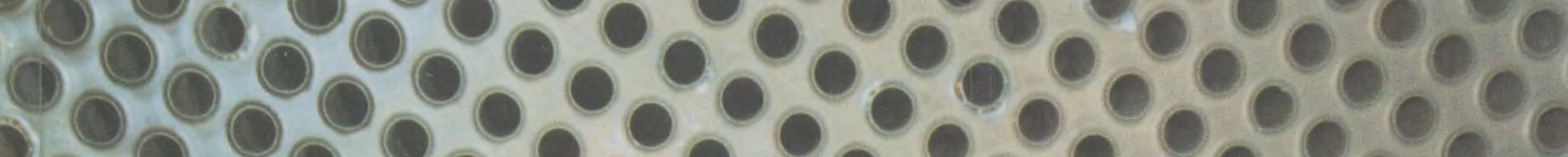

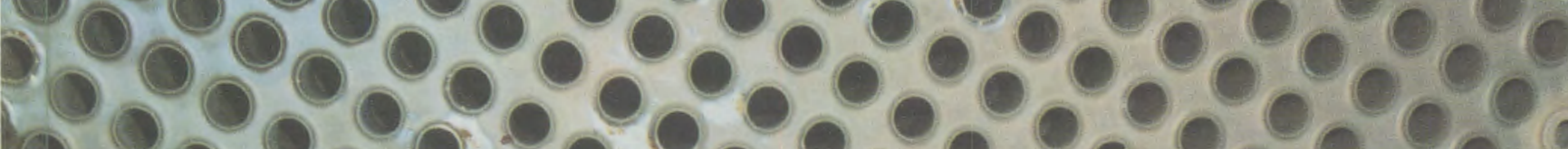

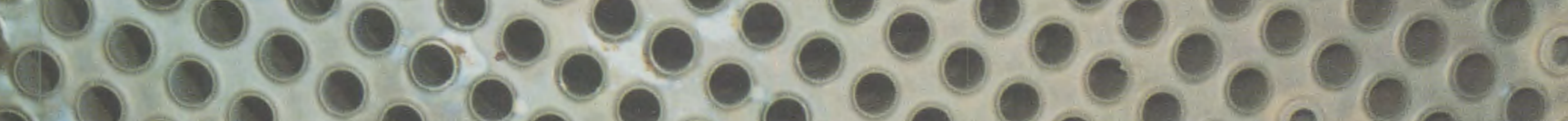

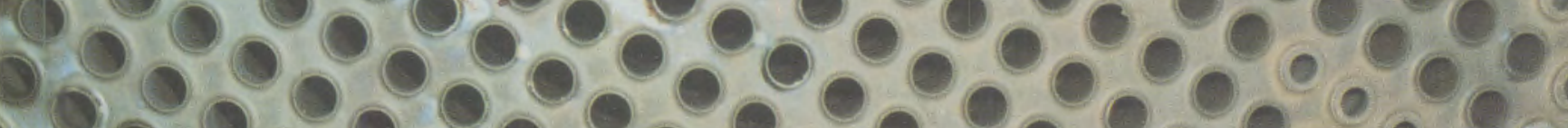

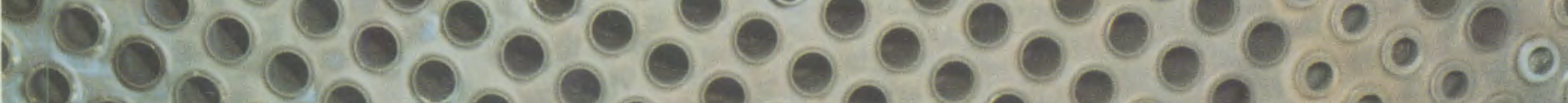

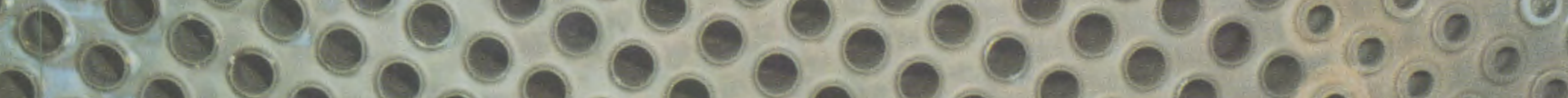

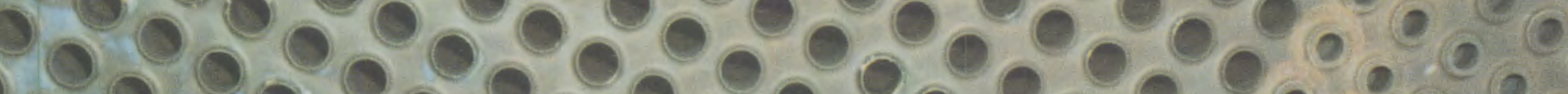

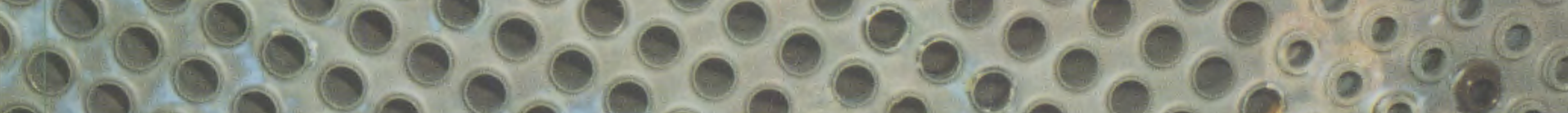

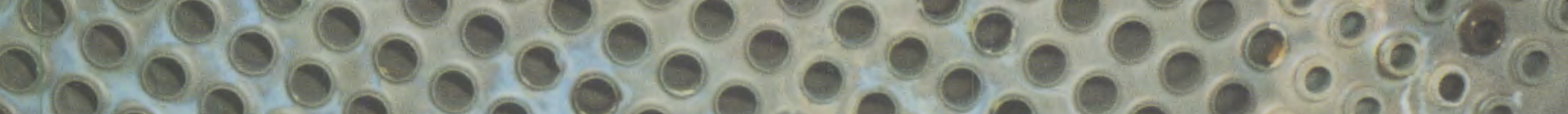

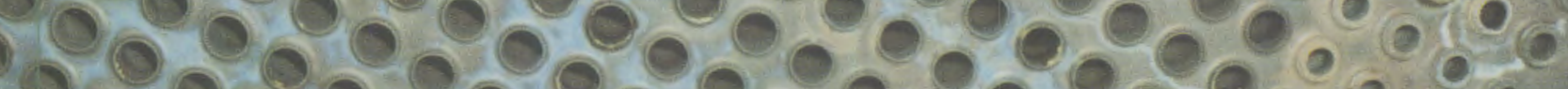

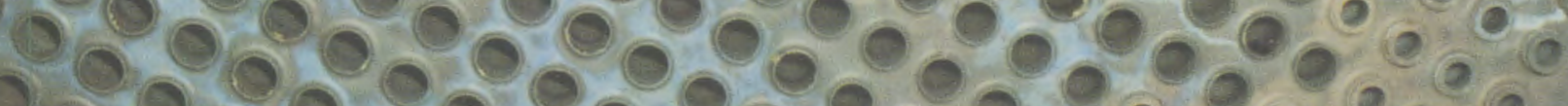

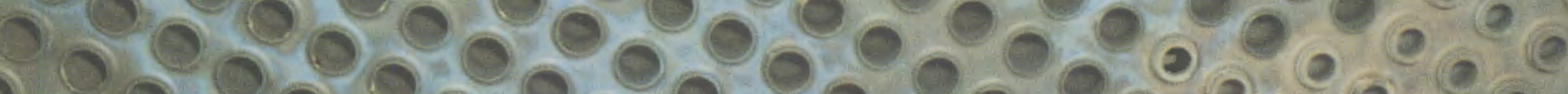

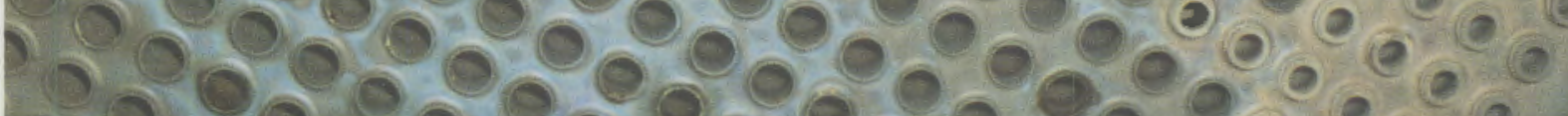

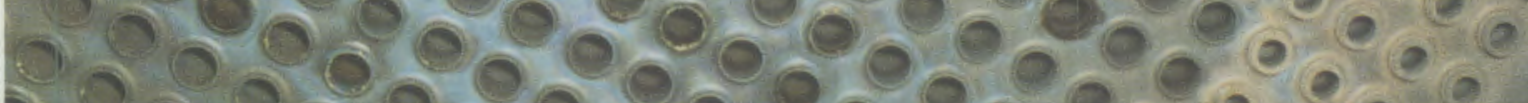

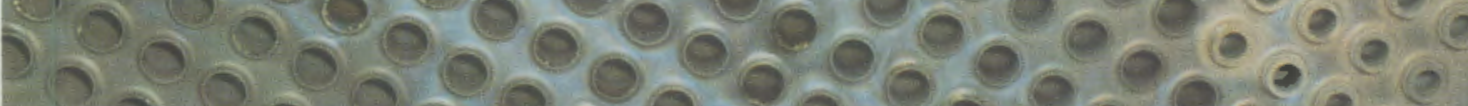

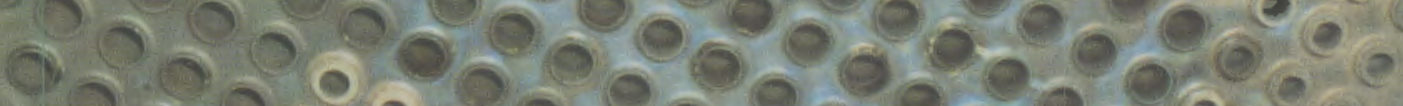

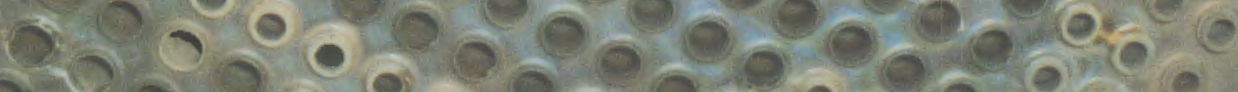

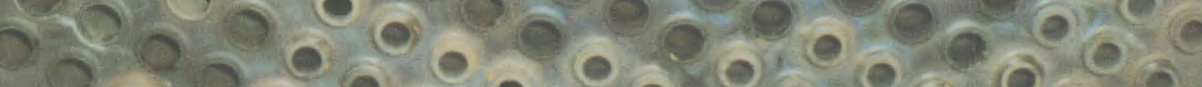

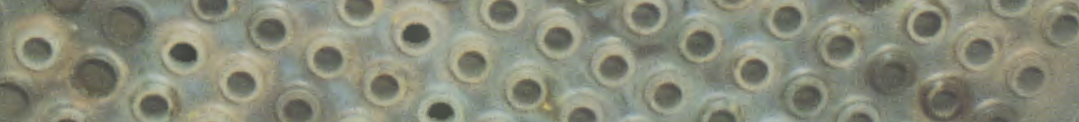

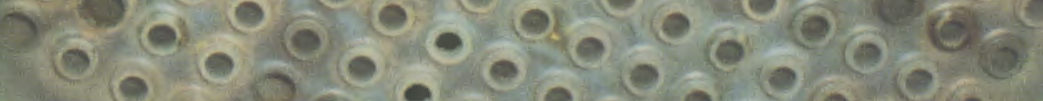

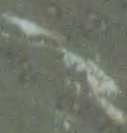




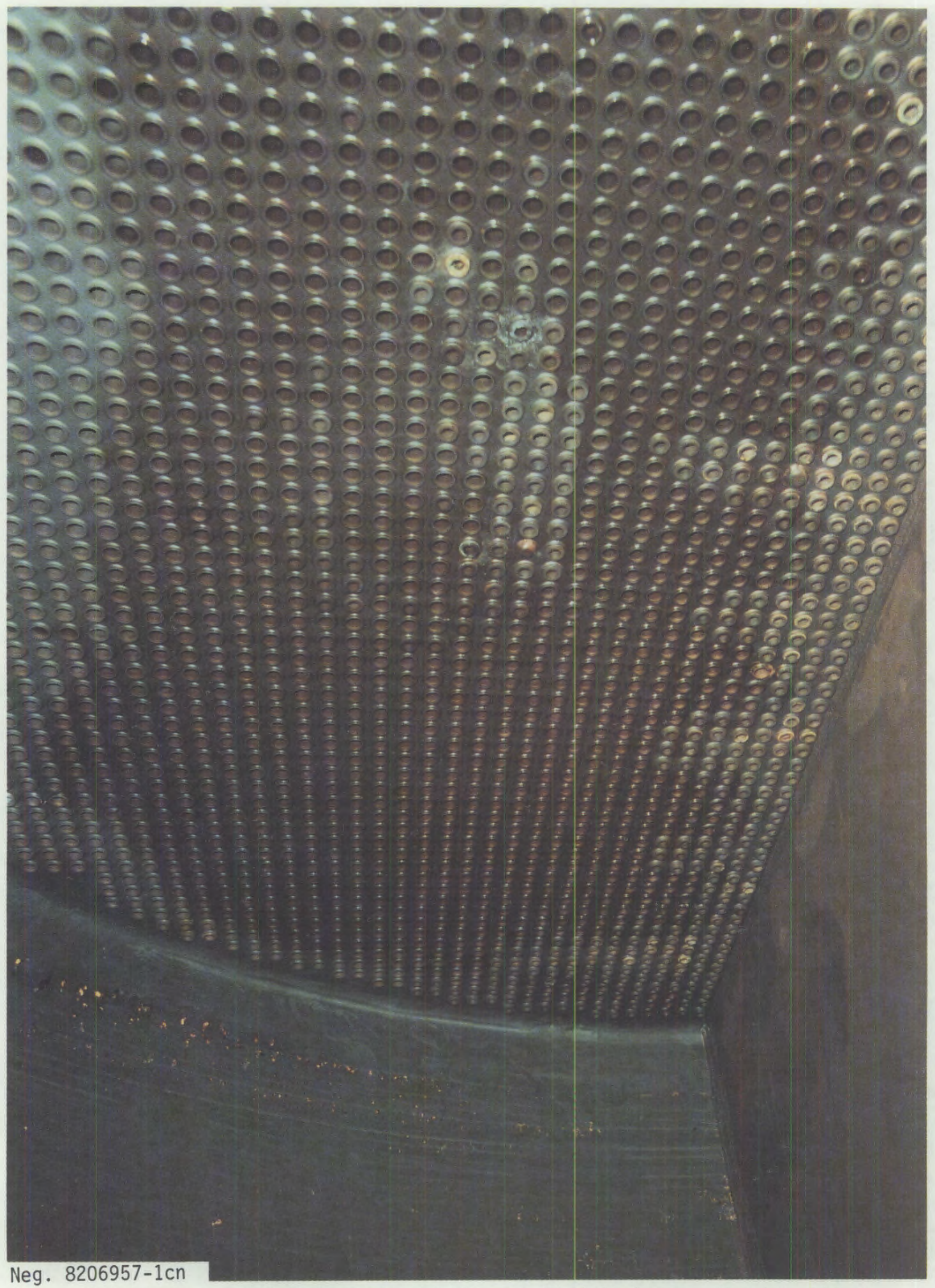

FIGURE 59. Initial Condition of Channel Head Surfaces - Hot Leg Side 


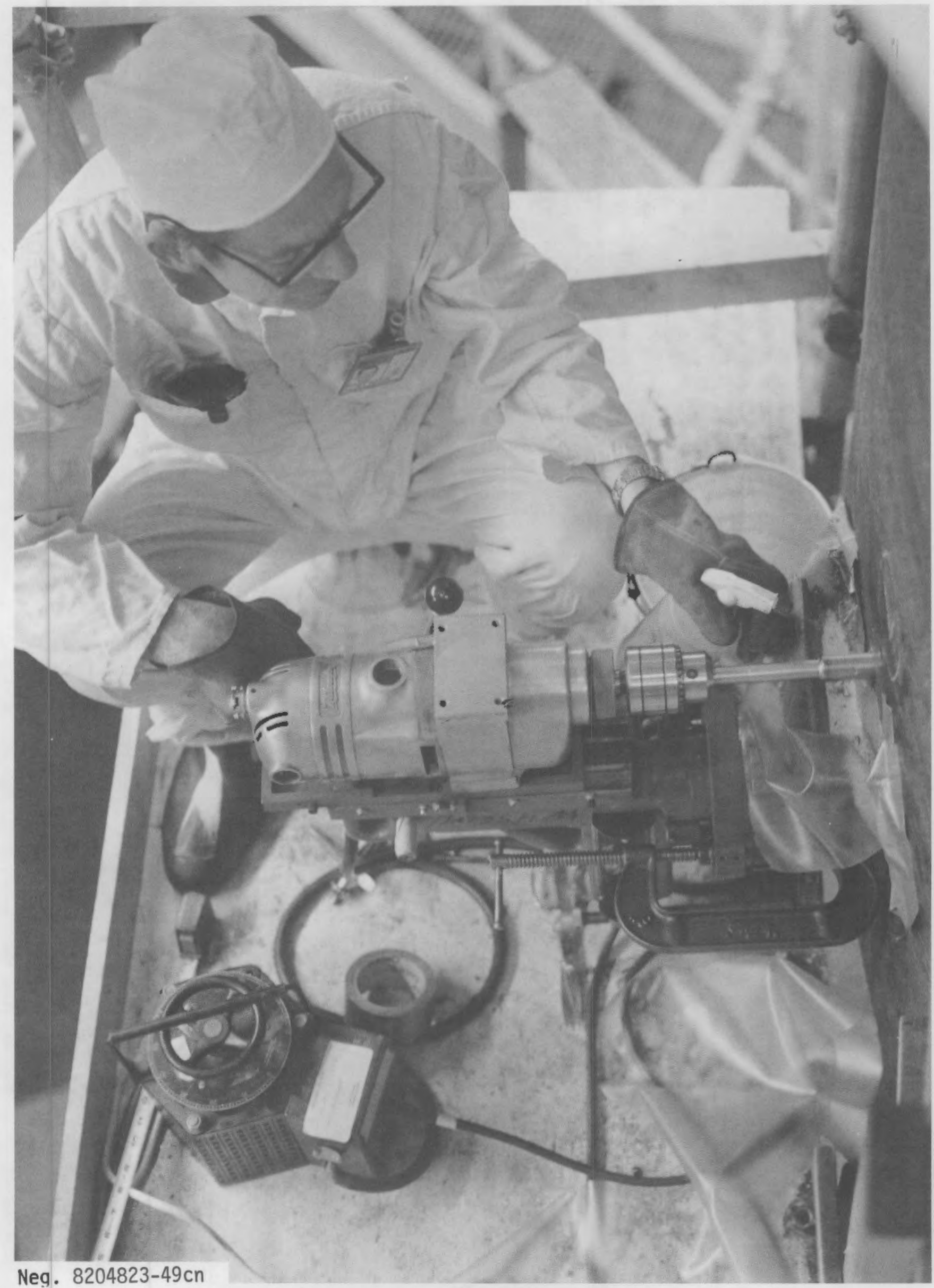

FIGURE 6D. Drilling Core Sample from Channel Head 


\section{CHANNEL HEAD CORE SPECIMENS}
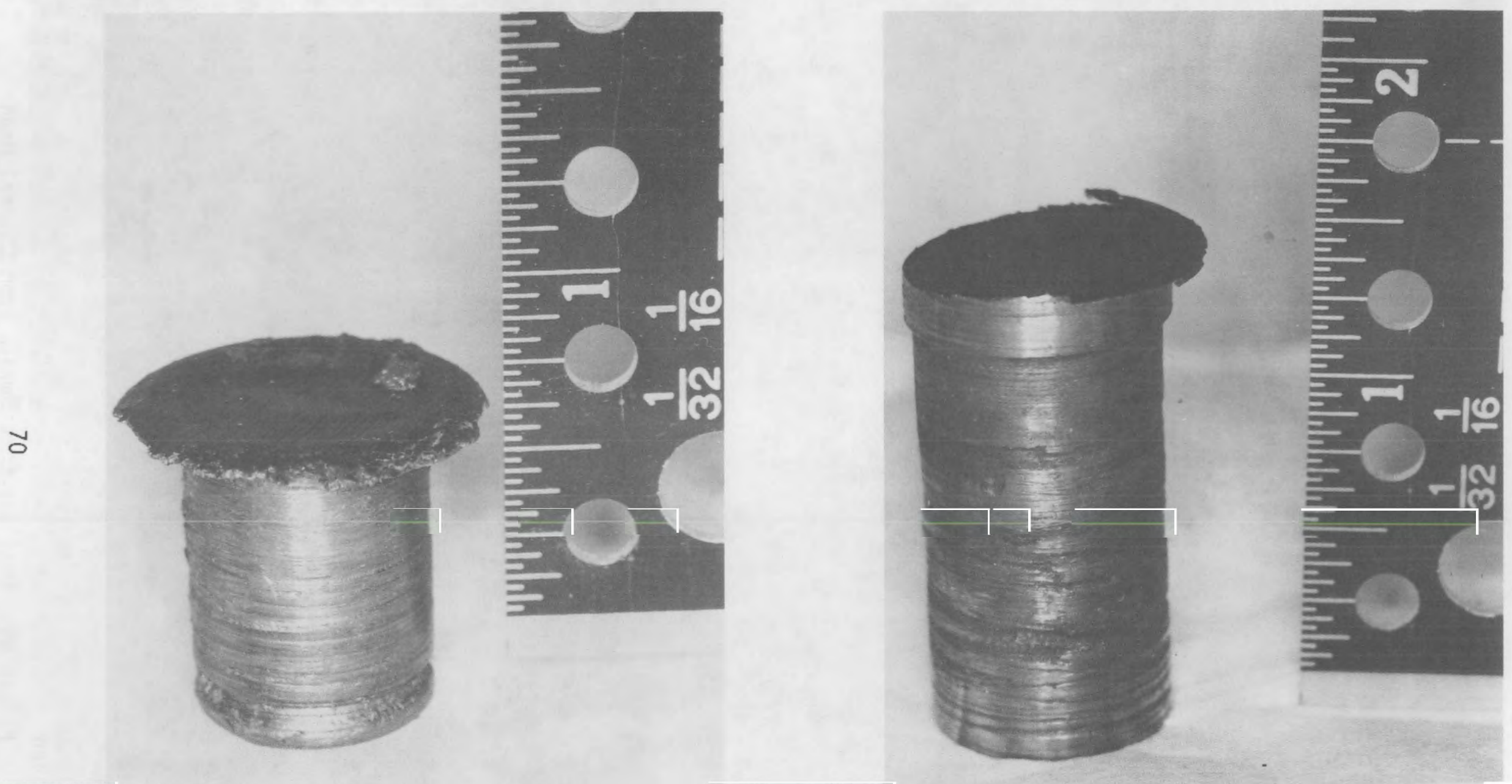

HOT LEG

COLD LEG 


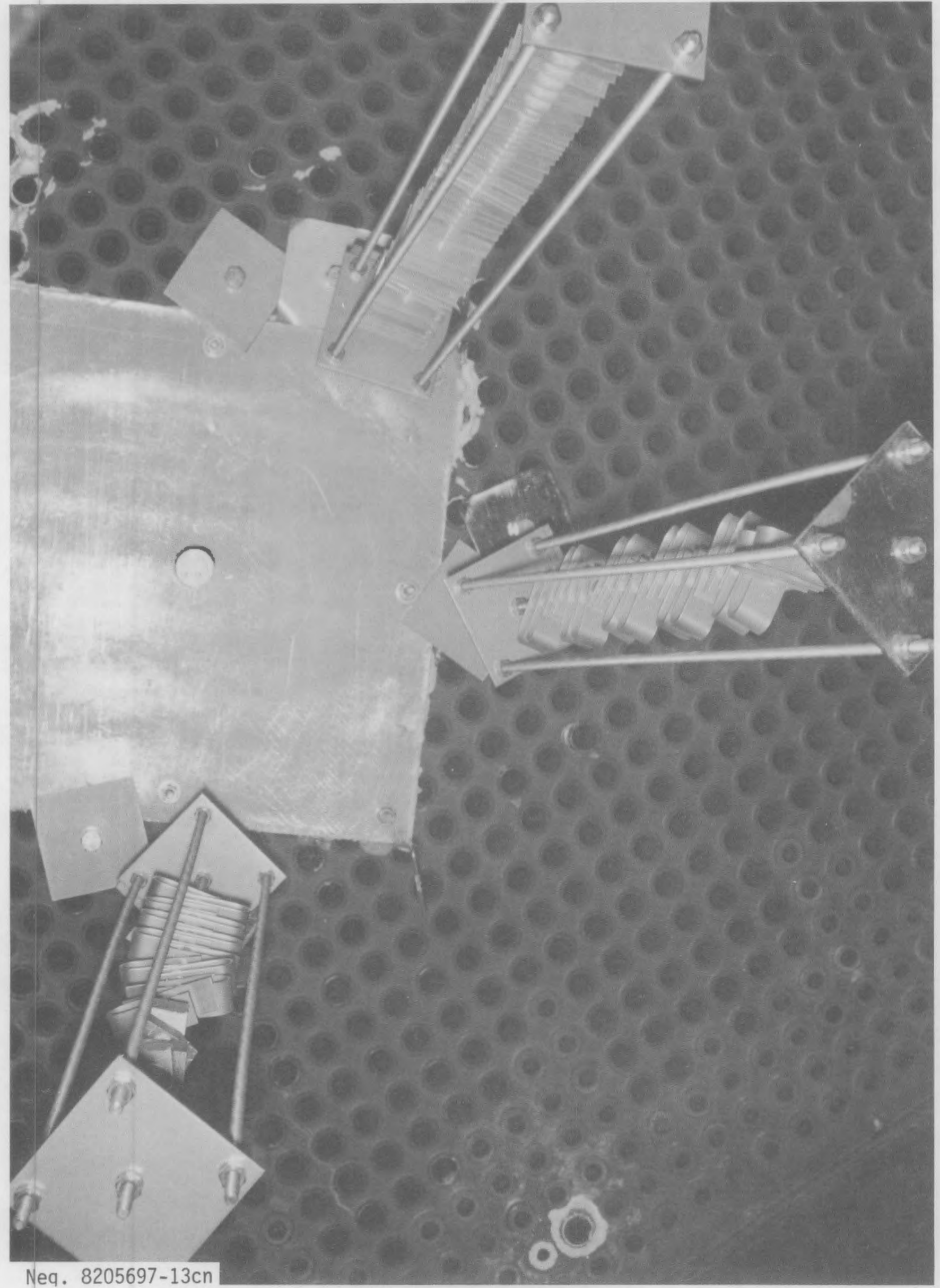

FIGURE 62. View of Tube Sheet Showing S.S. Protective Plate and Corrosion Samples 


\section{COUPON RACKS BEFORE DECONTAMINATION}
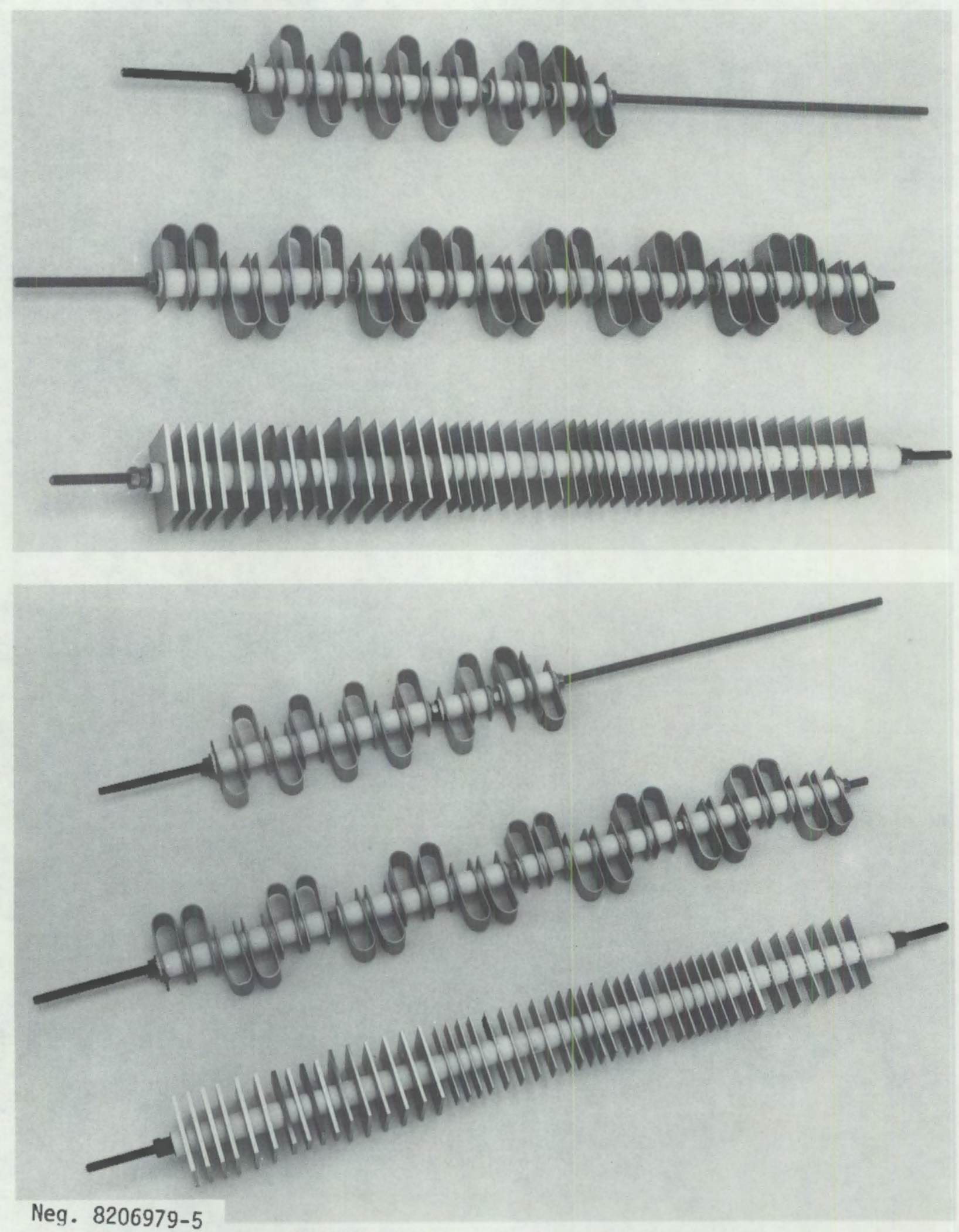

FIGURE 63. Corrosion Specimens 


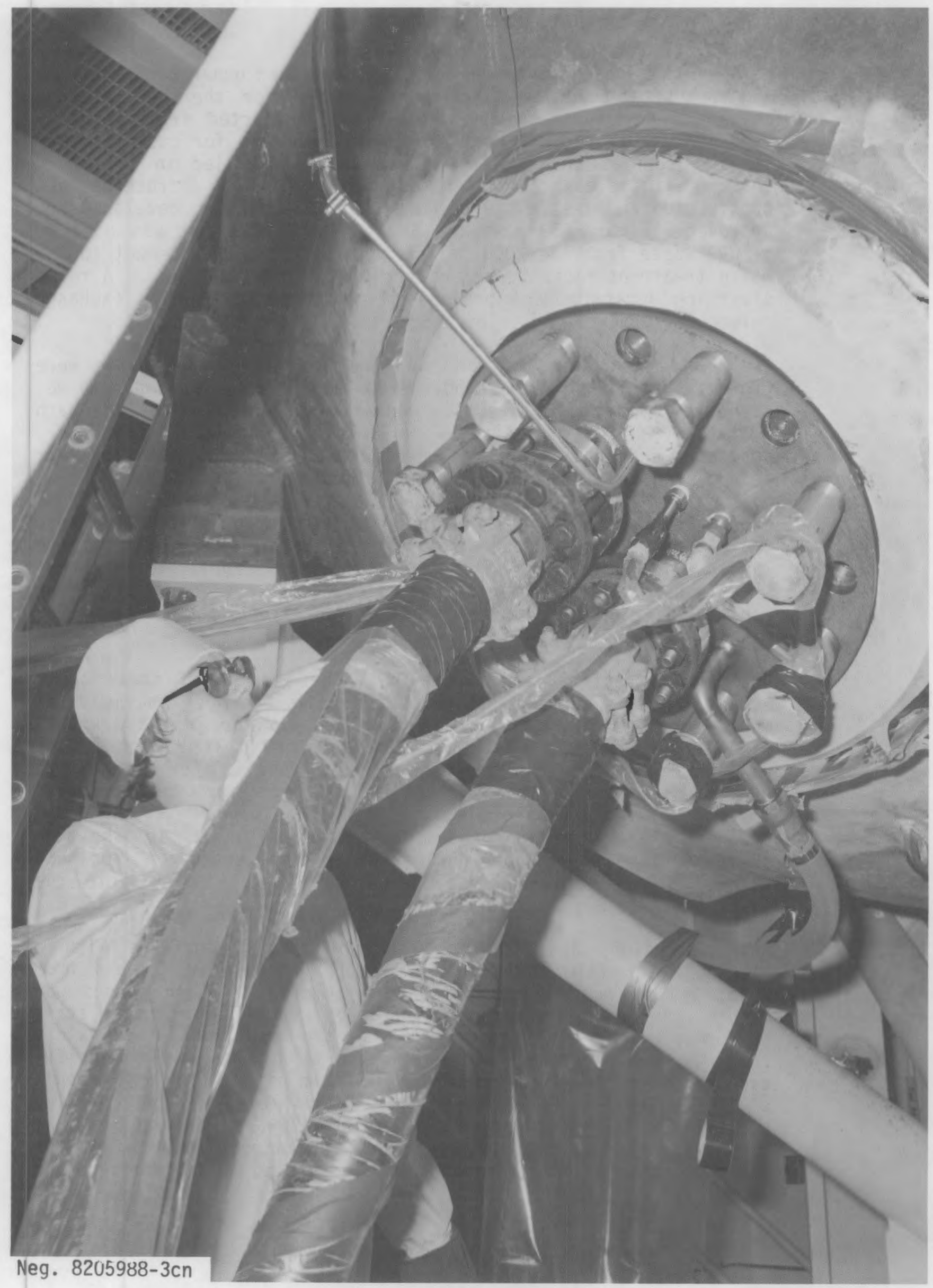

FIGURE 64. Manway Cover with Piping and Instrumentation Connections 
between the ion exchange columns and the steam generator. Shielding walls of concrete block were erected for the ion exchange columns. A deionized water supply was connected from a nearby laboratory building. A heat exchanger and drain for cooling water to cool samples and process streams were installed in the truck lock. A liquid waste transfer tank for mounting on a truck bed was constructed and tested. Procedures for its use were developed and approved. Figure 65 shows the 500 gallon tank as it was used to remove waste from the 2000 gallon tank in the SGEF basement to the waste treatment facility in another part of the 300 Area. A resin slurrying apparatus and procedures for emptying the ion exchange columns were developed. The apparatus is shown in Figure 66 .

The entire truck lock floor and lower 5 feet of the walls were protectively coated with Carboline 305 and Butvar. A sump pump was added to the truck lock sump. Radiation work procedures for each operation in the process were written and approved. Laboratory apparatus and analytical instruments to support the operation were accumulated and set up in the SGEF laboratory (Figure 67).

London Nuclear Company equipment was skid-mounted. Their pump skid was lowered into the SGEF basement so that it could sit in the liquid containment tray along with the waste tank. Three other skids containing the ion exchange columns, heaters, chemical mixing tanks, and controls were placed in the truck lock (Figures 68 through 70).

Both subcontractors performed well. The results of their operations are considered to be satisfactory as shown by the measurements recorded in Figures 30 through 35, earlier in this report. From analysis of the wastes, it is estimated that 2.1 curies of Co-60 were removed from the cold leg side, and 1.3 curies from the hot leg side. At least a part of the difference may be attributed to radioactive material being loosened and flushed from the tubes overhead by an excursion of decontaminating solution into the tube sheet portion of the tubes during the cold leg operation. On both sides, water evaporated from the process solutions up into the tubes where it was condensed.

Both operations left their respective treated surfaces with a smearable tan film that could be easily wiped off. Smears from about $100 \mathrm{~cm}^{2}$ were contaminated with several thousand counts per minute. Therefore, after each operation, Battelle technical staff performed a flushing of this film with a pressurized jet of water. This was very effective in removing the film, although no significant radiation level change was observed on either side as a result of this water-lancing operation. Radiation levels on the cold leg side were observed to drop by a factor of two as a result of the decontamination of the hot leg side. Radiation "shine" from the overhead tubes still contributes a large amount of radiation to the 


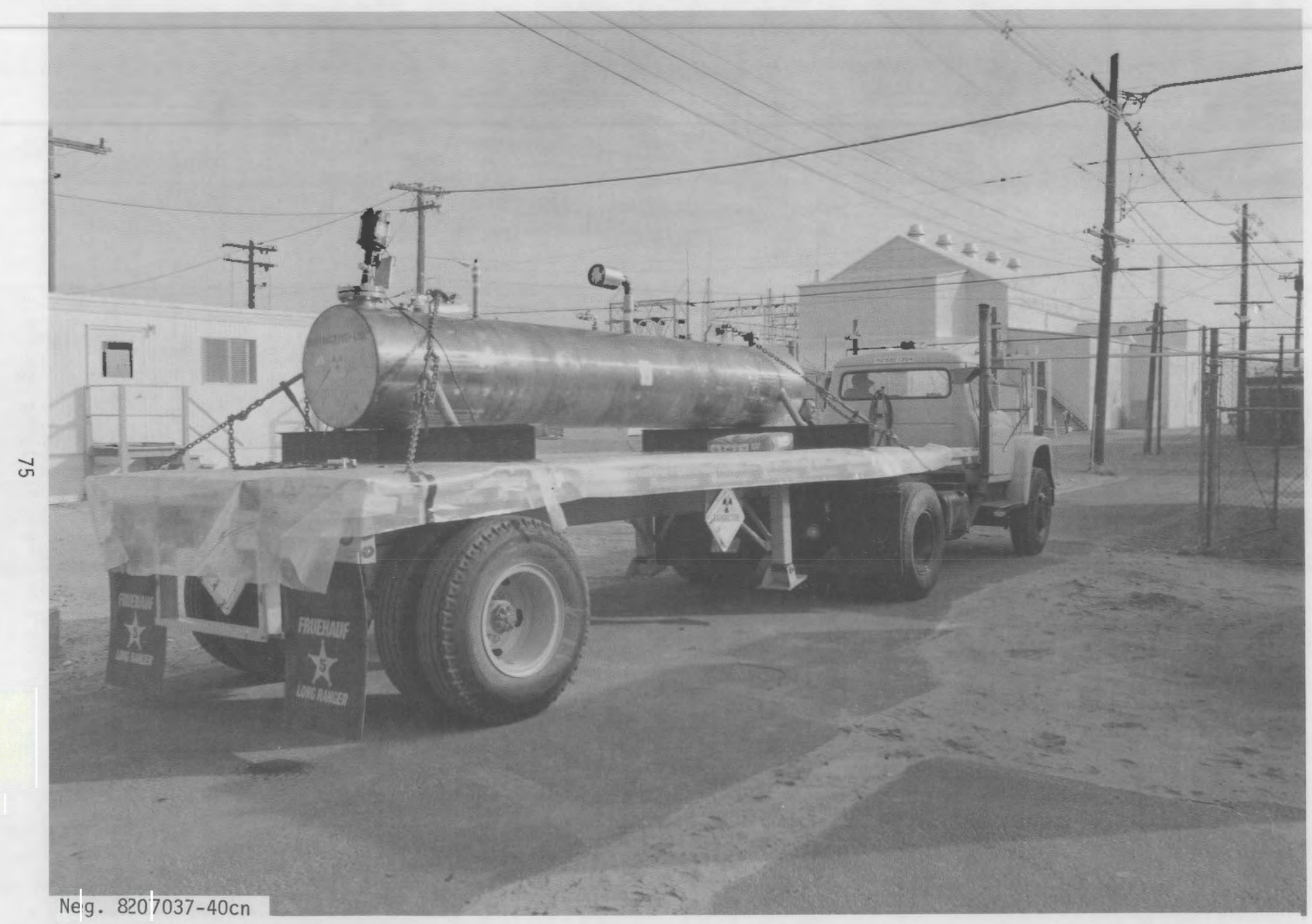

FIGURE 65. Liquid Waste Transfer Tank 


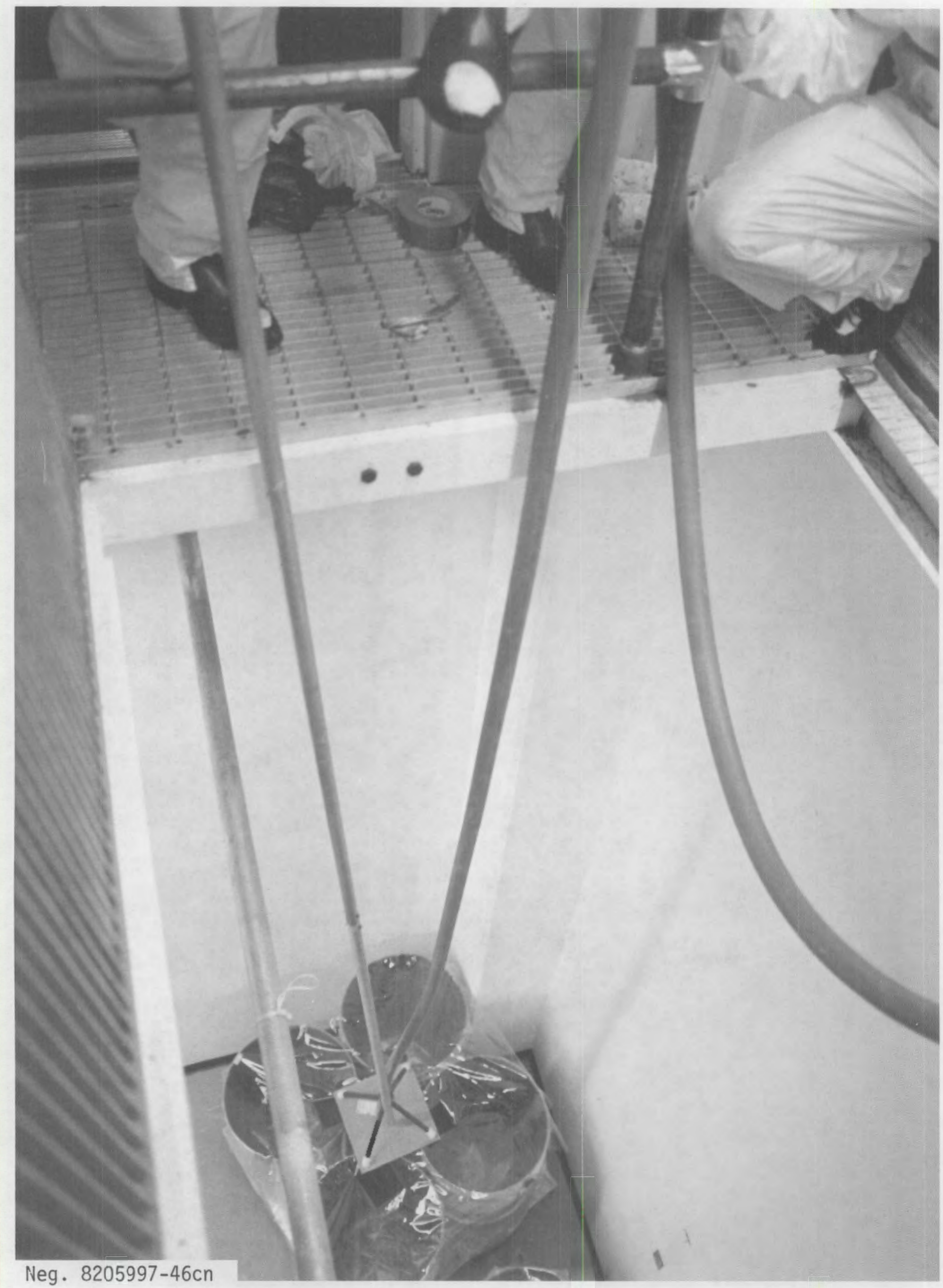

FIGURE 66. Resin Slurrying Apparatus 


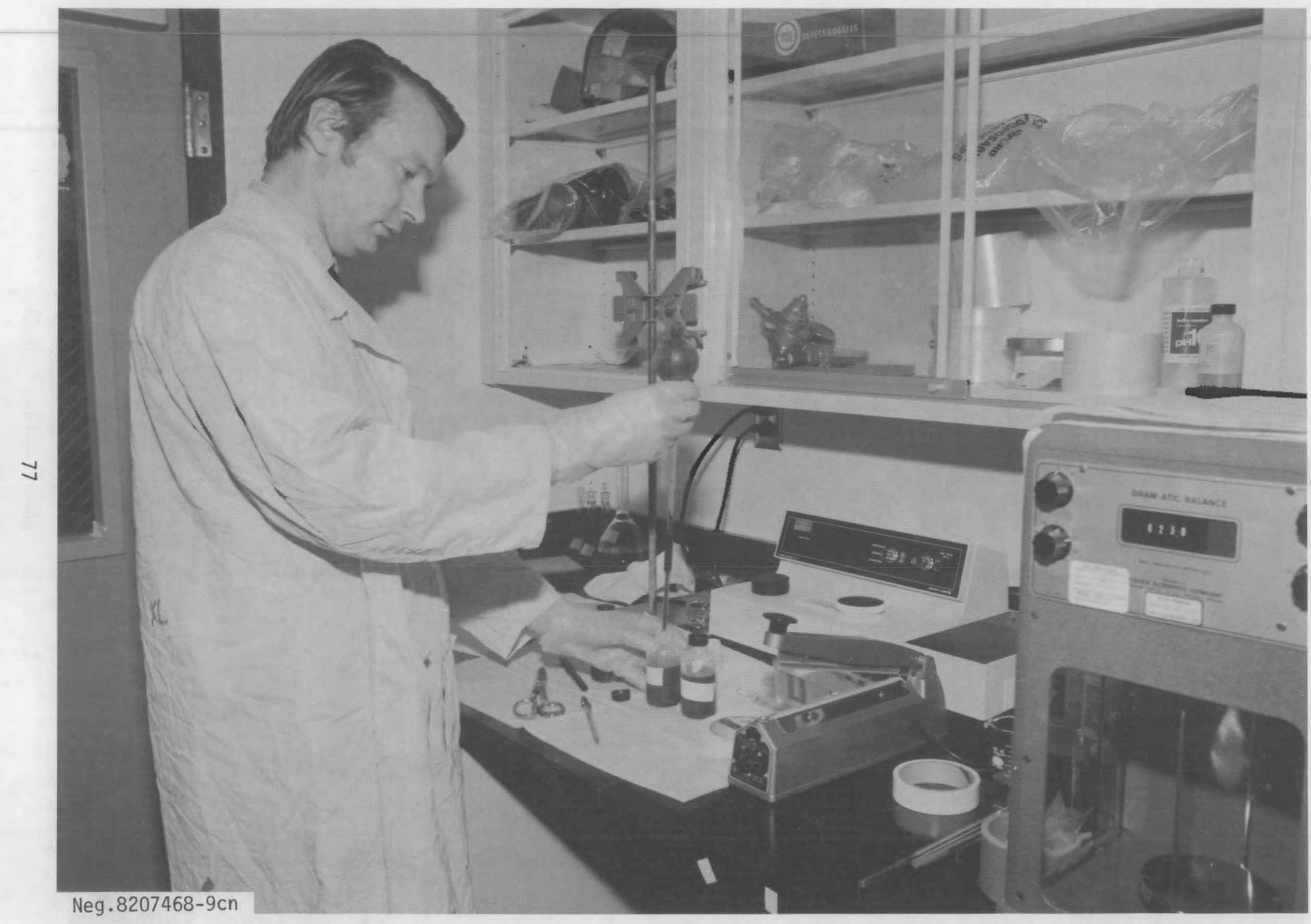

FIGURE 67. Analytical Laboratory 


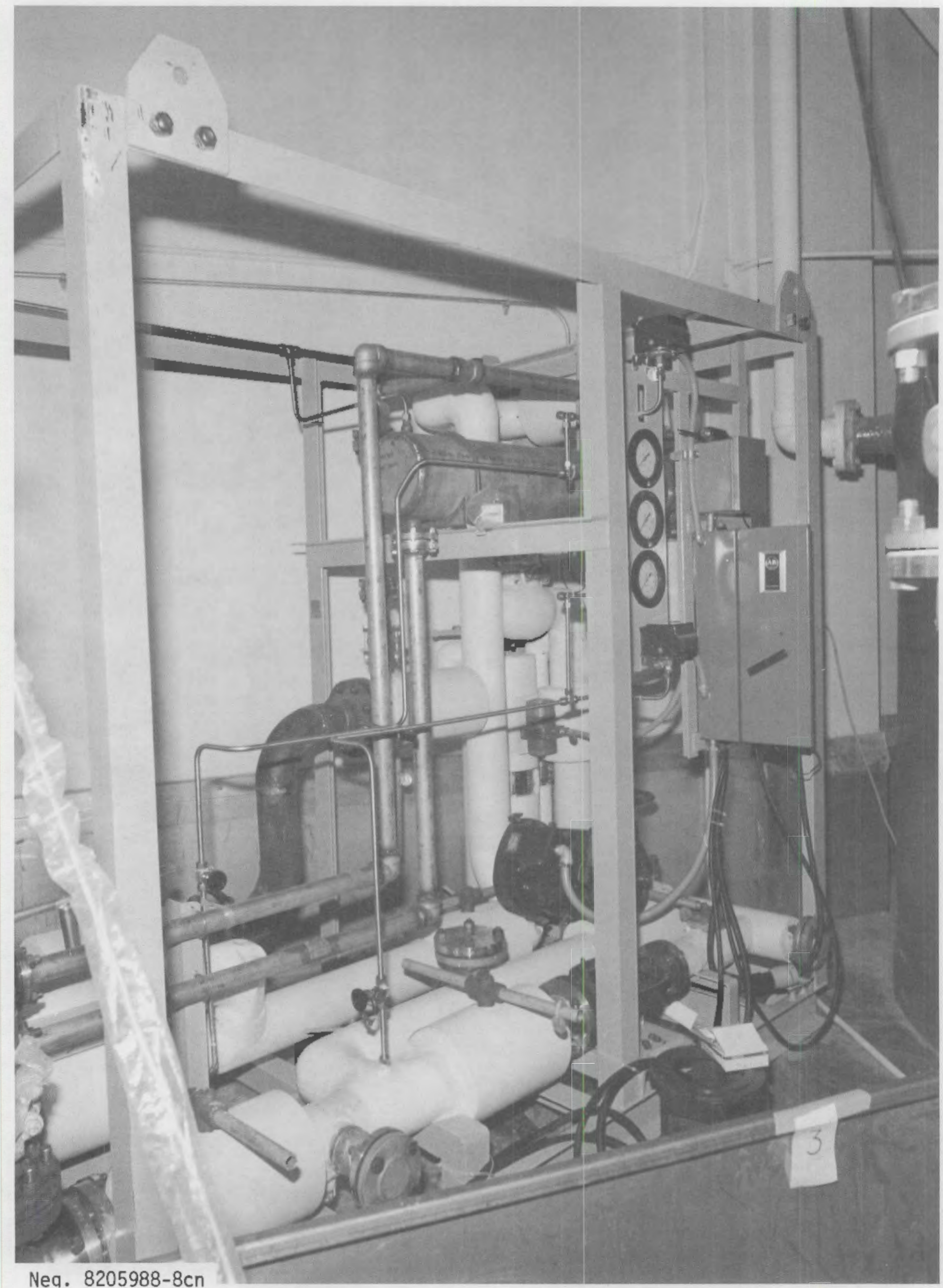

FIGURE 68. London Nuclear Pump Skid 


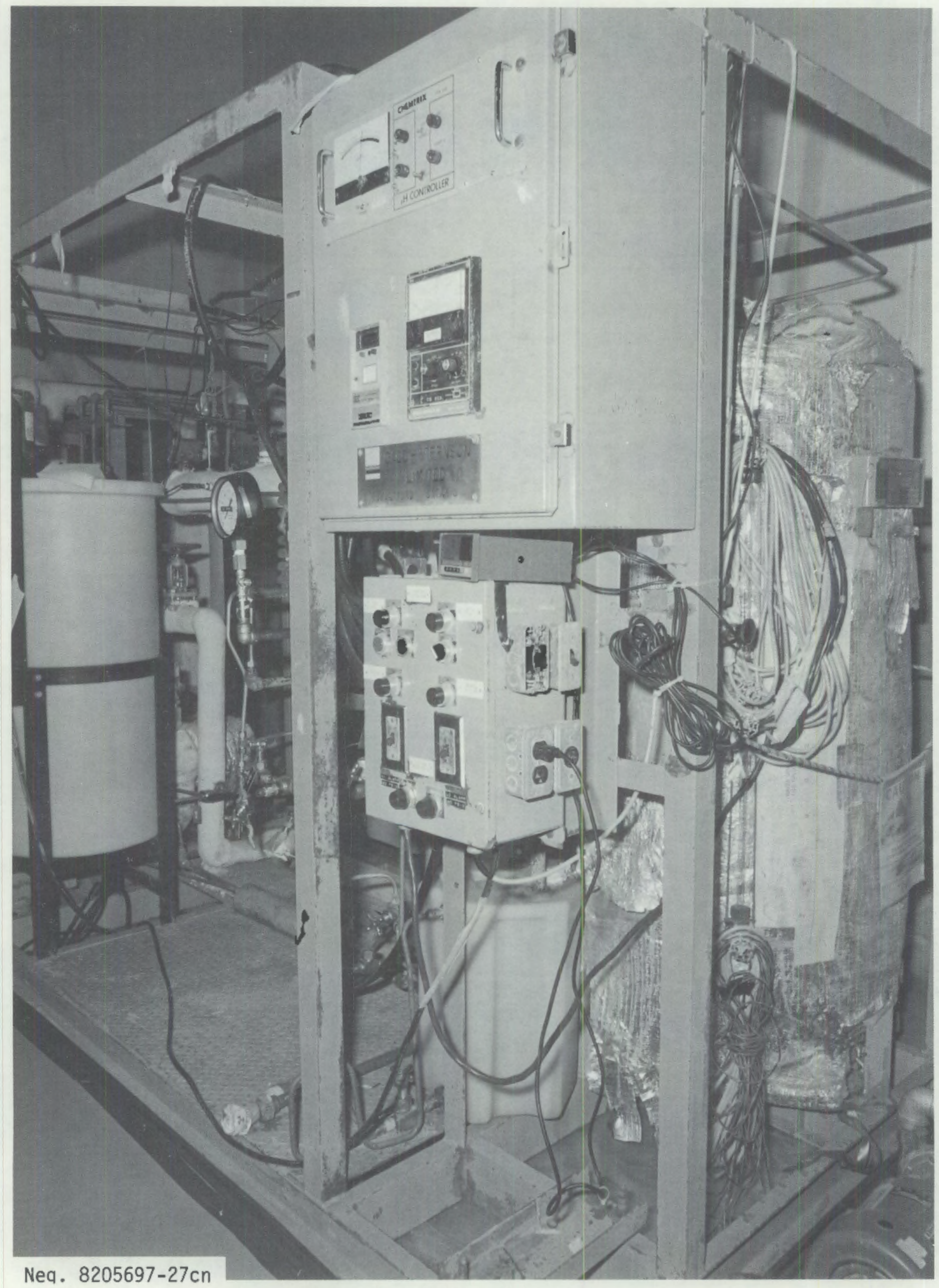

FIGURE 70. Heater Skid 
channel head volume. Whereas surface decontamination factors (DF's) of 30 to 50 were measured, volumetric DF's were only 6 to 7. Nevertheless, this reduction, along with removal of the smearable film, makes future tasks much easier to perform. Longer safe working times are permissible, and contamination control will be superior.

A number of lessons were learned from the decontamination operations. The capability of the SGEF to house large scale, wet chemical operations was tested. Although not ideal for the purpose, the facility served well with minor modifications and adaptations. For example, interconnecting openings between the tower, the laboratory and the truck lock were required for passage of hoses and people. These were installed, and are now available for future operations. A detailed liquid waste transfer procedure and equipment to perform the operation were developed. The importance of back-up units for major pieces of process equipment was brought home forcefully. The London Nuclear pump failed in mid-process. It was replaced with the SGEF waste transfer pump which was about one-third (50 gpm) the original pump's capacity. It appears that flow of the solutions had an important effect on the quality of the result. A through-flow pattern produced a more uniform-appearing result than one which allowed the fluid to enter and leave from the same area. Probably, a change in the entrance manifold would have been effective in preventing "short-circuiting" of the solutions. The effect of flow is illustrated in Figure 71 , showing a shiny, thoroughly clean area where incoming solution impacted directly on the surface. Figure 72 shows another flow-related effect, a splotchiness, or non-uniform decontamination result.

It appears that it is worthwhile, at least in the SGEF as it is constructed, to include a step that concentrates the radioactive waste. Either process could operate with a concentrating ion exchange column to minimize the volume of Tiquid waste. This arrangement was actually integral to the CANDECON process, and was demonstrated to be feasible for the LOMI process.

Electropolishing (Figure 73) was demonstrated to be an effective "touch-up" method after the Quadrex operation. It was used to clean each of the manway areas to a shiny metal state so that personnel contamination was greatiy reduced during subsequent entries to the channel head.

After completion of all the decontamination operations, all equipment was cleaned to required standards for shipment, and returned to the subcontractors. The SGEF was likewise cleaned and returned to normal condition for additional program tasks. 


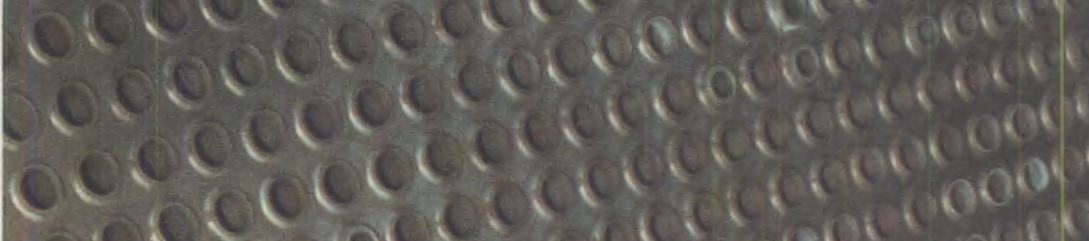

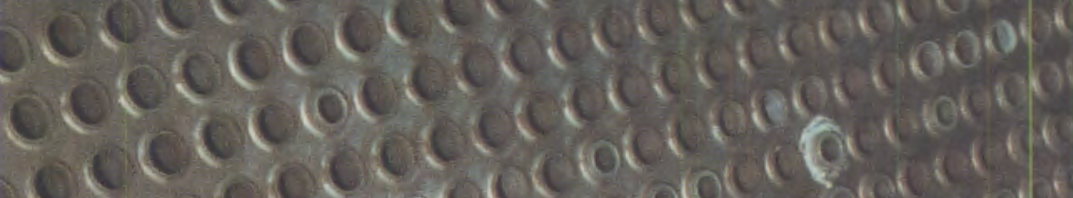
00000

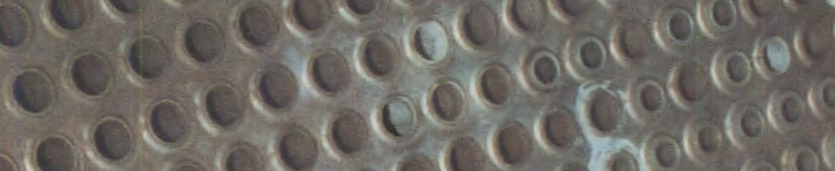
.00000 cold

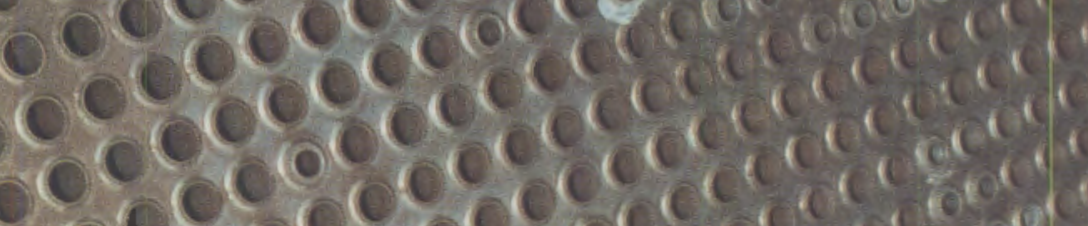

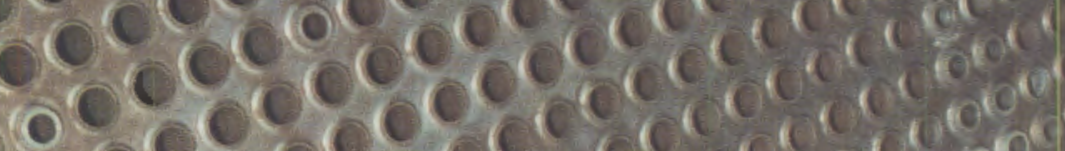

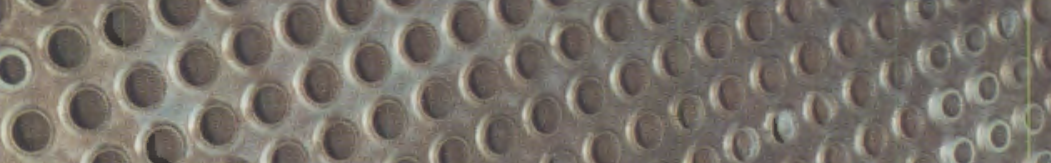

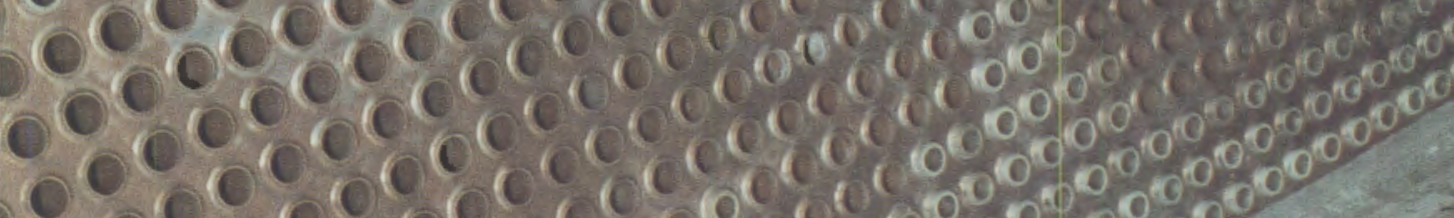

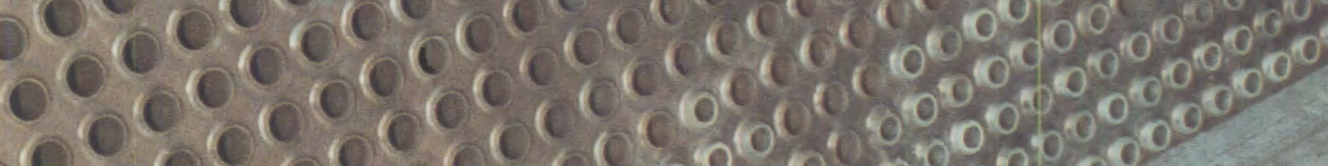

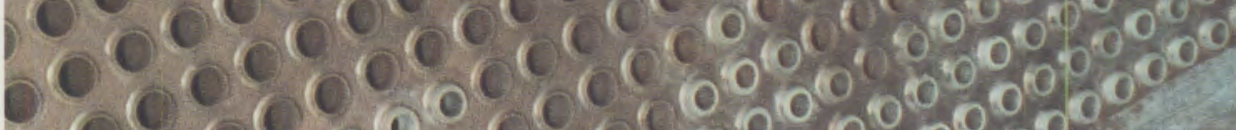

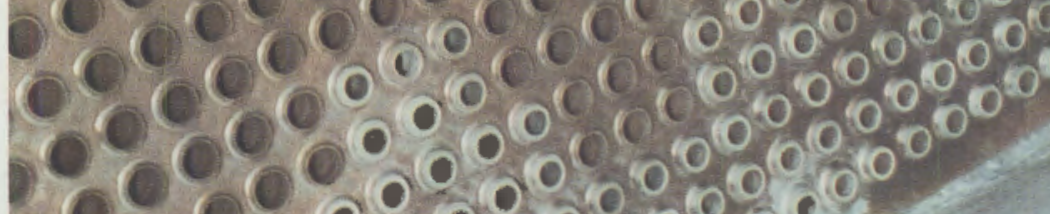
$98 \%: 0001007$ 0000000

0.0000

000.000

50.000

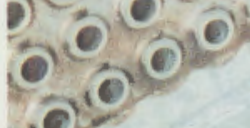

(6) 


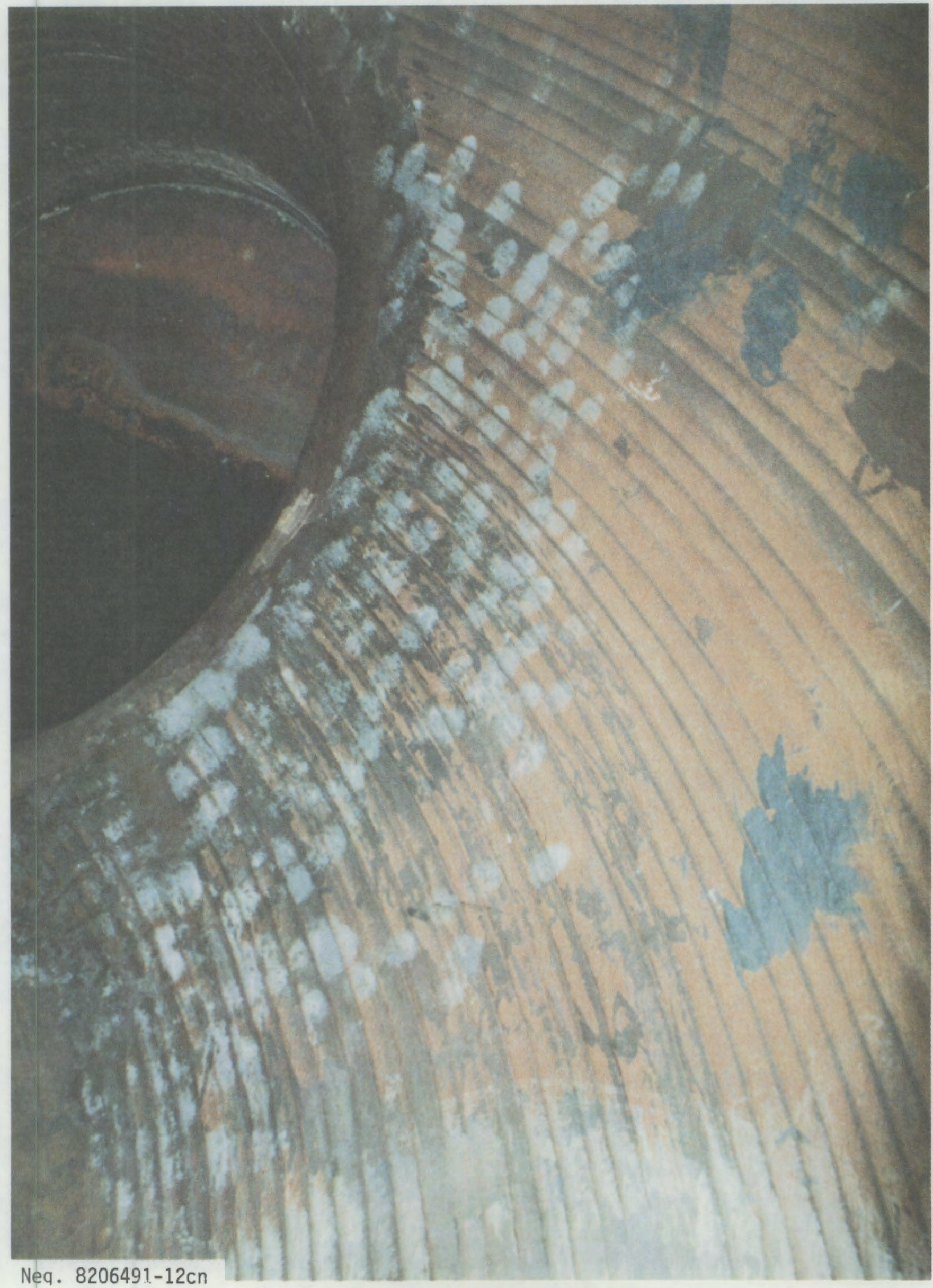

FIGURE 72. Splotchy Appearance of Film 


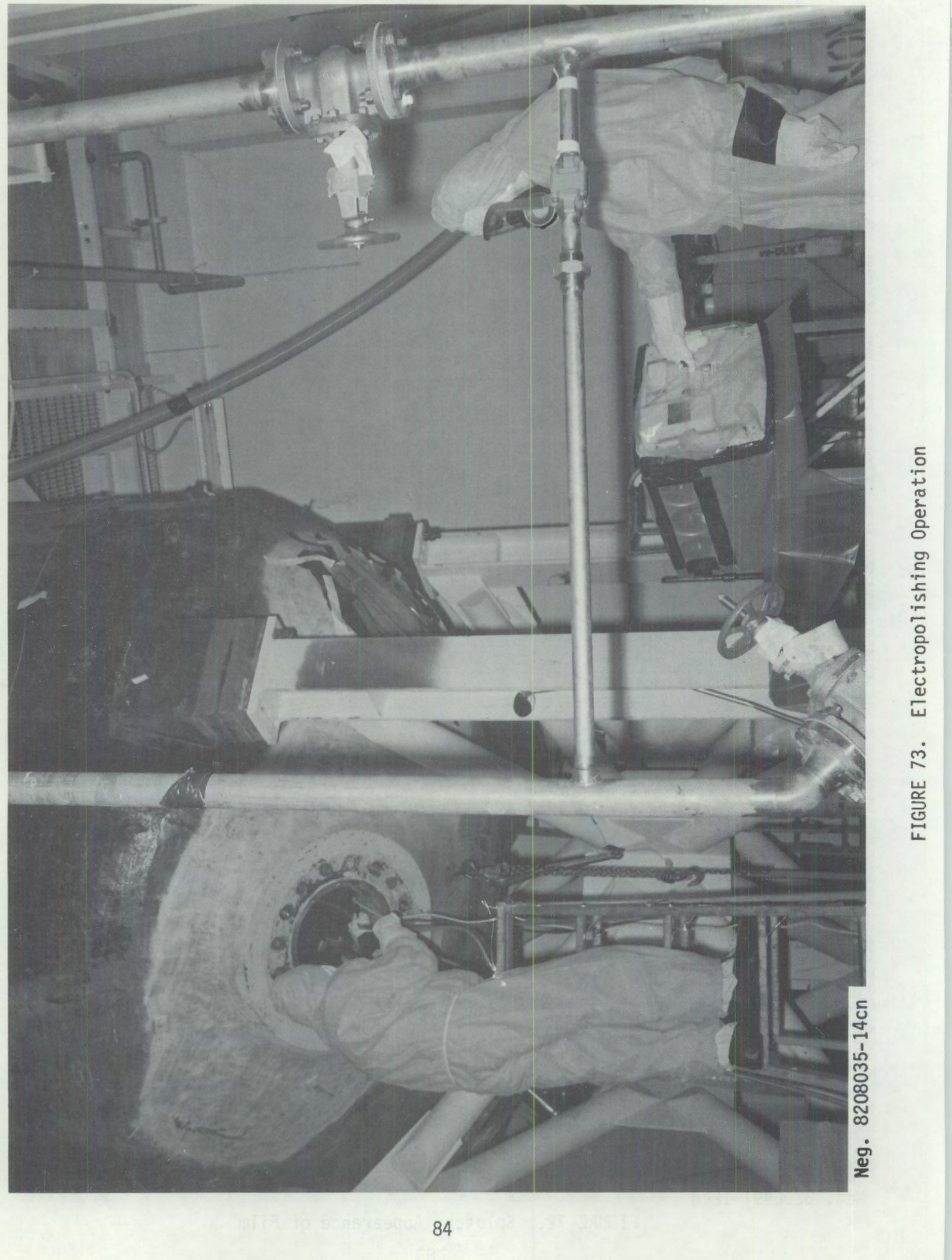


Originally, all of the tubes in the steam generator were to be eddy current tested, including the 748 that had been plugged during the six years of the generator's active life. Owing to the high cost of unplugging, only 461 of the 748 will be opened. Some of the plugs need to be retained in the tube sheet for stress evaluations and destructive assay under Task 11, "Tube Sheet Section Removal". The plugs to be removed have been selected to maximize the NDT information. Figure 74 illustrates the new unplugging plan, which takes advantage of the symmetry of the steam generator. In the diagram, all tubes to the left of the vertical line will be unplugged. To the right of that line, only selected tubes will be unplugged, including leakers and tubes with known defects as well as a statistical sampling to confirm our symmetry assumption. These are shown in Figure 74 by a circle around the tube symbol. Many tubes that were plugged on the basis of engineering judgement, with no specific defect, will be left plugged. Severely dented tubes, which could not pass at least a $0.610^{\prime \prime}$ diameter probe, were given low priority in this plan. Probes as small as that will wobble in the tubes and provide unsatisfactory signals. Excessive space between a small probe and the tube wall leads to poor coupling and weak signals.

Equipment purchased for the baseline study is shown in Figure 75 , including the pusher/puller, video monitor, remote control system, communication system, cables, and encoder assembly pieces. Probes will be purchased on the basis of the results from a profilometry test described below. Personnel training, testing of defect models, and equipment calibration have proceeded. Owing to schedule slippage in the tube unplugging task (see Task 8 ), the baseline study will probably not begin until May, 1983. An RFP to select an NDE subcontractor is ready for distribution to potential bidders.

In order to specify the sizes of probes required for the baseline study, a 96-tube profilometry experiment was performed (Ref. 6). By measuring the maximum deformations in this sample of tubes, several minimum probe sizes could be identified along with an indication of the number of each size required. Ninety-six neverplugged tubes were measured with a $0.600^{\prime \prime}$ profilometry probe using a Zetec MIZ-15 eddy current apparatus. Figure 76 identifies the tubes that were selected to provide a good statistical sample over the entire tube sheet, including many tubes adjacent to areas of known denting, along the flow slots, hard spots and in the sludge area where many tubes are plugged. A videotape of the entire experiment was made, including personnel training beforehand.

Most denting was detected on the hot leg, or inlet side. Three tubes would not pass the probe at all. Eleven readings were obtained below $0.700^{\prime \prime}$ (minimum was $0.65^{\prime \prime}$ ). Only two hot leg tubes 


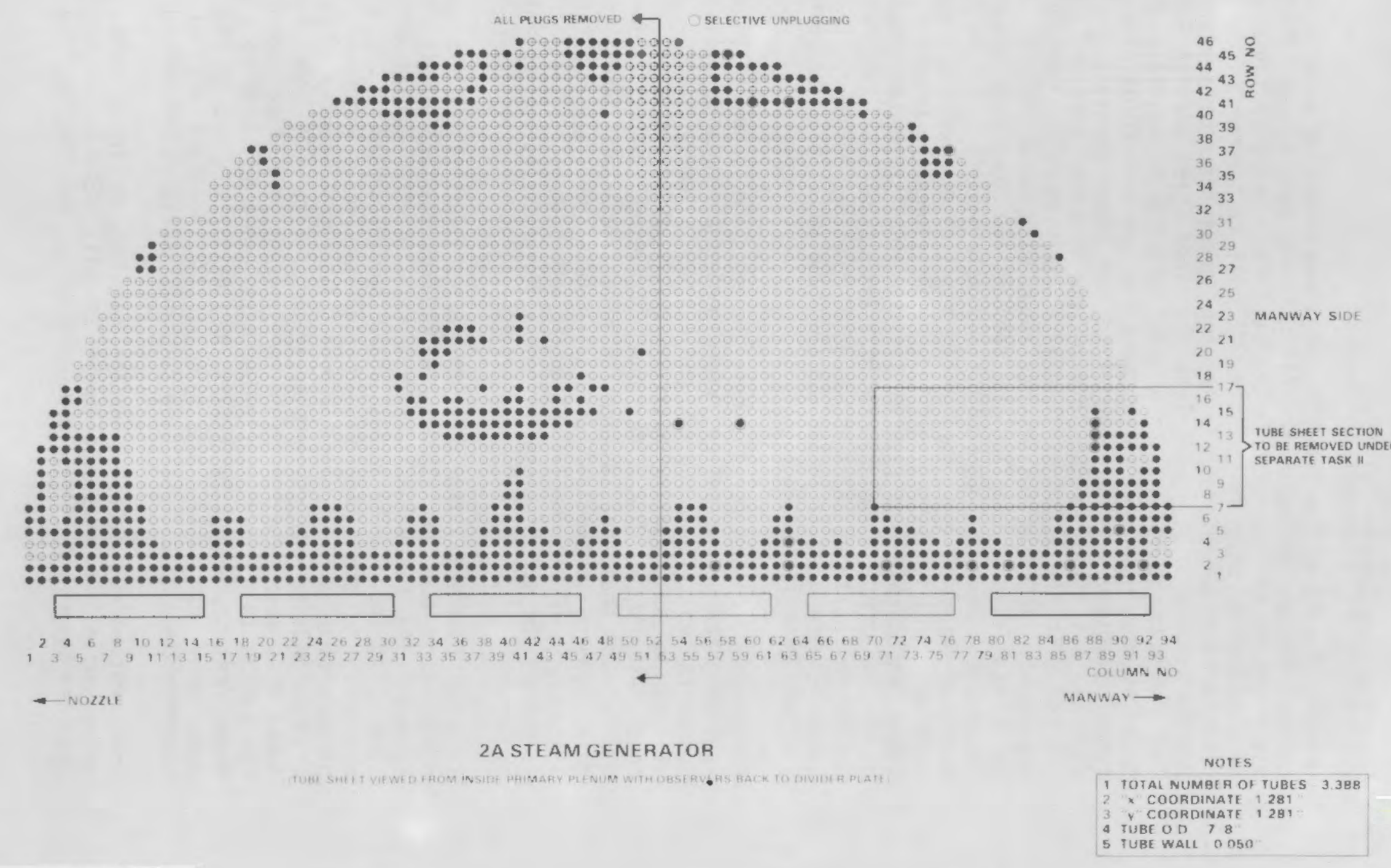

Neg. $8206748-1 \mathrm{cn}$

FIGURE 74. Tube Unplugging Map 
HP 3968AZ

EIGHT CHANNEL

TAPE RECORDER

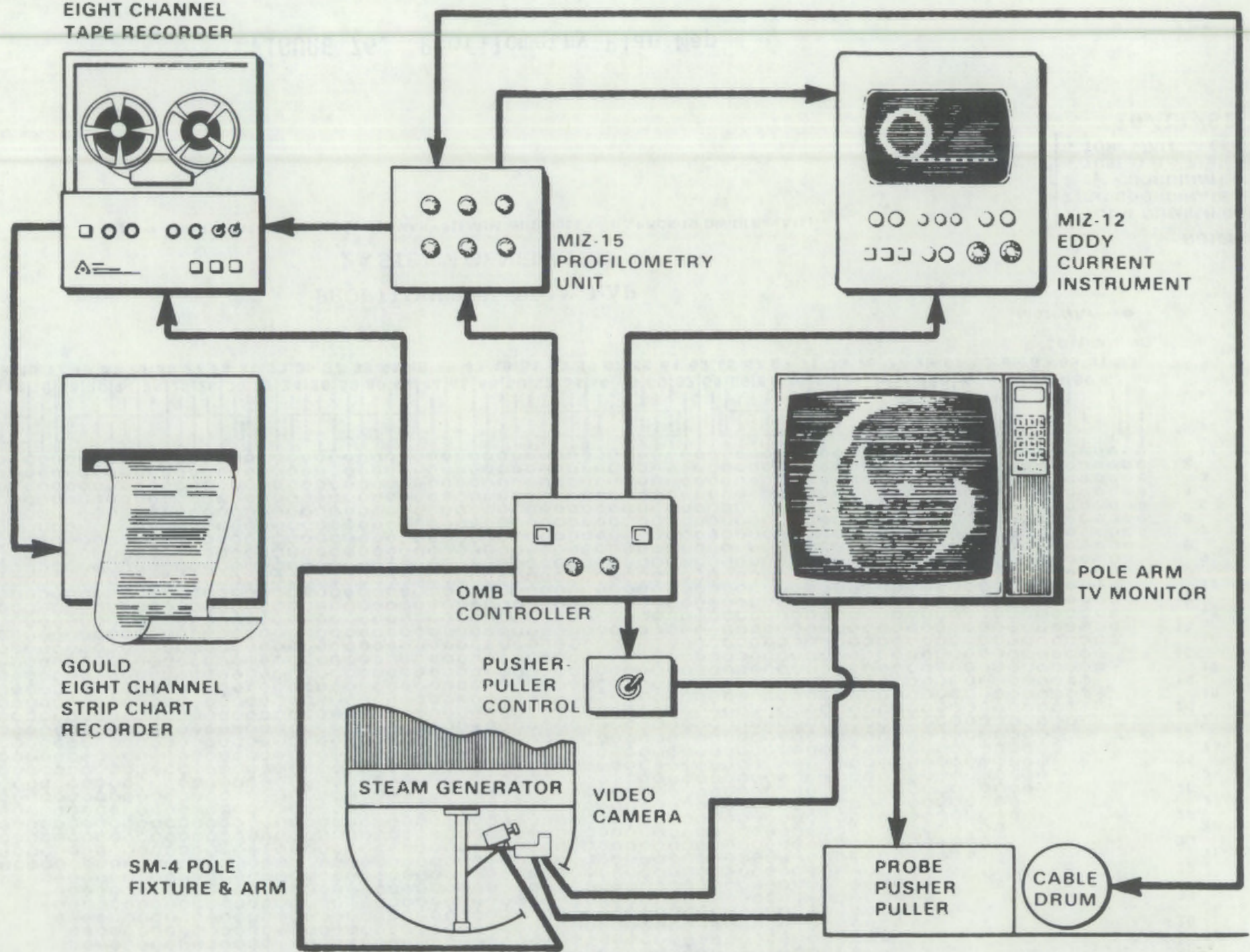

FIGURE 75. Equipment for the Baseline Eddy Current ISI 


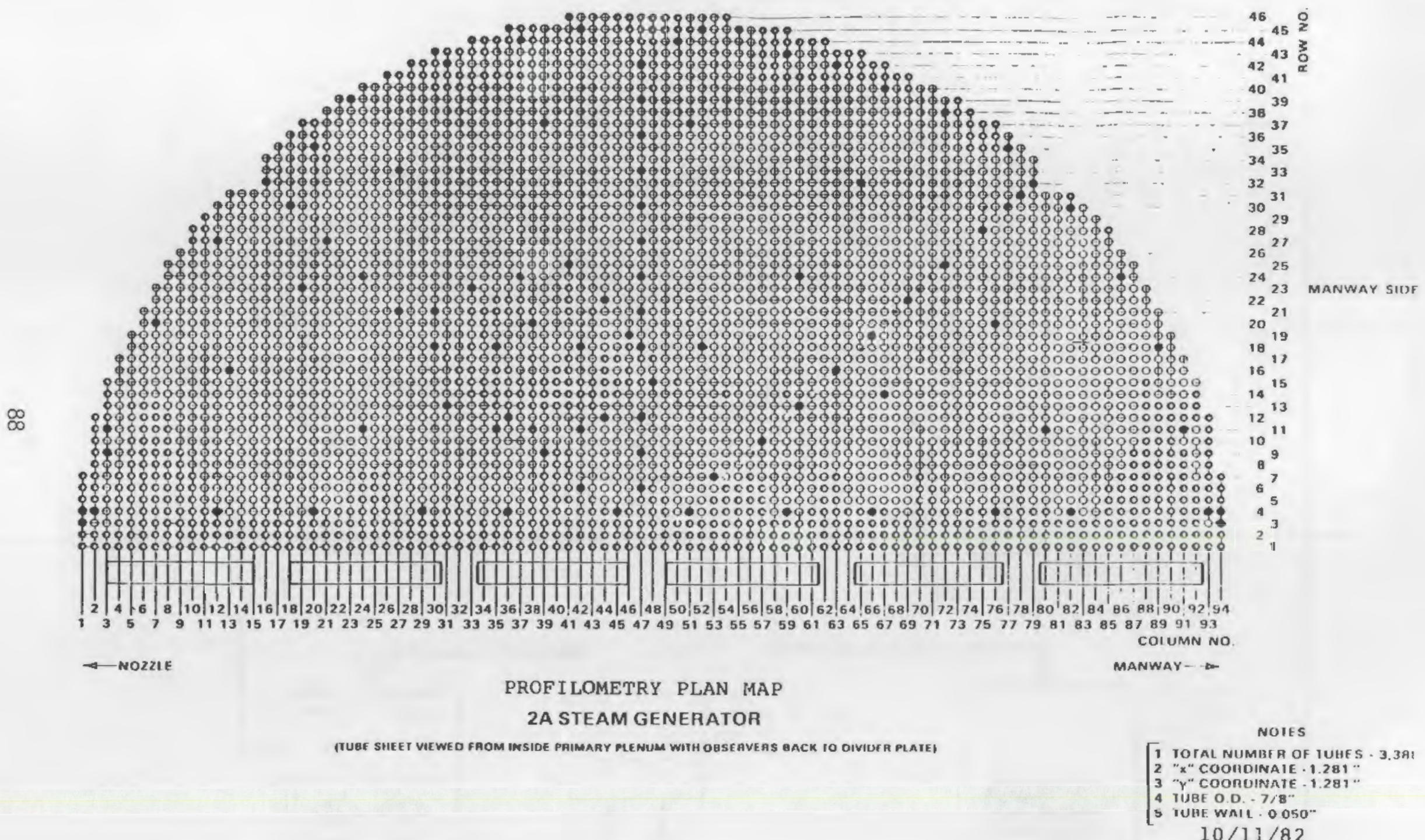

FIGURE 76. Profilometry Plan Map 
showed no denting. On the cold leg side, no obstructions were encountered, and only three measurements were less than $0.740 "$. A statistical overview of the test data is shown in Figures 77 through 80 . One interesting result of the profilometry was that tubes immediately adjacent to those plugged for denting were often not severely dented. Based on these results, we expect to use full size probes with adequate fill factor on the cold leg side. We should be able to achieve a relatively sensitive examination with minimum noise from probe wobble.

The hot leg side tubes may require at least two separate examinations. Access to some tubes may have to be by passing a flexible probe from the cold leg side over the U-bends and down into the upper reaches of the hot leg. Results of this test, however, lend confidence that a good inspection will be possible on a significant sample of those tubes now plugged.

\section{- $\quad$ Tube Unplugging (Task 8)}

A request for a fixed price proposal to unplug 250, 500, or all 748 of the plugged tubes in the Surry $2 \mathrm{~A}$ steam generator was sent to eleven bidders who had expressed an interest in performing the task. None could be accepted because of unresponsiveness to certain terms in the RFP. Recognizing that uncertainties in the required operation probably deterred bidders from making fixed price bids, a new bid package was prepared and issued. The new request called for bids on a time and material basis, and it requested removal of plugs from both ends of the 461 tubes designated in Figure 74. The basis for selecting these particular tubes is described in the section of this report on Task 7 .

The proposals that were received contained unacceptable conditions. Negotiations are continuing in the hope of resolving the problem areas. Program participants have also been requested to offer their services. Battelle is considering undertaking the task. It is clear that there will be a significant delay in the program as a result of these procurement problems. At best, a three-months delay is anticipated. In addition, there is some potential that the number of tubes to be unplugged may have to be reduced in order to stay within the task budget.

\section{- NDT Round Robin (Task 9)}

A round robin evaluation of current and advanced examination technology is planned to follow the baseline study. Techniques will be evaluated on parameters such as detection reliability, sensitivity limitations, and ability to characterize defect size and type. Factors such as tube constrictions at dents and U-bends, secondary side corrosion products, other spurious signal sources, and personnel attributes will also be evaluated for each method. Information from the round robin task will help increase reactor system availability, as well as lead to inputs on regulatory and code requirements. The most important result of this task will be its impact on tube inspection and plugging criteria. 


\section{OCCURENCE OF MAXIMUM DENTING PER TUBE}

HOT LEG

SURRY 2A STEAM GENERATOR

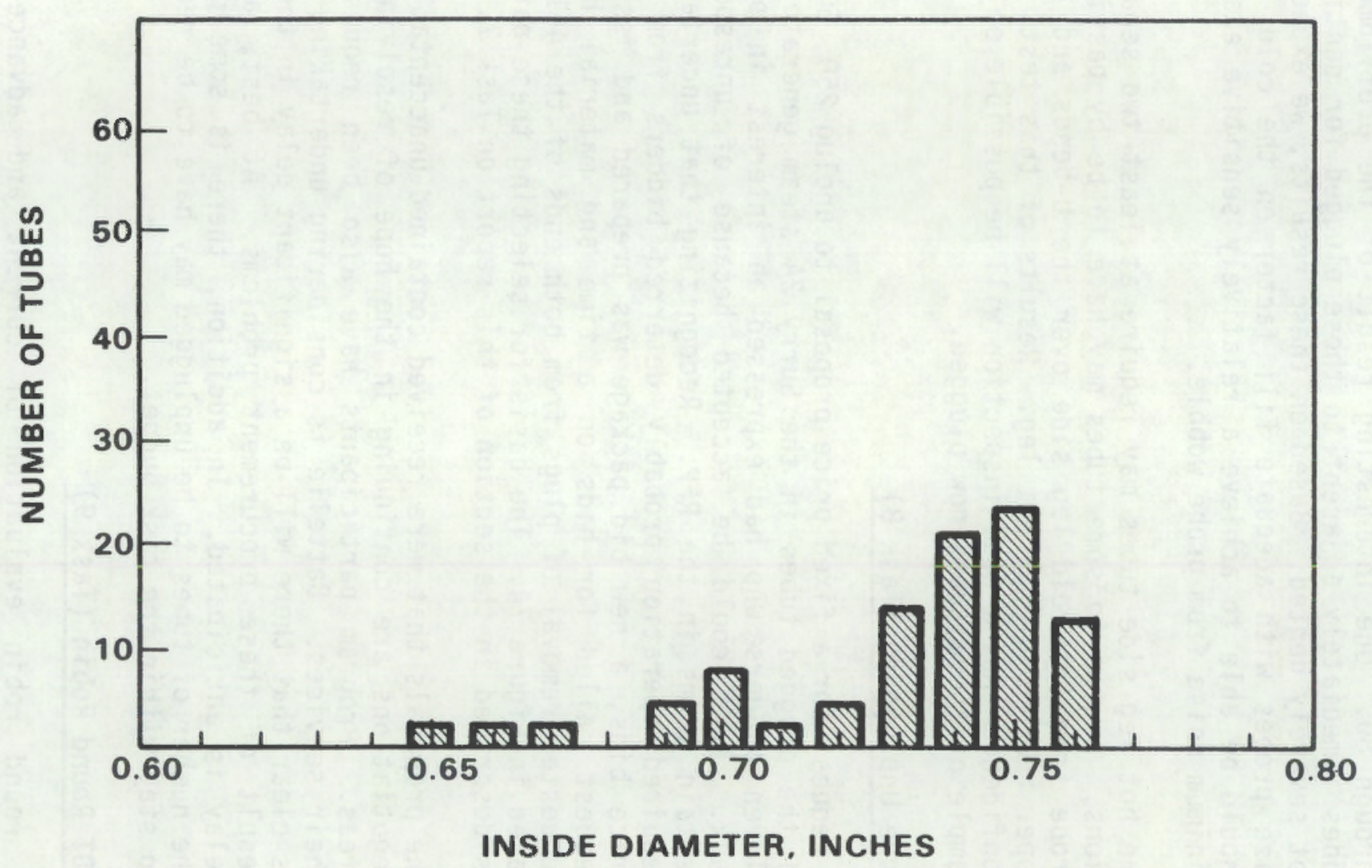

FIGURE 77. Occurence of Maximum Denting Per Unplugged Tube - Hot Leg 


\section{OCCURENCE OF MAXIMUM DENTING PER TUBE COLD LEG \\ SURRY 2A STEAM GENERATOR}

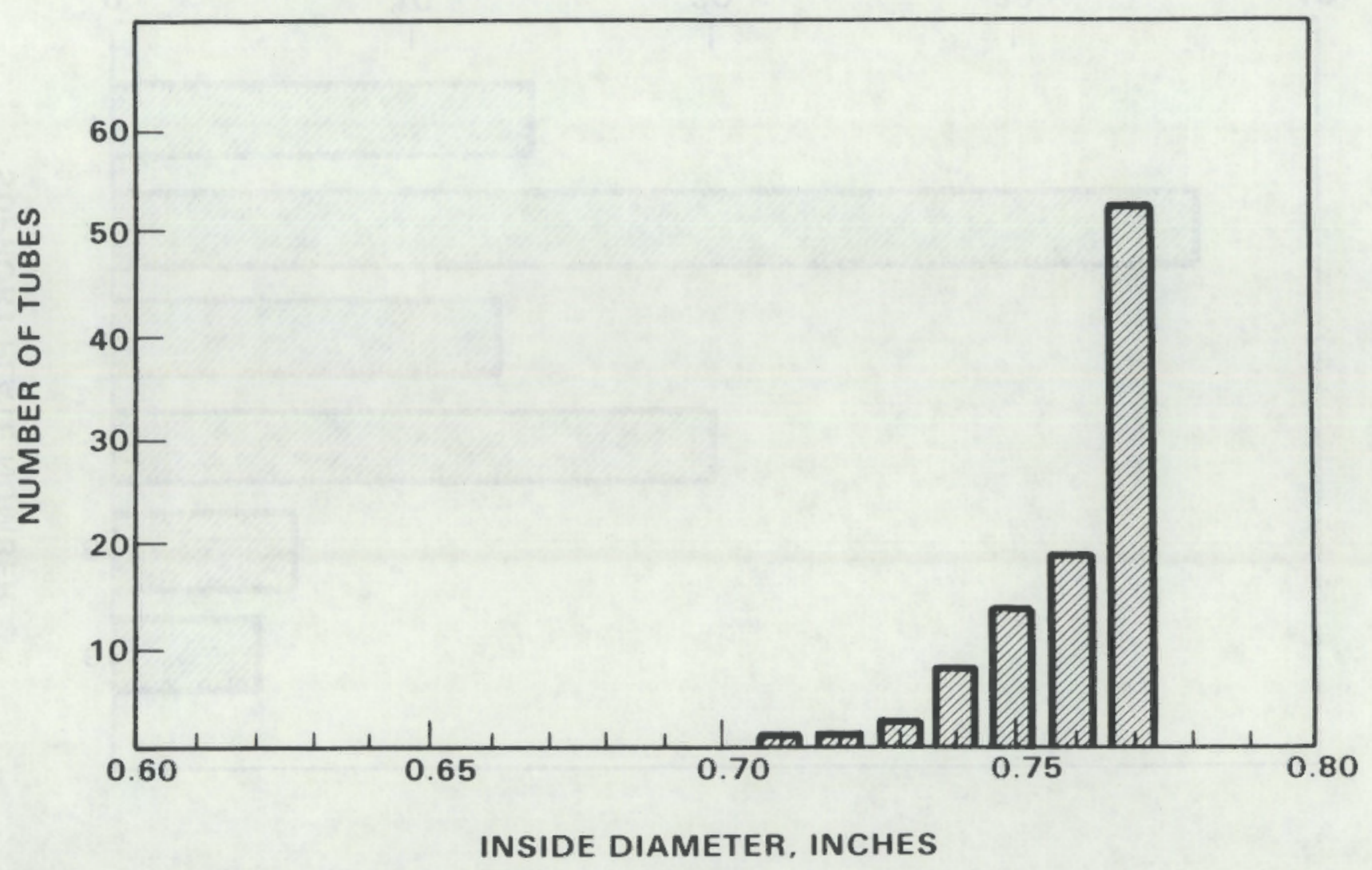

FIGURE 78. Occurence of Maximum Denting Per Unplugged Tube - Cold Leg 


\section{LOCATION OF MAXIMUM DENTING}

HOT LEG

SURRY 2A STEAM GENERATOR

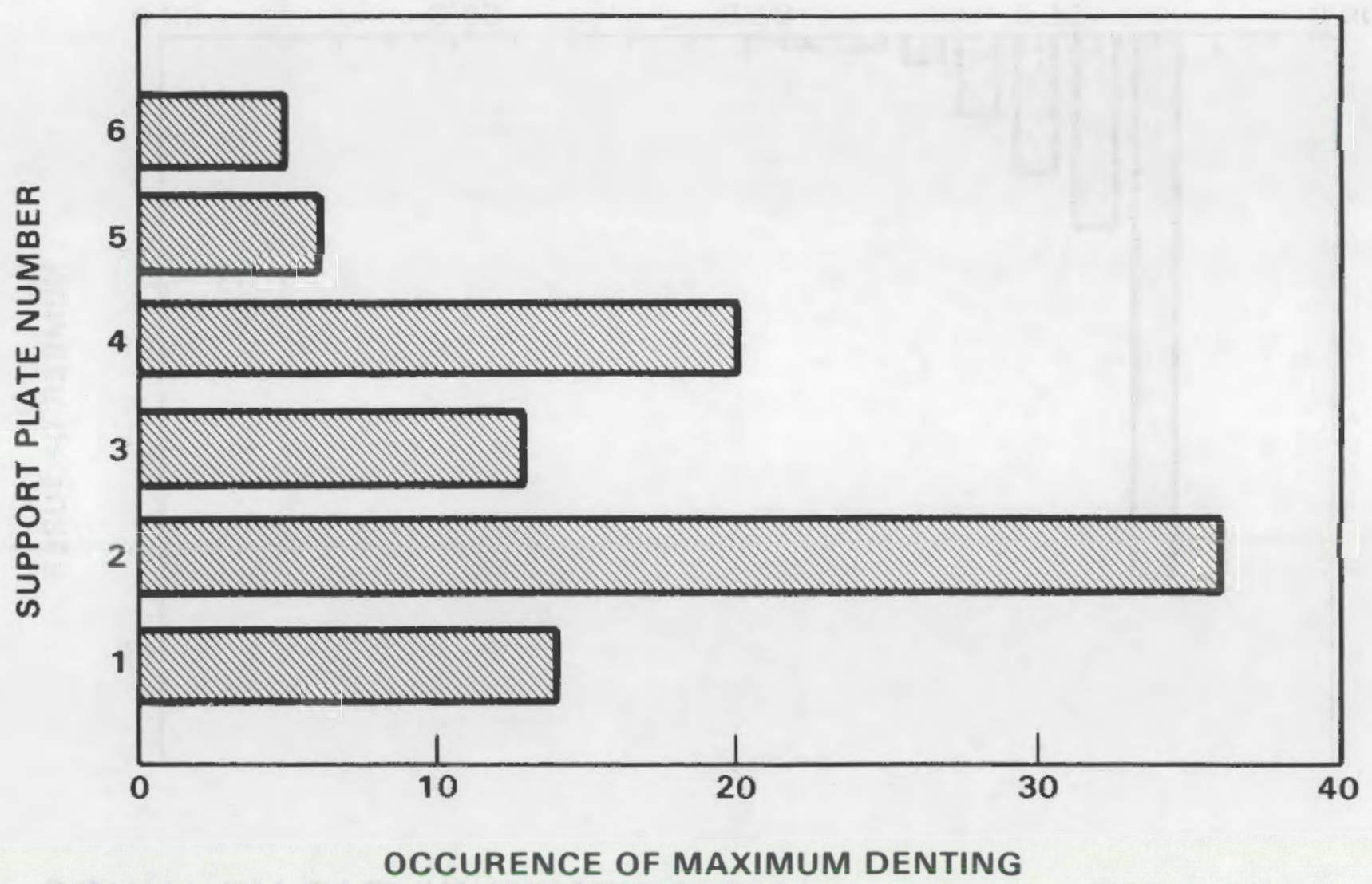

FIGURE 79. Distribution of Denting in Unplugged Tubes - Hot Leg 


\section{LOCATION OF MAXIMUM DENTING \\ COLD LEG \\ SURRY 2A STEAM GENERATOR}

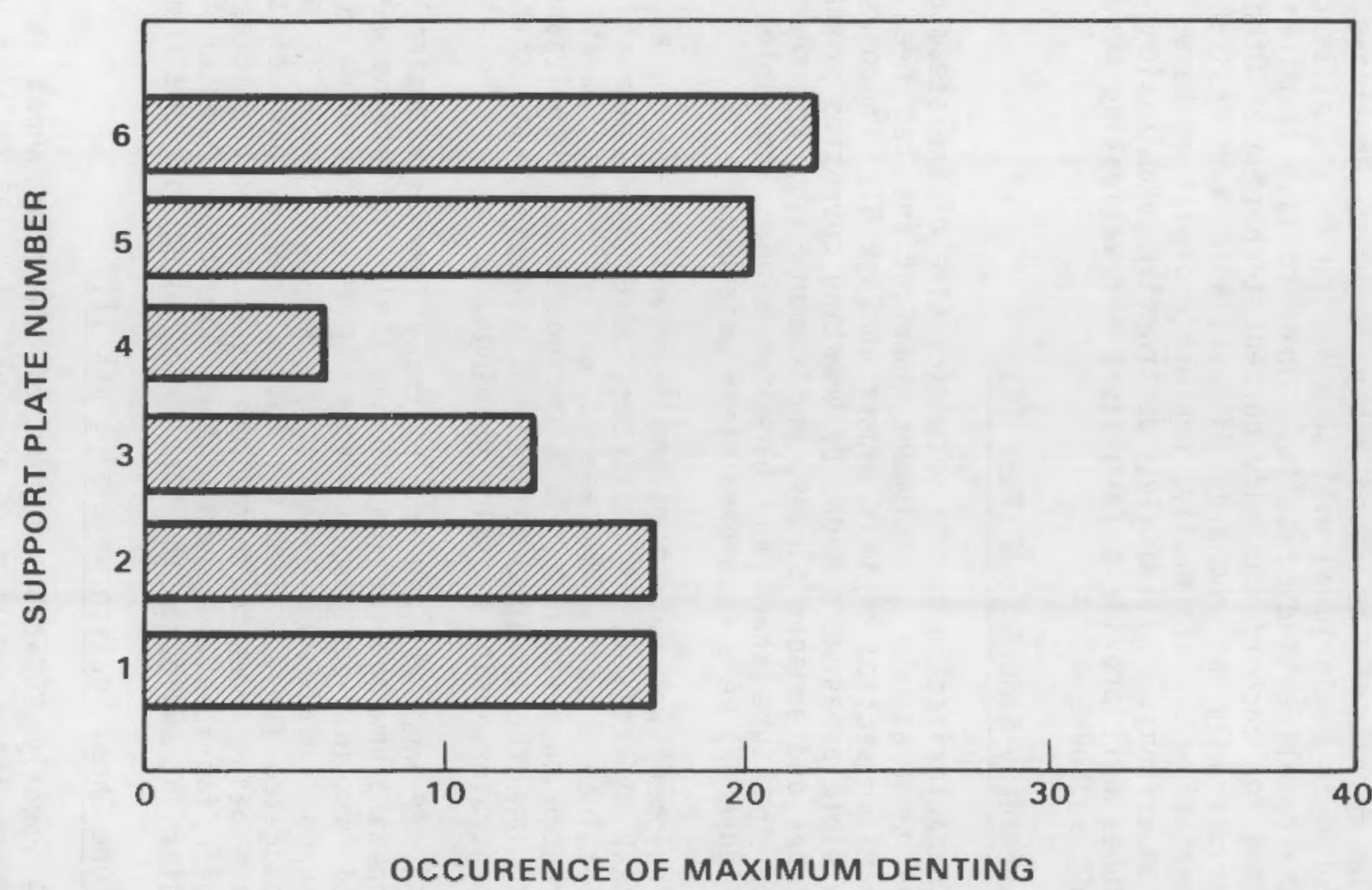

FIGURE 80. Distribution of Denting in Unplugged Tubes - Cold Leg 
Interest in participating in the round robin examination activities is increasing among domestic and foreign vendors and service groups. They see the program as a valuable test bed to demonstrate new equipment and techniques. More are being contacted as time goes on.

The format of the round robin is being developed. A matrix of tubes to be included will be selected in a statistical analysis of the baseline study results. Three to five teams will probably be used for each of two eddy current techniques. Other non EC techniques will be compared if available and desirable to program participants. Initially, evaluations will be based on statistical comparisons. Ultimately, destructive examination of the matrix tubes will provide a firm basis for validating accurate, reliable NDE methods.

\section{- Secondary Side Access (Task 10)}

Characterization of the secondary side of the steam generator began as soon as the preshipment penetrations had been reopened (see earlier section of this report on Task 5). Photographs of all the visible areas were made, documenting corrosion products, damage to tubes and support plates, and amounts (or lack thereof) of sludge on the tube sheet and blowdown pipe. Removable fragments (see Figure 47) were recovered where possible.

Equipment was purchased and borrowed to use in accomplishing the task objectives. A periscope, borescopes, and a fiberscope were obtained along with cameras and video equipment with which to record observations. Task engineers and technicians were trained to use the equipment first on a mockup, and then in the steam generator, using existing openings.

An RFP was prepared and is ready for distribution to bidders for opening new penetrations in the shell. Locations were selected for 14 six-inch-minimum diameter holes to provide access to each support plate and as much of the tube bundle as possible within budgeted funds. Sampling tools, some as part of the fiberscope, are being used to remove corrosion product samples. Guides have been fabricated to permit the fiberscope to enter the tube bundle at right angles to the tube lane and explore the sludge pile.

\section{- Tube Sheet Section Removal (Task 11)}

A roughly 200 -tube section of the tube sheet is planned to be removed for destructive examination. The outline of the proposed section is delineated in the lower right corner of Figure 74 . It will consist of rows 7 through 17, and columns 70 through 94 . This will include sections of tubes that have never been plugged, some that were plugged but not unplugged, and some that will have been unplugged under Task 8. It will also include tubes which were surrounded by significant amounts of sludge. 
The section will be removed to a facility where it can be further sectioned to study the following effects:

1. Corrosion product buildup in the tube-tube sheet annuli.

2. Sludge buildup around the tubes.

3. Tube sheet stresses from tube plugging and unplugging operations.

4. Intergranular corrosion of tubes and the tube sheet from alternate wetting and drying, and chemical deposits, at the mouths of the tube-tube sheet crevices.

5. Stress corrosion cracking at the tube-tube sheet interfaces. The ability of NDT methods to detect defects such as these will be validated.

6. Safety implications of circumferential cracks, if found, in tubes above the tube sheet.

7. Denting of tubes inside the tube sheet from annular corrosion product deposition.

8. Damage or corrosion to tube plugs that result in leakage or potential loss of plug integrity. (Note evidence of leaking plugs in Figure 55).

\section{MEETINGS}

Two project meetings were held during the year. The first, on February 3-5, 1982, was at Battelle in Richland, Washington. It was an organizational meeting with detailed descriptions of SGGP task plans. Representatives of domestic and foreign organizations discussed the benefits of participating in the program. A tour of the SGEF and a view of the steam generator were available to all of the visitors. As a result of this meeting, and additional presentations at other locations, four consortiums have joined the program. Consortiums from Italy, France, and Japan, along with EPRI have committed themselves to full participation.

The second meeting was held at Cadarache, France on October 20-22, 1982. Program accomplishments through Task 6 , Decontamination of the Channel head, were reviewed in detail. Participants provided input to plans for upcoming tasks. Tours of the extensive Cadarache facilities for steam generator research were made available to all visitors. 


\section{PRESENTATIONS AND PUBLICATIONS}

1. March 25, 1982, "A Steam Generator Odyssey" was presented to the Tri-Cities Chapter of the American Society for Metals, by M. Lewis.

2. June 8, 1982, "Initial Inspection of a Service Degraded Steam Generator Removed from Service" was presented to the 1982 Annual Meeting of the American Nuclear Society, by K. R. Wheeler. (PNL-SA-10501).

3. June 16, 1982, "Battelle Northwest Steam Generator Research Program" was presented to the Steam Generator Replacement Seminar, Lake Bluff, Illinois, by M. Lewis.

4. June 17, 1982, "Battelle Northwest Steam Generator Research Program" was presented to the Materials Research Department of Battelle Memorial Institute, Columbus, Ohio, by M. Lewis.

5. October 13, 1982, "Steam Generator Integrity Program/Steam Generator Group Project" was presented at the Tenth Water Reactor Safety Research Information Meeting at Gaithersburg, Maryland, by M. Lewis. (PNL-SA-10804). 


\section{REFERENCES}

1. Clark, R. A. and J. Muscara, "Surry Generator Research Program Plan," February 1982.

2. Reece, W. D., "Subtask 3.1, Steam Generator Radiation Mapping," (to be published).

3. Doctor, P. G., "A Description of the Data Acquisition and Statistical Analysis Computer Systems for the Steam Generator Group Project," PNL-3955, (to be published).

4. Wheeler, K. R. and R. A. Clark, "Initial Inspection of a Service Degraded Steam Generator Removed from Service," Presented to the 1982 Annual Meeting of the American Nuclear Society, PNL-SA-10501, June 1982.

5. Wheeler, K. R. and R. A. Clark, "Initial Inspection of a Service Degraded Steam Generator Removed from Service," Task 5 Topical Report, (to be published).

6. Birks, A. S., et al., "Evaluation of Tubes in a Removed from Service Steam Generator Using Eddy Current Profilometry," PNL-SA-11121A, (to be published). 


\section{ACKNOWLEDGEMENT}

The assistance of the Virginia Electric and Power Company (VEPCO) in obtaining the use of the research generator removed from service at their Surry Nuclear Station Unit 2 is hereby acknowledged. VEPCO has also provided valuable assistance with historical information on the generator's operation inspection and maintenance. 
APPENDIX A 


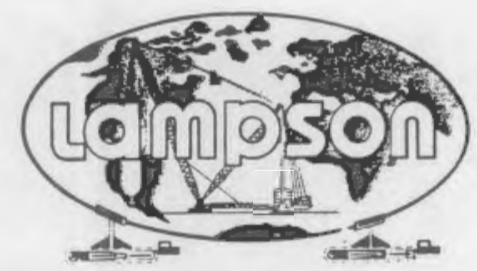

\section{LAMPSON UNIVERSAL RIGGING}

December 28, 1981

LUR-81-477

Battelle Pacific Northwest Laboratories

P. 0. Box 999

Battelle Boulevard

Richland, Washington 99352

Attention: Mr. V. F. Fitzpatrick

Materials Development Section

Subject: Pre-Qualification of Rigging Gear

P.N.L. Subcontract No. B-C2435

LUR, Inc. Job No. 336

Gentlemen:

As per our discussion this date, all slings that require qualification, and will be used during the work involved per the subject Subcontract, are qualified per Certifications of Proof Loads contained within the material submitted to you on December 18, 1981. The specifics of these proof loads versus working loads are shown on the attached calculation sheets. Also shown is a calaculation that proves qualification of the two (2) 67 ton shackles (Reference: LUR Drawing 2227-D) by derating them to $75 \%$ of the manufacturer's rating.

This leaves only the 250 ton spreaders to be qualified. For use during loading and unloading of the Retired Steam Generator, the attached calculations show without question that the December 28, 1980 load test, derated, is acceptable. For use during upending and setting, the load test falls just short of being qualifying. That is, as shown on the attached calculations, the load test subjected each spreader to 340.5 tons and would have had to be 371.7 tons to have been qualifying. In other words, the spreaders, at $26^{\prime}-6^{\prime \prime}$ long, can only be derated $82 \%$, rather than $75 \%$, of their rating as qualified by the December 28, 1980 load test and still be qualified to set the Retired Steam Generator in the configuration shown on LUR, Inc. Drawing 2227-D. 


\section{LAMPSON UNIVGRSAL RIGGING}

December 28, 1981

LUR-81-477

Page 2 of 2

However, some additional rating is reasonable by virtue of the shorter length used during setting of the Retired Steam Generator. A very simplified approach, which sufficiently uprates the spreaders, is shown on the attached calculations. This calculation does not take into consideration the difference in sling fleet angles (which makes the calculation misleading on the liberal side) nor stresses due to the interaction of compression and dead load bending (which makes it misleading on the conservative side). The two should about cancel each other out, and for the sake of needing only another $7 \%$ of capacity, we hope you will find the approach satisfactory.

Very truly yours,

LAMPSON UNIVERSAL RIGGING, INC.

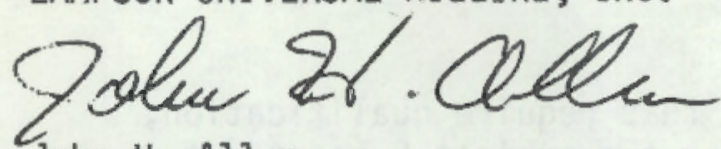

John H. Allen

Project Manager

$\mathrm{JHA} / \mathrm{ksb}$

Attachments: As Noted

CC: B.R. Knight

J.W. Bozung

File 
ATRCHMEWT \#5

k.jk

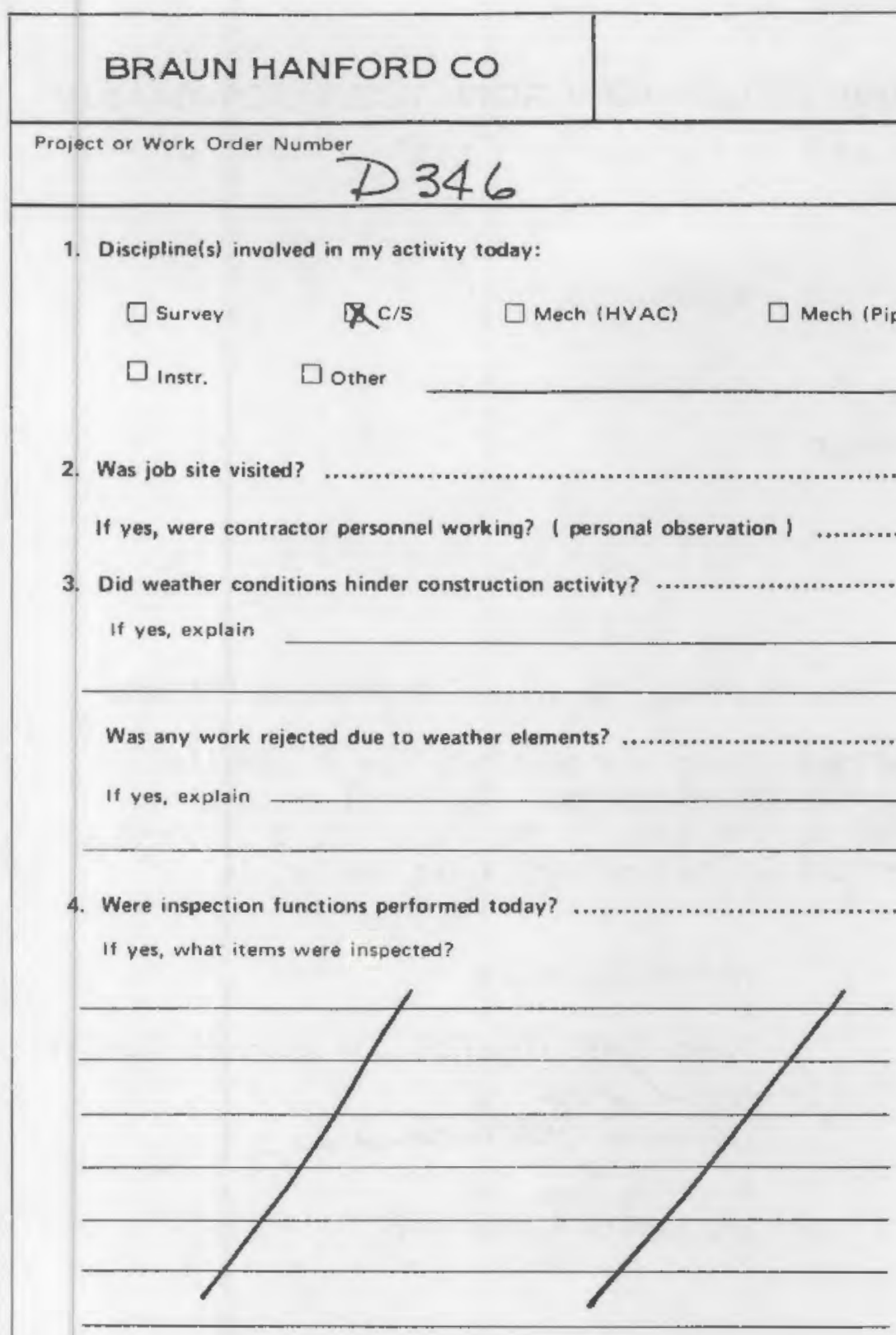

INSPECTION REPORT 
801 FIRST STREET - RICHLAND, WASHINGTON - 99352 (509) 376.6707 JS-006

December 29, 1981

Mr. Marvin E. 0lson, Project Manager

Pacific Northwest Laboratories

OSB Building / 3000 Area

Richland, Washington 99352

Dear Mr. 01son:

RE: LAMPSON UNIVERSAL RIGGING, INC. PROPOSAL FOR STEAM GENERATOR RELOCATION

Mr. Craig Hauber of my staff and myself have reviewed the initial and final Lampson proposal for the steam generator relocation. The final proposal addressed the requests and recommendations made by the JAJ Safety Department initially. The final proposal of the subject matter, after review, is considered acceptable.

Very truly yours,

J. A. JONES CONSTRUCTION SERVICES COMPANY

HJM: vim

cc: J. T. Pierce

W. L. Anderson

C. W. Hauber

File 


$$
\begin{aligned}
& \text { LRMPSON UNIVERSAL RIGGING } \\
& \text { CALCULATION SHEET }
\end{aligned}
$$

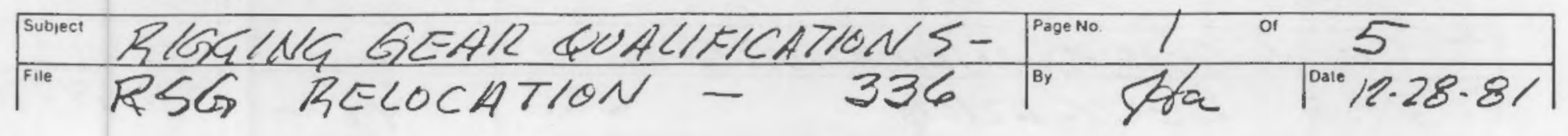

$$
\begin{aligned}
& 3^{\prime \prime} \times 50^{\prime} \text { SLINGS }
\end{aligned}
$$
KlORKING LOAD PER PART AS USED
ON LUR-ZZZ4-D

$$
=\frac{240 \text { TONS } \times 2 \mathrm{~K} / \text { TON }}{4 \text { PARTS } \times \cos 7.7^{\circ}}=121.092 \mathrm{KIPS}
$$

WORKING LOAD PER PART HS USED UN $\angle U R-22 Z\rangle-D$

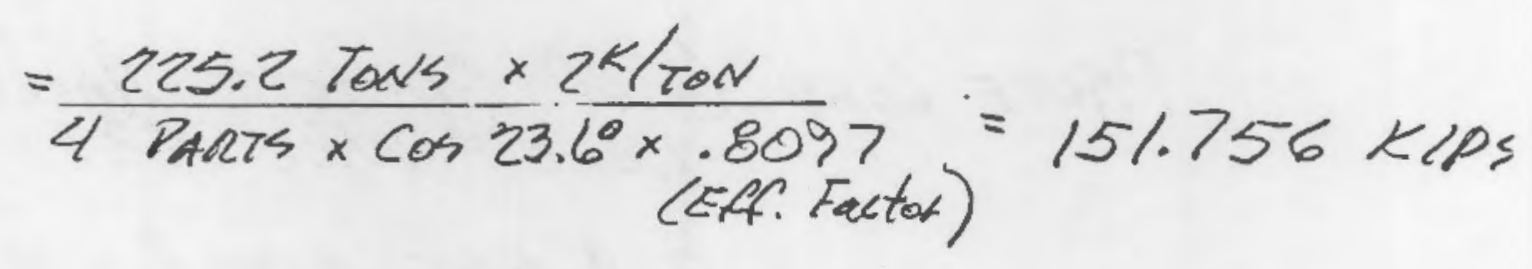

$$
\begin{aligned}
\text { BEAD TEST LOAD } & =151.756 \times 1,25 \times 1000^{*} / \mathrm{K} \\
& =189,695 \mathrm{LBS} .
\end{aligned}
$$

Proof LOAD (Ret floods Lorain Supply cert. \# $20085 \mathrm{dtd} 9 / 3 / 8 /)$

$$
=210,000 \mathrm{LBS}(>189,695)
$$

A-5 
LAMPSON UNIVERSAL RIGGING

CALCULATION SHEET

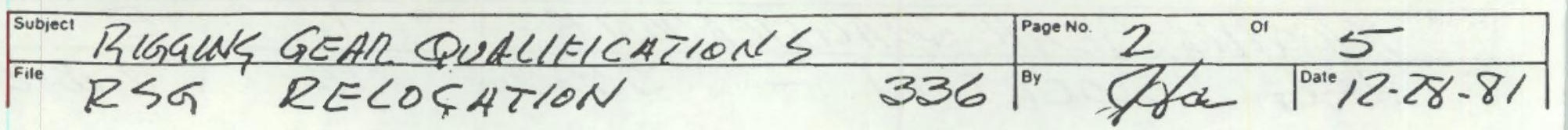

$2 Z^{\prime \prime} \times 50^{\prime}$ SLINGS (REF LUR -2224-D).

KlORKINIS LOAD PER PART

$$
=\frac{245.1 \text { ToNS } \times 2 K / \text { TON }}{8 \text { PARTS } \times \cos 23^{\circ} \times-8334}=79.874 \text { kiPs }
$$

$$
\begin{aligned}
\text { Req'd Test load } & =79,874 \times 1,25 \times 1000^{*} / \mathrm{K} \\
& =99,842.5 \mathrm{LBS}
\end{aligned}
$$

Proof lo ab (Ref Everett Anchor i Chain Co cert * WRE 281 dtp 4/15/81)

$$
=241,600 \mathrm{CBS}(>99,842.5)
$$

$$
\left.2^{\prime \prime} \times 50^{\circ} \text { slings (Ref } 20 R-2227-0\right)
$$

WlOdKINS LOAD RER PART

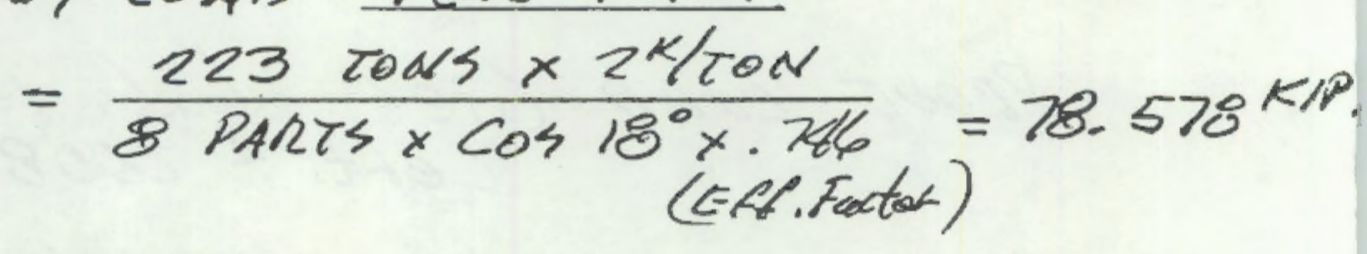

Req id Test loads $78.578 \times 1.25 \times 1000 \# / \mathrm{c}$

$$
=98,222.2 \angle B S
$$

PROOF LOAD (Ref! Wools Loquina Supply cert \#20089 dated 12-11-81)

$$
=198,000 \mathrm{LBS} \text { (>98,222) }
$$

A-6 


$$
\begin{aligned}
& \text { sAMPSON UNIVERSAL RIGGING } \\
& \text { CALCULATION SHEET }
\end{aligned}
$$

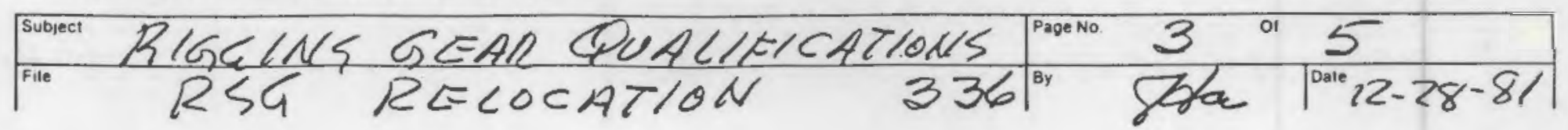

$$
\begin{aligned}
& 67 \text { TON SHACKLE (REF; LUR-2227-D) } \\
& \frac{223 \text { tons }}{8 \times \cos 18^{\circ}}=29.31 \text { tons }
\end{aligned}
$$

Mouofactuden's Rating $=67$ Taus.

$$
67 \times .75=50.25 \text { Tows }(729.31)
$$

$\frac{250-\text { ton Spreaders - 16'- } 0^{\prime \prime} \text { Configuration }}{\text { (Ref LUR -2224-D) }}$ Working load per spreader

$$
=\frac{(480+2 \pm)^{K I P S}}{2 \times \cos 77^{\circ}}=243.2 \mathrm{kIPs}
$$

TEST LOAD OE 12/28/80 (REA (UR-1764-D)

TEST LOAD PER SPREADER

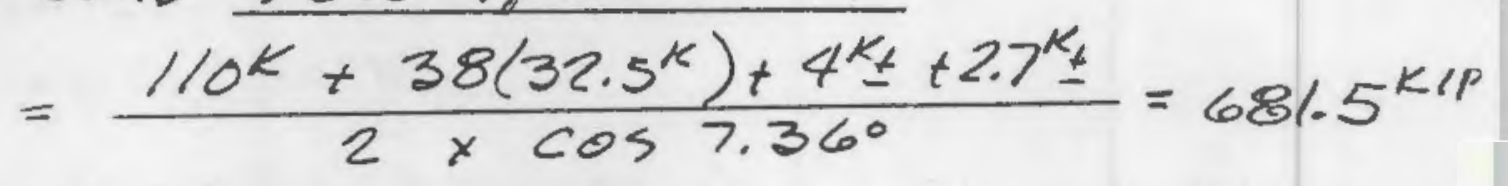

SPREADERS WERE THUS QUALIFIED FOR $681.5 \times \frac{1}{1.25}=545(t) \mathrm{kPS}$

DELATE: $545 \times .75=408.9 \mathrm{kIP4}(>243.2)$

NOTE THAT THIS CALCULATION DISREGARDS BENEFIT OF SHORTENING FROM $26^{\prime} \cdot Z_{A-7}^{\prime \prime}$ TO $16^{\prime}-0^{\prime \prime}$ \& IS $\therefore$ CONSERVATIVE 
LRMPSON UNIVERSAL RIGGING

CALCULATION SHEET

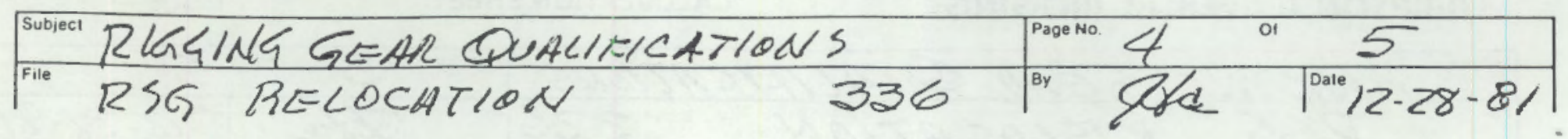

250-ton Spreader -20'- $\frac{0^{\circ} \text { Configuration. }}{(\text { Ref: } \angle U R \cdot 2227-0)}$

Working load $=(223 \times 2 \mathrm{~K} / \mathrm{row}=446 \mathrm{kips}$

TEST LOAD (SEE PREVIOUS PASE) $=681,5 \mathrm{kIPS}$

QUALIFICATION WAS $681.5 \times \frac{1}{1.25}=545(t) \mathrm{kIPS}$

Reference Information

spreader Bar Bony is

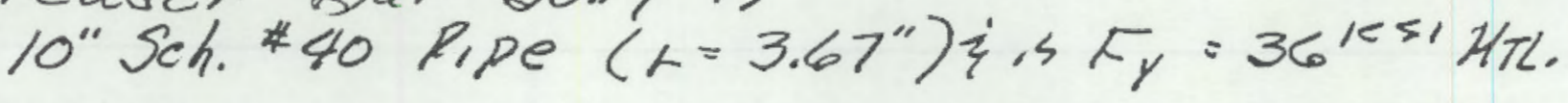

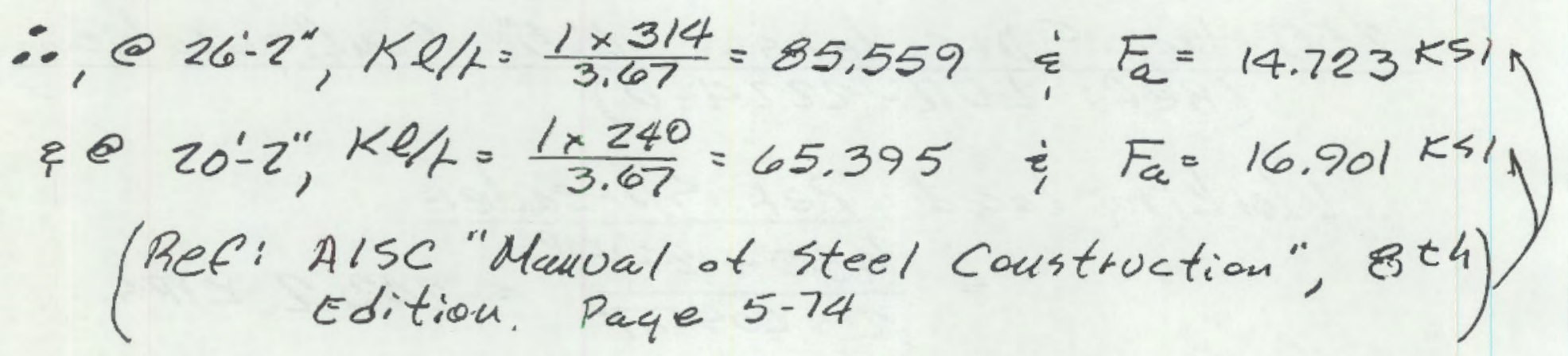

IF USED "AS 15", TEST SHOULD HAVE BEEN $\frac{446 \mathrm{kIPS} \times 1.25}{-75}=743.3 \mathrm{kIPS}($ OR $371.7 \mathrm{TOAls})$

RHTHEIL THAN 681.5 KIPS

HOWEVER, IF SHORTENED SPREADERS ARE

UPRATED BY THE RATIO OE THE TWO ALLOWABLE COMPRESSIVE STRESSES REFERENCED ABOVE, THE EFFECTIVE COAD TEST ON A 20-0" SPREADER MOULD HAVE BEEN:

$$
681.5 \times \frac{16.901}{14.723}=782.3 \text { KIPS }
$$




$$
\text { LAMPSON UNIVERSAL RIGGING }
$$

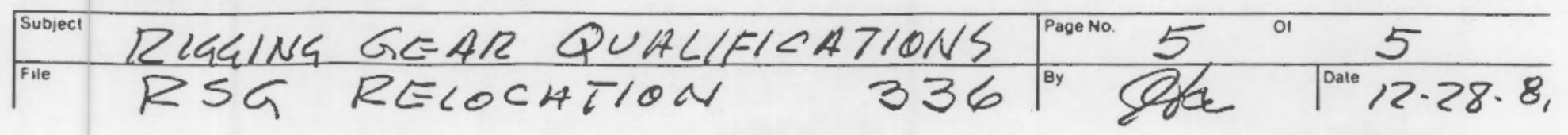

250-ton Spreader - 20'0' Coufiguration, (Coutc.

BASED ON AN EFFECTIVE TEST LOAD OF 782.3 KIPS, 20'0" SPREADLICS WELE QUALITIED FOL $\triangle$ LOAD OF

$$
781.3 \times \frac{1}{1.25}=625.8 \mathrm{KIPS}
$$

DERATE: $625.8 \times .75=.469 .38 \mathrm{KIPS}(>446)$

A-9 

APPENDIX B 
Pacilic Northwest Laboratories

Date October 22, 1981

To V. F. FitzPatrick

rom D. E. Hurley

Subject Steam Generator Trunnion Lifting Stress
Internal Distribution

11. Lewis

R.A. Clark.

R.S. Kemper

$\mathrm{File/LB}$

As requested, I have analyzed the lifting trunnion on the steam generator. The generator has a $15^{\prime \prime} \times 15^{\prime \prime}$ inspection opening, the bottom of which is only 2 " above the top of the trunnion. At first glance this appears structurally unsound for lifting. When the generator is lifted the rip out shear stress will be a maximum because this opening is right in line with the lifting forces. The rip out shear stress will be on planes $A-A$ and $B-B$ and is of

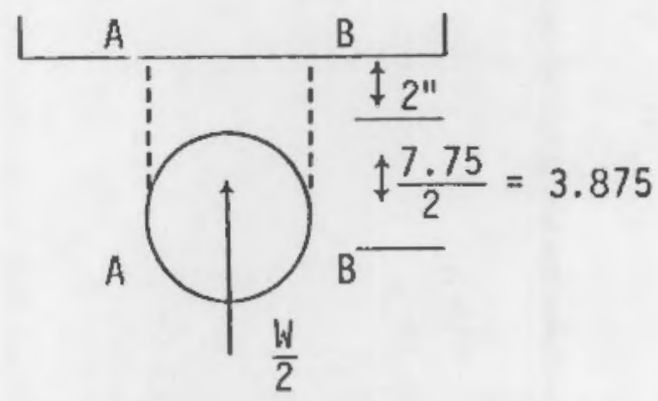

$$
\begin{aligned}
\text { magnitude } \tau \max & =\frac{\left(\frac{W}{2}\right)}{t L} \\
& =\frac{\left(\frac{440,000}{2}\right)}{2 \times 3.0 \times(2+3.875)}=6,242 \mathrm{psi}
\end{aligned}
$$

The material is $\mathrm{SA}-533$ Grade $\mathrm{A}, \mathrm{Class} 1$ and has a minimum yield strength of 50,000 psi. Shear yield would be half of that or $25,000 \mathrm{psi}$. So you have a safety factor of

$$
\text { S.F. }=\frac{25,000}{6,242}=4.01
$$

DEH:mi 



\section{DISTRIBUTION LIST}

No. of

Copies

OFFSITE

U.S. Nuclear Regulatory Commission

Division of Technical

Information \& Document Control

7920 Norfolk Avenue

Bethesda, MD 20014

10 Dr. Joseph Muscara

Materials Engineering Branch

Division of Engineering

Technology

Nuclear Regulatory Commission

M/S 1130 SS

Washington, DC 20555

Dr. B. D. Liaw

Materials Engineering Branch

Division of Engineering

Technology

Nuclear Regulatory Commission M/S 1130 SS

Washington, DC 20555

Dr. C. McCracken

Nuclear Regulatory Commission

M/S P-302

Phillips Bldg.

Washington, DC 20555

$3 \mathrm{Mr}$. J. A. Mundis

Electric Power Research

Institute

3412 Hillview Avenue

P.0. Box 10412

Palo Alto, CA 94303

5 Mr. H. S. McKay

Virginia Electric Power Co.

The Electric Bldg.

P.0. Box 564

Richmond, VA 23204
No. of

Copies

Foreign

3 Dr. J. L. Campan

Department Manager

Water Reactor Service

C.E.A./Caderache B.P.N. ${ }^{0} 1$

13115 Saint-Paul-Lez-Durance

FRANCE

3 Mr. M. Oishi, Manager

Steam Generator Project NUPEC

No. 2 Akiyama B1dg., 6-2, 3-Chome

Toranomon, Minatoku, Tokyo 105

JAPAN

4 Dr. R. De Santis

R\&D Manager

Ansaldo DBGV

Viale Sarca 336

Milano, ITALY 20126

ONSITE

50

Pacific Northwest Laboratory

R. A. Clark (43)

Publishing Coordination (2)

Technical Information (5) 



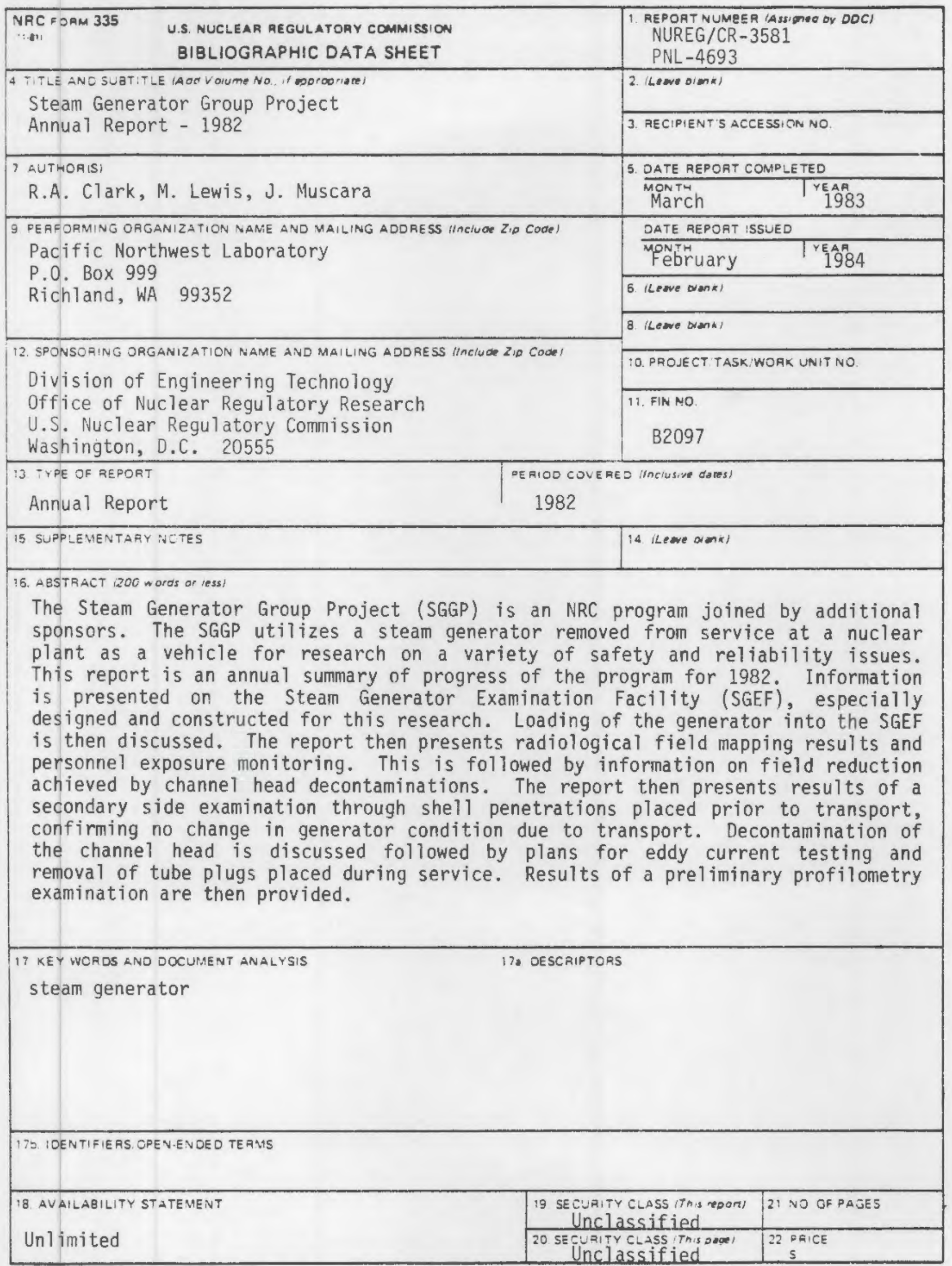


